\title{
The Autocratic Welfare State: Old-Age Pensions, Credible Commitments, and Regime Survival*
}

\author{
Carl Henrik Knutsen ${ }^{\dagger}$ and Magnus Rasmussen ${ }^{\ddagger}$ \\ $\dagger$ Professor, Department of Political Science, University of Oslo \\ $\ddagger$ Senior Researcher, Institute for Social Research, Oslo \\ Contact: c.h.knutsen@stv.uio.no
}

December 21, 2017

\begin{abstract}
In this paper we argue that autocratic regimes are no less likely than democracies to adopt old-age pensions, although autocratic programs are less universal in their coverage. Our theoretical argument focuses on the strong incentives that autocratic regimes have for enacting and maintaining such programs to ensure regime survival. Autocratic pension programs can be considered club goods that I) are targeted to critical supporting groups and II) solve credible commitment problems on promises of future distribution, thereby mitigating probability of regime breakdown. We test three implications from the argument, drawing on a novel dataset on welfare state programs and including 140 countries with time series from the 1880s. First, we find that autocracies are no less likely than democracies to have old-age pension programs. But, second, autocracies have less universal pension programs than democracies. Third, pension programs effectively reduce the probability of autocratic breakdown.
\end{abstract}

${ }^{*}$ We are grateful to Øyvind Skorge, Andrej Kokkonen, Carsten Jensen, Michael J. Donnelly, Jørgen Møller, Kalle Moene, Johannes Lindvall, Thomas Brambor, Jonas Pontusson, Sirianne Dahlum, Tore Wig, Merete Bech Seeberg, three anonymous reviewers, the editors of CPS, participants at the 2014 APSA Annual Meeting in Washington D.C., and participants at workshops and seminars at the Department of Political Science, Lund University, at the Department of Political Science, Gothenburg University, at ESOP, Department of Economics, University of Oslo, at the Department of Political Science, University of Oslo, and at the Department of Political Science and Government, Aarhus University for valuable comments and suggestions. We are also grateful for the support from ESOP, the Department of Economics, University of Oslo, in partly financing data collection efforts related to this paper. The research was partly funded by Knutsen's Research Council Norway, "Young Research Talent" grant, pnr 240505. 


\section{Introduction}

The welfare state literature has considered social policy programs either as mechanisms for providing individuals with insurance against risks such as job-loss or illness, or as tools for progressive redistribution (see Moene \& Wallerstein 2001). Hence, different theoretical models are well suited to explain the existence of social policy programs in democracies; most voters are risk averse (Chetty 2006), thus preferring even costly insurance, and the (relatively poor) median voter often has incentives to vote for parties promising income redistribution (Meltzer \& Richard 1981). Yet, also autocracies adopt social policy programs. The perhaps most famous examples are the sickness, accident, and old-age pension programs adopted in Bismarck's Germany, but these are not exceptions. Mares and Carnes $(2009,97)$ count that the vast majority of the 38 "non-industrialized" countries for which they have data adopted their first old-age pension system under autocracy. Analyzing more than 140 countries, with time series from the 1880 s, we show that autocracies are no less likely than democracies to adopt or have old-age pension systems. But, why would autocrats adopt such programs and spend resources on pensions rather than keeping tax revenues for private consumption, or for investment in repressive capacity to ensure regime survival?

We propose that old-age pension programs in autocracies are, indeed, used for political survival purposes, and our statistical tests estimate a clear and sizable effect of pension programs on regime survival once adjusting for the endogenous adoption of such programs. Social policies, and notably old-age pensions, involve targeted distribution of resources to particular groups, and thus constitute a special form of co-optation. While formalized social policy programs have received comparatively

little attention in the literature on co-optation in autocracies, which often focuses on discretionary distribution and patronage networks, this notion is not new. Mares and Carnes (2009), for instance, argue that social policies are used for targeted distribution to critical groups. However, neither Mares and Carnes nor the wider literature have elaborated on a second key feature of such programs, namely how they allow autocrats to make credible promises of future distribution. We thus respond to the theoretical challenge raised by Acemoglu \& Robinson (2006); why would any group trust a dictator's promise of future distribution (see also, e.g., Svolik 2012)?

We conceptualize pensions, in autocracies as club goods, and make a theoretical contribution to the welfare state and autocratic politics literatures by formulating a novel argument highlighting that such programs combine two characteristics - i) inter-temporal credibility and ii) potential for 
targeting - which make them instrumental for autocratic survival. First, in contrast with discretionary distribution of private goods, old-age pensions are fairly transparent, stable and predictable, and not easy to reverse without substantial costs for rulers. Hence, distribution through these programs not unlike particular institutions such as ruling parties or legislatures (Magaloni 2008; Gehlbach \& Keefer 2011, 2012; Svolik 2012; Boix \& Svolik 2013) - can mitigate credible commitment problems. Second, in contrast with pure public goods, pensions can be targeted towards identifiable groups. Hence, autocrats can design programs channeling resources (only) to groups they need support from to stay in power ("critical supporters") rather than spending precious resources on irrelevant groups. Combining these insights, we clarify how autocrats' incentives to secure long-term support from critical groups is key to understanding how and why welfare states develop and, conversely, how the adoption and design of pensions contributes to explain why some autocracies endure longer than others. By doing so, we bridge the welfare state literature, which has mainly focused on (developed) democratic contexts, and the rapidly growing literature on autocratic politics.

The argument generates different empirical implications, which we test using our new Social Policies Around the World (SPAW) dataset with global coverage and extensive time series. Leveraging these data, thereby going beyond the usual post-war OECD country focus of most welfare state studies, we make several empirical contributions. First, we provide more stringent and comprehensive tests of relationships between regime type and different features of social policies. Using data from countries across the world from the 1880s onwards, we corroborate the finding on developed western countries from Kim (2007) that democracies provide more universal pension benefits than autocracies. We also provide more systematic corroborating evidence for the claim by Mares and Carnes (2009) that autocracies are as likely as democracies to implement old-age pensions. Second, we introduce the first explicit large-n tests on how social policy programs affect regime survival, thereby informing the autocratic politics literature, which has mainly focused on structural conditions, political institutions, or discretionary policies as determinants of regime survival. Finally we contribute to the welfare state literature by highlighting the unique role played by old-age pensions, for instance showing that such programs clearly enhance autocratic regime survival, while other transfer schemes do not. The estimated effect of pensions, which holds in models accounting for the implementation of pensions being endogenous to the security threats facing the regime, is robust and substantial in size. Hence, future research can benefit from studying the historical development and effects of pensions 
separately from other programs.

After having reviewed relevant literature (Section 2), we present our argument (Section 3). We thereafter describe the relevant variables from the SPAW dataset (Section 4). In the empirical analysis (Section 5), we report evidence that autocracies are as likely as democracies to adopt and have pension systems, although autocracies - as theoretically anticipated, due to autocracies typically having narrower coalitions of critical supporters than democracies (see Bueno de Mesquita et al. 2003) have less universal systems. Finally, we report and discuss tests showing that pension systems reduce the probability of autocratic regime breakdown.

\section{Literature}

Most welfare state researchers have focused on OECD democracies (Esping-Andersen 1990; Huber \& Stephens 2001; Iversen 2005). Different theoretical accounts then also suggest that social policies - and the provision of public services such as basic health-care and primary education (e.g., Lake \& Baum 2001; Stasavage 2005; Harding \& Stasavage 2014) - should be more widespread, better financed, and have broader coverage in democracies than in autocracies (Boix 2003; Acemoglu \& Robinson 2006; Haggard \& Kaufman 2008; Ansell 2010). There is evidence that Western countries expanded welfare spending due to franchise extensions from the 19th century onwards (Lindert 2005), and Ansell \& Samuels (2014) identify a positive effect of democracy on various social spending measures, even when controlling for country-fixed effects.

Yet, other empirical studies employing alternative specifications report that democracies are not, on net, associated with higher social spending (e.g., Mulligan, Sala-i Martin \& Gill 2003). ${ }^{1}$ A historical pioneer in implementing welfare policy programs was Imperial Germany, under the strategic guidance of Chancellor Bismarck (see Rimlinger 1971). Former Communist dictatorships presided over extensive social policy programs (Milanovic 1998), but so did autocracies such as PRI-Mexico (Magaloni 2006). Desai, Olosgård \& Yousef (2009) find that - among autocracies - those with harsher repression provide more welfare spending. Different extant studies provide two pertinent insights about autocratic politics, which we combine in our argument on why autocratic regimes often

\footnotetext{
${ }^{1}$ There are likely systematic differences in social policy design and spending also within the broader regime categories, both among democracies and among autocracies. For instance, democracies with proportional representation (PR) electoral systems may enhance social spending and induce more universal programs than plural-majoritarian (e.g., Persson \& Tabellini 2003; Iversen \& Soskice 2009). In this paper, however, we focus on differences between the more general regime categories.
} 
implement targeted pension systems: First, policies with distributional consequences are intentionally designed by many autocrats to remain in power. Second, ensuring that promises that are made to the regime's critical supporters are credible, is of utmost importance:

Regarding the first insight, some autocrats might be genuinely concerned with the welfare of their citizens (Wintrobe 1998, 95-96), and provide, for instance, old-age pensions to improve their life quality. However, the literature often considers policy-making as a strategic tool used mainly for enhancing regime survival, and numerous studies suggest that autocratic regimes rely on particular, critical groups for their political survival, prioritizing economic policies that satisfy these groups. Bueno de Mesquita et al. (2003) theorize that whereas large-coalition rulers find it cost-effective to spend resources on public goods, small-coalition rulers should allocate private goods directly to their few vital supporters. Democracies, because of larger coalitions, should thus observe more spending on public goods than dictatorships (see also, e.g., Lake \& Baum 2001; Stasavage 2005). Regarding social policies, more specifically, regime survival was widely considered a core motivation for Bismark's reforms (Rimlinger 1971), and Mares and Carnes (2009) and Haggard \& Kaufman (2008) outline how social policies have been targeted to key groups, at least in part, for political-survival reasons in various autocracies.

Regarding the second insight, Acemoglu \& Robinson (2006) highlight how autocratic elites often cannot credibly commit to future redistribution, even when faced with revolutionary threats; they would expectedly stop redistributing (i.e., "wasting resources") once the threat is removed. The dictator may ensure survival through repression, but this is costly (Wintrobe 1998), and co-optation is often preferable (see Gandhi 2008). While autocrats face difficulties in making promises of future distribution credible, this is not impossible. Different studies (North \& Weingast 1989; Geddes 1999; Magaloni 2006; Gandhi 2008; Wright 2008; Gehlbach \& Keefer 2011, 2012; Svolik 2012; Boix \& Svolik 2013, for democracies, see Iversen 2005) point out that autocrats can reduce credible commitment problems through establishing institutions, such as regime parties or legislatures, that allow for monitoring and constraining the actions of the ruler. We propose that also the design of distributive policies may matter; formalized social policy programs - and particularly pensions - can reduce credible commitment problems. 


\section{Why would autocrats implement pension programs?}

Democratic governments are widely assumed to have strong incentives to implement social policy programs to please broad groups of voters, either because of redistribution to relatively poor voters or as insurance to risk-averse voters against various risks. Despite this, we argue that it remains theoretically indeterminate whether democratic governments are more likely (than autocratic) to adopt certain social policy programs, especially pensions. While previous contributions have highlighted that such indeterminacy may stem from adopting a more realistic understanding of how democracies work (see Ansell \& Samuels 2014), this also follows from a more realistic understanding of autocratic politics:

To summarize, the core of our argument is that autocratic regimes often have strong incentives to implement pensions to please groups of "critical supporters" - even if these groups can be fairly few in numbers. By critical supporters we mean individuals who support the regime and, if they were to retract their support, would substantially increase the probability of the regime ending. ${ }^{2}$ Institutionalizing the distribution of resources through pensions makes future distribution to particular supporting groups more credible than promises of discretionary private-goods distribution. When distributive policy is clearly codified, the autocrat cannot, for reasons we detail below, easily backtrack on promises once the relevant group no longer poses an imminent threat. Implementing generous pension programs does imply unwelcome future costs. Yet, this is something the autocrat willingly accepts if the alternative is losing power; when promises of future distribution are considered credible, the benefiting groups will more likely continue to support the regime. Program benefits in autocracies should, however, be targeted towards the specific groups that the regime needs support from - be it industrial workers or soldiers - whereas "irrelevant" citizens should receive little. By appeasing groups that might otherwise contest the regime, the introduction of such programs should bolster autocratic regime survival.

Old-age pensions should be a particularly suitable policy for ensuring regime survival. First, the amount of resources channeled through pensions often dwarfs the amount channeled through

\footnotetext{
${ }^{2}$ Following Geddes (1999), we define a regime as the set of formal and/or informal rules essential for choosing political leaders and maintaining them in power. Further, we conceptualize autocratic regimes broadly as "non-democracies", implying that these regimes lack truly competitive elections and/or extensive franchise rights. In autocracies, the dictator and a close circle of collaborators are thus often the relevant policy-making actors.
} 
other programs, such as unemployment benefits (to illustrate, OECD's Social Expenditure data show that old-age pensions expenditures, for 22 OECD countries with data across recent decades, are, on average, more than five times larger than unemployment benefits expenditures). Second, pensions can be designed to target a variety of groups; they are co-optation devices that can channel resources to a more eclectic pool of potential critical supporters than, e.g., maternity leave. Pensions are not restricted to pre-given groups, such as women of child-bearing age, that may or may not be relevant for political survival. Unemployment benefits advantage those with high risks of losing their jobs, and autocracies have typically focused on ensuring the job safety of critical supporting groups through employment protection and other means (e.g., Mares and Carnes 2009). Disability insurance might come in handy for the autocrat's critical supporters, but the prospect of a disabilitating injury is relatively small compared to that of growing old. Further, old-age pensions speak directly to the temporal dimension of the credible commitment problem (we elaborate on other features of pensions pertinent to this problem below). For most concerned individuals, pensions will be paid out in the not-too-near future - i.e., when current coalition members are retired from their positions, and thus perhaps less capable of holding the autocrat accountable. Absent old-age pension schemes, current coalition members may not trust dictators to provide future resources. Below, we explore the argument and its assumptions in more detail.

\subsection{Pensions and targeting}

First, we leave repression aside and consider co-optation through current and (promised) future distribution of resources as the key type of policy tool that the regime can employ to retain power. ${ }^{3}$ Further, we simplify by considering the population in dictatorships - in addition to the dictator and his/her very close collaborators, representing the regime - as divided into two groups, namely the regime's "critical supporters" and "other citizens". We assume that the regime actors are mainly concerned with regime survival, and since the regime only requires the approval of critical supporters to retain power it will only be concerned with pleasing them. The group of critical supporters may, depending on the context, consist of, e.g., soldiers, land-owners, civil servants, former army veterans, salaried professionals, business owners, or industrial workers. One key aspect for our purposes, however, is that members of this group are identifiable according to some observable features (e.g. "Participated in war of independence" or "Works in the manufacturing sector").

\footnotetext{
${ }^{3}$ Yet, repressive strategies are likely endogenous to autocrats' co-optation strategies (Desai, Olosgård \& Yousef 2009; Frantz \& Kendall-Taylor 2014).
} 
Critical supporters, we assume, care about present and future consumption, and thus require resources distributed to them today and credible promises of resources tomorrow. If not, they may seek to replace the regime with another regime more willing to comply with their demands, or even pursue democratization which has some benefits also to economic and other elites (Ansell \& Samuels 2014). The regime can basically co-opt the group of critical supporters through three strategies: 1) lumpsum provision of private goods to each critical supporter; 2) public goods provision benefiting both critical supporters and other citizens; or, 3) provision of club goods to the group of critical supporters. Club goods are non-rivalrous; their consumption have externalities, and club goods thus affect a group of individuals. But, in contrast to public goods, they are excludable. Pension checks are posted to individuals and consumed by them privately - distribution through pensions therefore has some private-good characteristics - but there are good reasons to consider targeted pension programs as club goods:

One key aspect of social policies is their insurance function (Moene \& Wallerstein 2001). Individuals cannot perfectly predict whether they will be incapable of working when they turn 70, and many would sacrifice some current income to insure against low income levels accompanying old-age. Payments should, importantly, be implemented under clearly specified conditions and in a rule-following manner. If the government could simply decide on a case-by-case basis which members should (not) receive payments, this would undermine the program's general credibility and reduce expected utility for all program members. Hence, the insurance aspects of welfare programs have non-rivalrous properties. Regarding excludability, this requires the presence of observable, codifiable criteria, such as occupation, for distinguishing program members from non-members. The excludability aspect of pensions, combined with the regime's incentives, indicates that regimes will aim to target programs (only) towards their critical supporters. This follows the general logic of Bueno de Mesquita et al. (2003) in that regimes with smaller "winning coalitions" (i.e., fewer critical supporters) prefer funnelling resources to these select supporters - leaving them with larger individual rewards, and greater potential income loss if the regime breaks down and they find themselves outside the new regime's coalition. This should, in turn, boost the "loyalty" of critical supporters, helping the regime solidify power. Thus, autocracies should have less universal pension programs than (typically larger-coalition) democracies, and these targeted programs should increase the longevity of autocratic regimes. ${ }^{4}$

\footnotetext{
${ }^{4}$ Although our account closely follows "selectorate theory" (Bueno de Mesquita et al. 2003), we only invoke "critical supporters" (corresponding to "winning coalition") and "other citizens", and
} 
Different historical examples illustrate how targeted policies can be used to co-opt critical supporters. Haggard \& Kaufman (2008) describe how social policies in various East European, Asian and Latin American countries have been targeted to critical groups: In Thailand and South Korea, for example, social insurance was limited "to core constituents in the state itself: the military and civil servants" (p. 140). In Fascist Italy, Mussolini's support-base notably included the independent farmers of Northern Italy, specifically in the Po Valley. When entering office, Mussolini immediately extended benefits to his coalition, with self-employed farmers becoming, for the first time, eligible for pensions with special conditions (International Labor Organization 1922). Argentinean history provides another example: Perón's ascension to power in 1946 was quickly accompanied by social policy actively being used to garner support (Epstein 1979). Pensions were immediately extended to Perón's core supporters, unionized industrial workers. Later, Perón used special programs to secure support from various strategically important groups that could potentially threaten his position (MesaLago 1978); at least 12 special programs operated in the early 1950s. When Perón fell in a military coup, so did the foundations for this complex system. With its power-base secure, the Argentine military regime removed existing special pension programs in 1967, instead setting up a unified program. Three notable exceptions were, however, made for the police, civil servants, and the military. These groups kept their special programs, presumably illustrating the importance of tailoring pensions to target groups critical for regime survival.

\subsection{Pensions and credible commitments}

Thus, autocratic regimes often have strong incentives to under-provide truly public goods; these are only "cost-effective" in ensuring political survival when the critical supporting groups are very large, which they typically are in democracies but not in autocracies (Bueno de Mesquita et al. 2003). But, why would autocratic regimes establish club goods - notably in the form of targeted pensions - for the group of critical supporters collectively rather than pursue discretionary distribution of private goods to such supporters individually? The latter does, indeed, have some benefits from the not the notions of "selectorate" or the resulting "loyalty norm" (Winning coalition size/Selectorate size). Yet, extending our theory could lead to implications resembling those related to the "loyalty norm": keeping selectorate size constant, narrowing the number of critical supporters should increase rewards (through receiving more individual pension benefits) and potential losses following regime breakdown. This should, in turn, increase the incentives of critical supporters to fight for upholding the current regime. 
regime's viewpoint. First, if the regime, at some point, strongly consolidates power, it can easily reduce the amount of private goods distributed, leaving more resources for, e.g., the autocrat's personal consumption. Formalized pension programs are, as discussed below, more difficult to adjust at will. Thus, dictators who consider themselves very safe in power might prioritize private-goods distribution. Second, discretionary distribution of private goods is arguably easier to direct exclusively to critical supporters. In practice, pension and other social programs may lead to "leakage" or "waste"; some citizens that are unimportant for the dictator's survival may receive benefits. For instance, former servicemen with little political influence are covered by veteran benefits, or "irrelevant" parts of the manufacturing sector producing in the periphery are covered by pensions for manufacturing workers, even if these are mainly intended for powerful firms and workers in the capital.

Yet, autocratic regimes, particularly when their grip on power is insecure, may prefer program targeting critical groups over private goods distribution. One reason is the exact same stability of such programs that make them monetarily more costly. The regime wants to avoid making critical supporters uncertain about future distribution; such uncertainty may induce the latter to attempt replacing the regime. Acemoglu \& Robinson (2006), among others, highlight the fundamental problems of time consistency and credibility of promises facing autocrats. They propose that relinquishing decision-making powers through political liberalization is the only viable solution for autocrats facing imminent threats. Still, recent contributions have highlighted how particular institutions in autocracies can alleviate this problem (Svolik 2012; Boix \& Svolik 2013). We further propose that the way in which distributive policies are designed influence whether promises of future distribution are credible or not. If the future reversal of policies entail high economic or political costs, autocrats can more credibly promise their continuation. Thus, autocrats may want to "tie their hands" when designing policies that channel resources to critical groups. One way of doing this is through codifying pension programs. Iversen (2005) observes that time inconsistency problems can arise also for social policies, and describes how democracies - especially under PR electoral rules - may resolve them through building programmatic parties and coalition governments. While (many) autocracies do not leverage these options, there are other reasons why autocrats reduce issues of time inconsistency and non-credible promises through pension programs:

Implementing pensions should stabilize distributive policy because of three features: 1) clear rules for payments; 2) frequent payments at regularized intervals, allowing actors to quickly observe rule 
violations; and, 3) substantial sunk costs with setting up pension programs. All three features suggest that pension programs allow for more credible promises than distribution through discretionary spending, whereas the second and third, to some extent, differentiate pensions from other social programs:

The first two features are decisive for supporters' ability to monitor and identify whether or not the regime reneges on promises. A comprehensive game-theoretical and applied literature on repeated games and de-centralized co-operation has emphasized that clear yardsticks and frequent interaction are key elements in upholding co-operation; non-cooperative behavior will be swiftly punished with high probability, increasing costs of non-cooperation and thus making promises of future co-operation credible (e.g., Keohane 1984). Discontinuation of pension payments or reversal of programs constitute identifiable events which could function as signals, or "sparks" (Kuran 1989), alleviating antiregime collective action. Older supporters will be immediately informed if co-operation is breached after payments are supposed to begin (date of retirement), and discontinued benefits for current pensioners from the same social group is an easily observable signal to younger supporters of the noncredibility of the autocrat's pledges. Compared to other programs, supporters do not have to wait for a specific event (e.g., a large economic crisis bringing about mass unemployment, relevant for unemployment benefits) to observe whether the autocrat is sticking to his/her side of the bargain. Regarding the third feature, pensions are associated with substantial sunk costs, as the regime initially needs to invest in administrative and monitoring capacity, including the hiring and training of officials, buildings, information and management systems for collecting contributions from firm payrolls, etc. This reduces (the relative) costs of continuing the program, and ensures more effective distribution of resources, once the system is up and running, creating lock-in effects (Pierson 2000). Further, while words are cheap, spending resources on setting up a targeted pension program provides a more costly, and thus credible, signal that the autocrat will channel resources to benefiting groups also in the future. Such sunk costs are presumably lower for the - in most observed contexts - fiscally smaller programs, such as maternity or work injury programs, and much smaller for discretionary spending.

While autocrats can roll back pensions or reduce payments over time (e.g., by not adjusting for inflation), pensions should thus provide fairly strong insurances to recipients of future distribution, thereby reducing coalition incentives to remove the regime. Indicatively, Ponticelli \& Voth (2011), using European data from 1919-2008, find that cuts in public spending generate unrest and anti- 
regime collective action. Our SPAW data also show that pension programs are durable and seldom retracted or scaled down substantially. Only $6 \%$ of country-year observations experience changes in terms of expanding or reducing the number of groups covered by pension programs, and in autocracies only $10 \%$ of changes are reductions. Moreover, such reductions in pensions are far less likely in established autocracies than immediately after regime change when autocrats may cut programs benefitting supporters of the old regime (see also Albertus \& Menaldo 2012). The relative frequency of pension reductions is almost three times higher in the first three years after regime change than in subsequent years. Withdrawing pension benefits from its critical supporters will likely endanger the regime. Anticipating this, critical supporters perceive promises of future resource distribution as credible if linked to pensions, particularly if the regime is expected to be long-lived. Hence, critical supporters have incentives to support the regime's hold on power once a program is in place.

\subsection{Summary and hypotheses}

In sum, pensions are particularly effective credible commitment devices for autocratic regimes because payments are frequent and come at regularized intervals and because of their sheer size and large sunk costs. Pension schemes are also co-optation devices for which the pool of beneficiaries can be adjusted to cover different types of critical supporters (not only, e.g., women of child-bearing age or workers facing great risks of unemployment). Hence, resources can be allocated directly to groups exhibiting the financial and organizational resources to challenge the regime, or groups from which the regime needs consent or even active support from to fend off coup attempts - the most common cause of autocratic regime death (Svolik 2012). ${ }^{5}$ Another pertinent feature of old-age pensions is that prospective recipients will be paid out after several years - i.e., when current coalition members are retired, and thus less capable of holding the autocrat accountable. The capacity to physically partake in revolts may decline with age, and supporters lose their relevance as economic producers and disengage from collective-action conducive organizations such as unions once they retire. Absent old-age pension schemes, currently influential "coalition members" may not trust dictators to provide them with future resources.

\footnotetext{
${ }^{5} \mathrm{~A}$ large theoretical and comparative case-study literature on autocratic breakdown (and democratization, in particular) suggest that industrial workers, business owners, salaried professionals, and other urban middle class groups are often key such groups, having requisite positions of influence in the economy and the ability to effectively organize (e.g., Rueschemeyer, Stephens \& Stephens 1992; Collier 1999; Ansell \& Samuels 2014).
} 
Our argument suggests (at least) three distinct hypotheses. First, even if the literature contains good arguments for why democratic governments should adopt social programs to please voters, autocratic regimes might be as likely as democracies to adopt certain such programs. While votemaximizing democratic politicians have strong incentives to provide (various) social policy programs, autocrats should have particularly strong incentives to provide old-age pension programs. Thus, our first hypothesis is

H1) Autocracies are no less likely than democracies to adopt/have old-age pensions.

We reiterate that our argument predicts weaker incentives for autocratic regimes to adopt other social policy programs, and we thus consider it more likely that democracy correlates positively with adoption/existence of such programs. ${ }^{6}$ Nonetheless, our argument also implies that the pension programs pursued in autocracies should typically be more targeted than in democracies, since autocracies have narrower supporting coalitions. This yields

H2) Old-age pensions are less universal in autocracies than in democracies.

Factors influencing the risk of regime breakdown might incentivize autocrats to initiate (or expand) pensions. However, forward-looking autocrats may implement such programs as safety-nets long before the economy crashes or protesters assemble in the streets (when it may be too late to save the situation). Nonetheless, the notion that such programs - once in place - boost autocratic survival prospects is another testable proposition following our argument. Hence, our final hypothesis is H3) Old-age pension systems reduce the risk of autocratic regime breakdown

\section{The SPAW dataset}

Our Social Policies around the World (SPAW) dataset covers all sovereign countries in the world with available sources, and some variables extend back into the 19th century. There are two main categories of variables, legislative changes and program characteristics. For both categories SPAW contains information on sickness, maternity, unemployment, disability/work injury, family allowances, and old-age pensions. SPAW draws on various sources, notably the ILO Legislative series (1919-) and

\footnotetext{
${ }^{6}$ To reiterate, this follows, e.g., from pensions being easier to target to all relevant groups of supporters and are typically associated with larger sunk costs than other programs. Yet, this is a matter of degree, as also programs such as family allowance benefits may be targeted to different groups and involve sunk investments in administrative capacity. Thus, we remain theoretically open to the possibility of other transfer programs being used for regime survival purposes and having regimestabilizing effects, though we much more clearly expect a sizeable such effect for pensions.
} 
US Labor Department SSPTW-reports (1937-). ${ }^{7}$ Much effort has gone into using multiple sources - both cross-country reports and country-specific sources - to cross-check validity and reliability. While this introduces an element of subjective judgement even for de jure measures, this is preferable to employing a single source, both for increasing coverage and for avoiding specific issues associated with the individual sources. Extant studies of social policies largely rely on aggregated spending measures. While interesting for some purposes, they are often poor proxies for welfare-state characteristics of proposed causal relevance (see, e.g., Esping-Andersen 1990; Scruggs 2006). We aim to capture whether benefits are targeted to specific groups. Overall spending measures are ill-suited for this purpose. Measures of the share of the population insured can also be problematic for our purpose, as insurance statistics will not distinguish countries where, e.g., only one small group, say industrial workers, is insured, from another where benefits accrue to all workers but a long required contribution period make only some eligible. In order to capture how autocrats use targeted benefits to placate particular groups, we draw on the following variables from SPAW:

First, we use measures on the first year of major reform and presence of (above-minimumthreshold) programs. Contrary to previous attempts to measure first year of legislation (e.g., Mares and Carnes 2009), we distinguish between major and special programs (see Appendix for closer discussion). Several countries legislated special public servant pensions during the 19th century, way before introducing old-age pension programs in their modern form. In Argentina, the first civil servant pension (originally for the judiciary and treasury) was enacted in 1803, whereas the first law covering industrial workers passed in 1946 (Mesa-Lago 1978). Previous attempts to measure "first laws" have often used SSPTW reports, but these lack consistent criteria over time (or between countries) on what constitutes a first law - depending on the edition, SSPTW reports switch between using special or major programs. Thus, we have drawn information from the entire archive of SSPTW reports alongside other sources, and our main source is the ILO Legislative series, which we deem as the most reliable.

More specifically, we use dichotomous measures of whether (national-level) pension (and other social policy) programs are adopted/exist or not, and the operational "minimum threshold" is that the program covers $\geq 1$ of the following 8 major social/occupational groups: agricultural workers; industrial/production workers; small-firm workers; self-employed; students; employers; temporary/casual workers; family/domestic workers. ${ }^{8}$ This categorization does not perfectly capture all groups of the-

\footnotetext{
${ }^{7}$ For details, see the Appendix and Rasmussen (2016).

${ }^{8}$ But, laws (generally) prescribing broad coverage might exclude, e.g., ethnic minorities (or ma-
} 
oretical interest. Pertinent groups, such as public servants and military officers, are not explicitly included, and in many contexts only (occupational or geographical) sub-sets of, e.g., "employers" or "industrial/production workers" will be relevant. Unfortunately, collecting comparable such data across countries and time would, at best, be extremely labor-intensive. Hence, empirical estimates on links between, e.g., autocracy and old-age pension program adoption may be downward biased, since programs targeted only to narrower groups are not counted. Nonetheless, theoretical and historical case studies on social groups and regime change emphasize the roles played by broader groups corresponding well with the SPAW categories, highlighting coalitions of, e.g., industrial workers or middle class groups such as self-employed or business owners (e.g., Rueschemeyer, Stephens \& Stephens 1992; Collier 1999; Ansell \& Samuels 2014). Insofar as the categories represent coalitions of actors relevant for regime survival, SPAW provides decent measures for testing our argument.

Second, we draw on Universalim Indices from SPAW, capturing what parts of the population are included on equal terms in the same program. ${ }^{9}$ The original indices range from $0-9.0$ designates when programs are absent and 1 when programs are means-tested based on some property criteria - income-based exclusions are not counted as means-tested programs. Further, contribution- or employment-based programs are scored as 1+number of groups covered (among the seven groups that we code; if all groups are covered, the score is $1+7=8$ ). Maximum 9-scores indicate all residents are automatically entitled to benefits - a fully universal system. ${ }^{10}$ When testing H2) on regime types and how widely targeted pension programs are, we omit observations without programs (0) or with only means-tested programs (1) to obtain a cleaner and theoretically more appropriate measure. ${ }^{11}$ Apjorities, as in Apartheid South Africa) or certain occupational groups. SPAW includes a measure capturing number of explicitly excluded groups. Second, although covered in general systems, groups might receive special benefits from additional programs. In SPAW, the (country-year) average is 3 special programs, with a maximum of 63 special programs (Greece 1983). However, the coverage on excluded groups and special programs is thin for our global sample.

${ }^{9}$ Below, we do not distinguish voluntary from compulsory coverage, or social insurance from private schemes (provident funds).

${ }^{10}$ If different pension programs exist, all are coded and we average over these programs.

${ }^{11}$ People with little or no property is not counted as a separate group for other programs, raising dimensionality and measurement level issues. Further, they presumably often lack in economic leverage and resources for organizing collective action, and scoring these programs lower than, e.g., employment-based programs for industrial workers does thus not reflect our argument on autocrats targeting programs to critical supporters well. 
pendix Figure A.1 shows the baseline Universalism Index distributions for the six major programs. Although this index is not of interval scale, we employ easy-to-interpret linear regression models as baselines and ordered logit/probit models or logit/probit models run on dummy variables (using different cut-offs) for robustness checks.

While the SPAW data allows us to capture theoretically important characteristics for an extensive sample, there are potential reliability and validity issues. First, coding de jure programs allows for an extensive dataset with comparable measures across time and space, but some programs may be "empty shells". Hence, our data could include pension programs that exist on paper only. While conducting systematic tests on de facto program characteristics would have been ideal, these are very difficult to code in a valid manner. Further, if many programs are simply empty shells, they would expectedly not fulfill the above-theorized roles and have a clear causal effect on regime survival. Hence, our strong results below may actually underestimate the "true effect" of pension programs on regime survival. Likewise, de facto dismantling of existing programs - which happen (see Mares and Carnes $2009,94)$, despite the presumably strong incentives of leaders to maintain them - should attenuate our estimates. Second, we do not differentiate groups according to size. In principle, one could weight scores by group size, but sufficiently disaggregated information for coding groups comparably across space and time is not available. We therefore use non-weighted measures. Third, the Universalism Indices do not make qualitative distinctions between the particular groups covered. Expectedly, some major groups - such as domestic workers - are constituencies that autocrats are unlikely to grant benefits, whereas other - such as industrial workers - are critical supporting groups in many contexts, due to superior power resources and organizational capacity. In democracies, leaders may need to cater to both groups to be re-elected, and autocracies should thus have less universal systems than democracies. Our results, which indicate higher universalism among democracies, would not reflect our argument well if pension systems were first enacted covering only domestic or family workers (while excluding, e.g., industrial workers). This is, however, not the case in practice. During our coding, we found no instances of coverage being extended to domestic/family workers without urban manufacturing/industrial workers also receiving benefits. ${ }^{12}$ While imperfect, the measures used thus

\footnotetext{
${ }^{12}$ Benefits were, historically, often first extended to urban employees such as industrial, commercial workers, or salaried employees, with or without restrictions on firm size. Where agricultural workers were also included, a distinction was often made between workers using and not using electric power, ensuring only workers close to urban centers were covered.
} 
capture our theoretical concepts fairly well.

\section{Empirical analysis}

We organize the empirical tests in three sub-sections. First, we test $\mathrm{H} 1$ on regimes and adoption of pensions. We then test $\mathrm{H} 2$ on how targeted or universal pensions are under different regimes. Finally, we test $\mathrm{H} 3$ by investigating how programs affect autocratic regime breakdown.

\subsection{Does regime type matter for probability of adopting pensions?}

We argued that old-age pensions can be effectively targeted towards groups capable of affecting the survival of autocratic regimes. But, as outlined in the introduction, democratic politicians also have strong incentives to adopt pensions and other social policy programs. Hence, while democracies and autocracies may adopt pensions for different reasons, we do not expect any clear and systematic regime differences in the probabilities of adopting or having such programs.
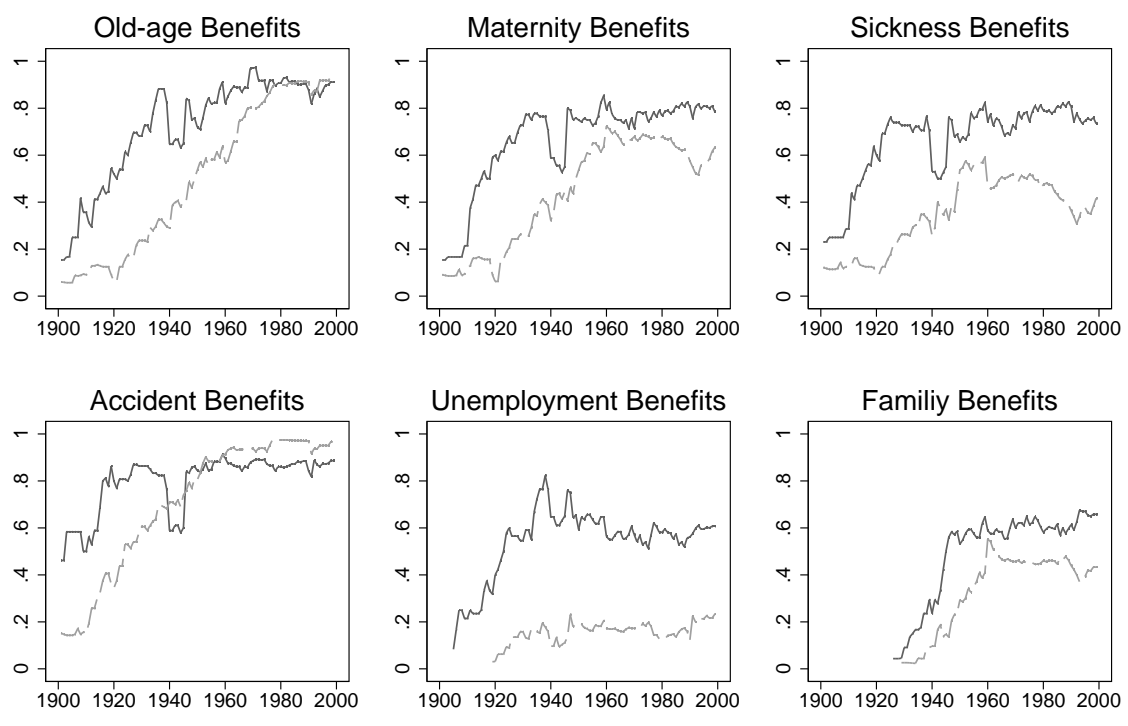

- Democracies -- Autocracies

Figure 1: Shares of democracies and autocracies, as operationalized by Boix, Miller and Rosato (2013), with programs in six social policy areas during the 20th century.

To test H1, we mainly use the dichotomous Boix, Miller and Rosato (2013) regime measure (henceforth BMR). BMR distinguishes between democracies and autocracies according to existence of free and fair elections and whether more than half of the male population can vote. ${ }^{13}$ The depen-

\footnotetext{
${ }^{13}$ The latter requirement means that for the early part of our time series, fairly competitive systems with restricted franchise are counted as autocracies. Nonetheless, we conduct tests on alternative democracy measures (e.g., Polity, which often code such cases as fairly democratic) and on restricted time series (post-1945) where few such "competitive oligarchies" exist, and results are robust.
} 
dent variable in Models A1-A3, Table 1, is a dummy recording whether an old-age pension system (covering $\geq 1$ major occupational/social group) exists, whereas Models A4-A6 have adoption of pension system as dependent variable. BMR and existence of pension system correlate by .26 (9166 obs. from Model A1); democracies more often have pension systems than autocracies, although the upper-left graphic of Figure 1 shows the difference has dwindled in more recent decades.

Nevertheless, this correlation ignores other factors affecting adoption of pensions. Pensions became increasingly common during the 20th century, although this expansion occurred earlier in some regions than others. Since also democratization has clustered in temporal waves, differently timed across regions (Huntington 1991), we always include year dummies and (eight) region dummies. We further include log GDP per capita; richer countries have more resources to spend on pensions, and income correlates with democracy. Appendix Table A.1 provides specifics on operationalization and sources used for the control variables. Our baselines are logit models with errors clustered on country to account for panel-specific autocorrelation. ${ }^{14}$

In Model A1, our most parsimonious specification accounting for income as well as region- and year-specific effects, the correlation between democracy and pension system vanishes. BMR is positive, but $t=0.3$. Model A2 adds two potentially relevant demographic controls, a (time-invariant) ethnic fractionalization index - a fractionalized society may make it more difficult, or less desirable, for leaders to implement pensions (see, e.g., Alesina, Baquir \& Easterly 1999) - and log population size. Although the latter control variable is statistically significant - larger countries more often have pensions, possibly due to the increased complexity of running distributive schemes though patronage networks in larger countries, necessitating formal programs - BMR does not change much. Model A3 further adds urbanization, which correlates with regime type and pensions, and two variables capturing available resources for, and alternative strategies of, co-optation (and repression). These are revenues from oil, gas, coal and metals as percentage of GDP and military personnel as percentage of the population. BMR turns negative in A3, but remains insignificant $(t=-0.03)$. These null-results

\footnotetext{
${ }^{14}$ We also tested Cox survival models and logit models using a dummy variable BCSTS specification (Beck, Katz \& Tucker 1998) or cubic splines (Carter \& Signorino 2010) to further account for temporal dependence. Our baseline results are fairly robust (see Appendix). Ideally, we would control for country-specific effects in our logit regressions, but this is infeasible. We include country dummies below when investigating degree of universalism, which provides far more within-country variation.
} 


\begin{tabular}{|c|c|c|c|c|c|c|}
\hline & A1 & A2 & A3 & A4 & A5 & A6 \\
\hline & \multicolumn{3}{|c|}{ DV: Existence pension program } & \multicolumn{3}{|c|}{ DV: Adoption pension program } \\
\hline & $b /(t)$ & $b /(t)$ & $b /(t)$ & $b /(t)$ & $b /(t)$ & $b /(t)$ \\
\hline \multirow[t]{2}{*}{ "Democracy (BMR) } & 0.128 & 0.095 & 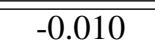 & 0.353 & 0.437 & 0.350 \\
\hline & $(0.32)$ & $(0.24)$ & $(-0.03)$ & $(1.11)$ & $(1.32)$ & $(1.09)$ \\
\hline \multirow[t]{2}{*}{ Ln GDP p.c. } & $0.498 *$ & $0.693 * * *$ & -0.123 & 0.098 & 0.190 & -0.178 \\
\hline & $(1.75)$ & $(2.59)$ & $(-0.42)$ & $(0.62)$ & $(1.03)$ & $(-0.59)$ \\
\hline \multirow[t]{2}{*}{ Ln population } & & $0.445^{* * *}$ & $0.424 * *$ & & $0.305^{* *} *$ & $0.317 * *$ \\
\hline & & $(2.85)$ & $(2.41)$ & & $(2.55)$ & $(2.47)$ \\
\hline \multirow[t]{2}{*}{ Ethnic fractionalization } & & -0.615 & -1.040 & & -0.273 & -0.842 \\
\hline & & $(-0.62)$ & $(-1.09)$ & & $(-0.46)$ & $(-1.27)$ \\
\hline \multirow[t]{2}{*}{ Urbanization } & & & $0.063 * * *$ & & & $0.029 * * *$ \\
\hline & & & (3.94) & & & $(2.70)$ \\
\hline \multirow[t]{2}{*}{ Military size } & & & -0.010 & & & 0.045 \\
\hline & & & $(-0.05)$ & & & $(0.51)$ \\
\hline \multirow[t]{2}{*}{ Resource dependence } & & & 0.001 & & & 0.004 \\
\hline & & & $(0.06)$ & & & $(0.25)$ \\
\hline Region dummies & Y & Y & $\mathrm{Y}$ & Y & Y & $\mathrm{Y}$ \\
\hline Year dummies & $\mathrm{Y}$ & $\mathrm{Y}$ & $\mathrm{Y}$ & $\mathrm{Y}$ & $\mathrm{Y}$ & $\mathrm{Y}$ \\
\hline $\mathrm{N}$ & 9166 & 8330 & 7881 & 1504 & 1344 & 1252 \\
\hline Countries & 140 & 137 & 137 & 114 & 111 & 107 \\
\hline
\end{tabular}

Table 1: Democracies, autocracies, and existence or adoption of pensions.

Notes: $* * * p<0.01, * * p<0.05, * p<0.10$. Logit regressions with errors clustered on country. Existence of minimum old-age pension system is dependent variable in $\mathrm{A} 1-\mathrm{A} 3$ and adoption in $\mathrm{A} 4-\mathrm{A} 6$ (here, countries already having systems are omitted). Year dummies, region dummies and constant are omitted from table. Maximum time series extend from late 1880s-2004.

are robust to adding other potentially relevant controls, such as civil war, British ex-colony status, literacy rates, or dependence on agriculture (Appendix Table A.3). We also control for trade to account for stronger incentives to adopt social policies in open economies (e.g., Mares 2005), and results are robust. Results are also retained when lagging all independent variables, substituting BMR with the continuous Polity index, controlling for many autocracies being Communist regimes, and running the models on post-1945 samples only (see Appendix). ${ }^{15}$

Models A4-A6 resemble A1-A3, but only include countries without pensions in $t-1$ and have introduction of pensions in $t$ as dependent variable. These models show that autocracies are no less likely to adopt pensions than democracies; while BMR is always positive, t-values range from 1.1 to 1.3. Thus, there is quite robust evidence that democracy is not systematically associated with having or adopting old-age pensions. This corroborates H1.

These results do not, however, imply that the typical "Autocratic Welfare State" is identical to the

${ }^{15}$ However, there are indications that democracies more often have pension systems once using the DD measure from Cheibub, Gandhi and Vreeland (2010). This partly reflects the shorter sample (post1945) - t-values are higher (though still insignificant) for BMR post-1945. We also tested various Cox duration model specifications. Here, the regime coefficient was sensitive to minor specification changes, with many models showing no effect and some showing a positive effect of democracy. 


\begin{tabular}{lccccc}
\hline \hline \multirow{2}{*}{ Program } & B1 & B2 & B3 & B4 & B5 \\
& Unemployment & Maternity & Family allowance & Work injury & Sickness \\
& $b /(t)$ & $b /(t)$ & $b /(t)$ & $b /(t)$ & $b /(t)$ \\
\hline \hline Democracy (BMR) & $1.002^{* *}$ & 0.272 & 0.289 & $1.036^{* * *}$ & $0.650^{* *}$ \\
& $(2.45)$ & $(0.91)$ & $(0.82)$ & $(2.79)$ & $(2.50)$ \\
Ln GDP p.c. & $1.184^{* *}$ & -0.209 & 0.272 & -0.446 & 0.002 \\
& $(2.45)$ & $(-0.58)$ & $(0.75)$ & $(-0.91)$ & $(0.00)$ \\
Ln population & $0.746^{* * *}$ & 0.279 & 0.092 & 0.002 & $0.560^{* *}$ \\
& $(3.62)$ & $(1.26)$ & $(0.42)$ & $(0.01)$ & $(1.97)$ \\
Ethnic fraction. & -1.676 & -1.052 & -0.787 & -0.396 & $-2.390^{* *}$ \\
& $(-1.25)$ & $(-1.03)$ & $(-0.74)$ & $(-0.29)$ & $(-2.12)$ \\
Urbanization & 0.015 & $0.024 * *$ & $0.039 * * *$ & 0.004 & -0.005 \\
& $(0.83)$ & $(2.05)$ & $(2.84)$ & $(0.18)$ & $(-0.41)$ \\
Size military & 0.260 & 0.106 & -0.303 & 0.347 & 0.020 \\
Resource dependence & $(1.38)$ & $(0.48)$ & $(-1.42)$ & $(0.78)$ & $(0.11)$ \\
& -0.011 & -0.004 & $-0.049 * * *$ & 0.011 & 0.009 \\
Region dummies & $(-0.33)$ & $(-0.33)$ & $(-2.58)$ & $(0.47)$ & $(0.55)$ \\
Year dummies & $\mathrm{Y}$ & $\mathrm{Y}$ & $\mathrm{Y}$ & $\mathrm{Y}$ & $\mathrm{Y}$ \\
\hline $\mathrm{N}$ & $\mathrm{Y}$ & $\mathrm{Y}$ & $\mathrm{Y}$ & $\mathrm{Y}$ & $\mathrm{Y}$ \\
Countries & 7039 & 7825 & 6724 & 7765 & 7894 \\
\hline \hline
\end{tabular}

Table 2: Democracies, autocracies, and the existence of various welfare programs.

Notes: ${ }^{* * *} p<0.01,{ }^{*} p<0.05,{ }^{*} p<0.10$. Logit regressions with errors clustered on country, with existence of program above minimum standard as dependent variables. Maximum time series extend from late 1880s-2004.

democratic. Indeed, our argument provided indications on how they may differ, for instance suggesting that autocracies might have relatively weaker incentives to adopt other types of social policy programs than pensions, as these are not equally effective as tools of political survival. Models B1-B5 in Table 2 resemble A3 from Table 1, but employ, respectively, the existence of (above minimumthreshold) unemployment -, maternity leave-, family allowance-, work injury-, and sickness benefits as dependent variables. BMR is positive and significant at 5 percent for unemployment- (B1), work injury- (B4), and sickness leave benefits (B5). These policies are presumably less easy (than pensions) to use for directing resources towards autocratic winning coalitions. However, democracy is not systematically related to maternity leave or family allowance programs. These findings are not predicted by our theoretical argument (but they do not directly contradict it either). We speculate that the results could partly stem from the active pro-natalist policies - with the intended purpose of increasing child births and expanding the population (for evidence that autocracies have systematically higher fertility- and population growth rates, see Przeworski et al. 2000, chapter 5) - pursued in many regimes to prepare for war (see Obinger \& Petersen 2017). Thus, we conjecture that while our argument focusing on "internal security threats" to the regime may explain the pension findings, a logic centering on "external security threats" might account for the maternity leave- and family allowances results. 


\subsection{Do autocracies adopt less universal pensions than democracies?}

Despite similar propensities for democracies and autocracies to have pensions, our argument also indicates that pensions should be targeted on fewer groups in autocracies. Indeed, the mean UniversalismIndex score for pensions is 3.4 for democracies and 1.5 for autocracies. In post-WWII samples, the respective numbers are 4.4 and 3.0. As noted, we omit observations without programs (0-score) and with means-tested programs (1-score) from our analysis. Figure 2 shows that also among the remaining observations, democracies typically have more universal programs, with the median democratic program covering four groups and the median autocratic covering three. Yet, income level, or countryspecific historical factors, could affect both regime type and pension features. We thus run different models, controlling for year- and country-specific effects, to test H2. We use linear models for our baseline specifications, but ordinal logit and probit specifications and logit and probit models using dummies (based on various cut-offs for the Universalism Index) give similar results.

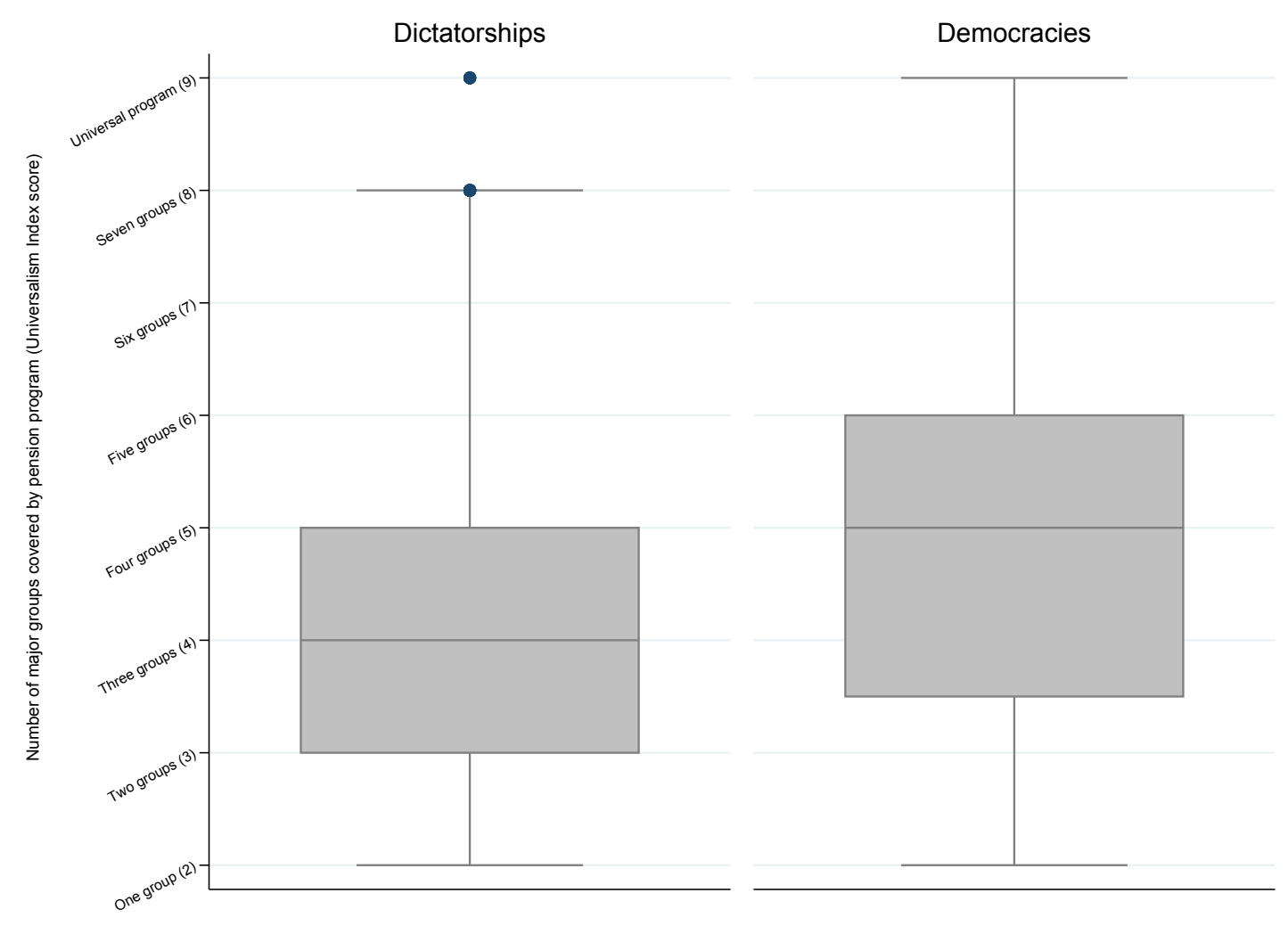

Figure 2: Box plots displaying the distribution of old-age pension programs according to the Universalism Index (omitting observations without programs or with only means-tested programs) for autocratic and for democratic regime observations.

Models C1-C2, Table 3, report standard fixed effects specifications with errors clustered on country. C1 controls for income level, and the point estimate indicates that going from autocracy to 


\begin{tabular}{|c|c|c|c|c|c|c|}
\hline & $\begin{array}{c}\mathrm{C} 1 \\
\text { Fixed Effects } \\
b /(t)\end{array}$ & $\begin{array}{c}\mathrm{C} 2 \\
\text { Fixed Effects } \\
b /(t)\end{array}$ & $\begin{array}{c}\mathrm{C} 3 \\
\mathrm{ECM} \\
b /(t) \\
\end{array}$ & $\begin{array}{c}\mathrm{C} 4 \\
\mathrm{ECM} \\
b /(t) \\
\end{array}$ & $\begin{array}{c}\text { C5 } \\
\text { System GMM } \\
b /(t) \\
\end{array}$ & $\begin{array}{c}\text { C6 } \\
\text { System GMM } \\
b /(t) \\
\end{array}$ \\
\hline Democracy (BMR) & $\begin{array}{c}0.320 * * \\
(2.00)\end{array}$ & $\begin{array}{l}0.281 \\
(1.59)\end{array}$ & $\begin{array}{c}0.168 * * \\
(2.52)\end{array}$ & $\begin{array}{c}0.162 * * \\
(2.21)\end{array}$ & $\begin{array}{c}0.259 * * * \\
(2.67)\end{array}$ & $\begin{array}{c}0.213 * * \\
(2.43)\end{array}$ \\
\hline$\Delta$ Democracy & & & $\begin{array}{c}0.043 \\
(1.11)\end{array}$ & $\begin{array}{c}0.044 \\
(1.06)\end{array}$ & & \\
\hline Ln GDP p.c. & $\begin{array}{l}0.203 \\
(1.02)\end{array}$ & $\begin{array}{l}0.266 \\
(1.33)\end{array}$ & $\begin{array}{c}0.151 * * \\
(2.01)\end{array}$ & $\begin{array}{c}0.148 * * \\
(2.01)\end{array}$ & $\begin{array}{c}0.379 * * * \\
(3.03)\end{array}$ & $\begin{array}{c}0.383 * * \\
(2.37)\end{array}$ \\
\hline$\Delta$ Ln GDP p.c. & & & $\begin{array}{l}0.009 \\
(0.08)\end{array}$ & $\begin{array}{l}0.075 \\
(0.66)\end{array}$ & & \\
\hline Ln Population & & $\begin{array}{l}0.310 \\
(0.80)\end{array}$ & & $\begin{array}{l}-0.058 \\
(-0.39)\end{array}$ & & $\begin{array}{l}-0.016 \\
(-0.14)\end{array}$ \\
\hline$\Delta$ Ln Popul. & & & & $\begin{array}{l}0.219 \\
(0.52)\end{array}$ & & \\
\hline Urbanization & & $\begin{array}{l}0.022 \\
(1.50)\end{array}$ & & $\begin{array}{l}0.008 \\
(1.41)\end{array}$ & & $\begin{array}{l}0.000 \\
(0.04)\end{array}$ \\
\hline$\Delta$ Urbanization & & & & $\begin{array}{l}0.000 \\
(0.02)\end{array}$ & & \\
\hline Size of military & & $\begin{array}{l}0.087 \\
(0.91)\end{array}$ & & $\begin{array}{c}0.073^{*} \\
(1.85)\end{array}$ & & $\begin{array}{l}0.035 \\
(0.67)\end{array}$ \\
\hline$\Delta$ Size milit. & & & & $\begin{array}{l}0.014 \\
(0.34)\end{array}$ & & \\
\hline Resource dependence & & $\begin{array}{c}-0.006^{*} \\
(-1.77)\end{array}$ & & $\begin{array}{l}-0.001 \\
(-0.80)\end{array}$ & & $\begin{array}{l}-0.002 \\
(-0.74)\end{array}$ \\
\hline$\Delta$ Res. dep. & & & & $\begin{array}{l}-0.002 \\
(-1.05)\end{array}$ & & \\
\hline Lagged dep. var. & & & $\begin{array}{c}-0.349 * * * \\
(-8.58)\end{array}$ & $\begin{array}{c}-0.352 * * * \\
(-8.46)\end{array}$ & $\begin{array}{c}0.260 * * * \\
\quad(9.18)\end{array}$ & $\begin{array}{c}0.276^{* * *} * \\
(8.55)\end{array}$ \\
\hline Year dummies & Y & $\mathrm{Y}$ & $\mathrm{Y}$ & $\mathrm{Y}$ & $\mathrm{Y}$ & $\mathrm{Y}$ \\
\hline $\mathrm{N}$ & 5064 & 4678 & 5006 & 4583 & 4910 & 4543 \\
\hline Countries & 132 & 131 & 132 & 131 & 132 & 131 \\
\hline
\end{tabular}

Table 3: Democracies, autocracies, and universalism of pensions.

Notes: $* * * p<0.01, * * p<0.05, * p<0.10$. Universalism Index for pensions is dependent variable (observations with non-existent program or means-tested program are excluded). (Non-differenced) independent variables in ECM models are lagged by one year. Errors are clustered on country. Maximum time series extend from late-1880s-2004.

democracy increases the pensions Universalism Index with $0.3(\mathrm{t}=2.00)$, a modest increase. Random effects specifications give similar results (see Appendix). However, BMR loses significance in C2 $(t=1.59)$, which adds population, urbanization, military size and resource dependence as controls. The somewhat weaker result in $\mathrm{C} 2$ mostly comes from the lower sample size. When re-running $\mathrm{C} 1$ on the 4678 observations in $\mathrm{C} 2$, the t-value drops from 2.00 to 1.72 . Thus, rejecting $\mathrm{H} 2$ based on Model $\mathrm{C} 2$ is premature, and we probe further specifications.

To investigate whether democracy predicts not only levels of, but also subsequent changes in, universalism we run Error Correction Models (ECM). In addition to country-fixed effects, these models control for the lagged dependent variable and (1-year lagged) levels as well as first-differences (from $t-1$ to $t$ ) for all independent variables. Hence, C3 and C4 investigate whether levels and/or changes in regime type affects changes in universalism from $t-1$ to $t$. Following standard interpretation 
of ECM models, a significant lagged-level coefficient suggests a long-term effect, and a significant first-difference coefficient a short-term effect. The ECM models show that only the lagged-level coefficient is clearly separable from zero $(\mathrm{t}=2.52$ for $\mathrm{C} 3$; $\mathrm{t}=2.21$ for $\mathrm{C} 4)$, suggesting a long-term effect. We also test the system GMM estimator from Blundell \& Bond (1998), which is particularly suitable for analyzing slow-moving variables such as regime type and pensions. As for ECM, system GMM models include lagged dependent variables. Both the parsimonious $(\mathrm{C} 5 ; \mathrm{t}=2.67)$ and extensive $(\mathrm{C} 6$; $\mathrm{t}=2.43$ ) GMM models find a positive democracy coefficient. ${ }^{16}$

While not entirely conclusive, the weight of the evidence thus suggests that autocracies target their pensions on fewer social groups than democracies do. The Appendix displays results on other social policy areas. We find that democracies have more universal unemployment benefits programs than autocracies but results are mostly insignificant for other programs. In sum, there is evidence that democracies pursue more universal welfare policies, but only in the realms of unemployment benefits and - as anticipated by our argument - old-age pensions.

\subsection{Do pensions reduce risks of autocratic regime breakdown?}

We test $\mathrm{H} 3$, which states that pension programs should reduce the risk of autocratic regime breakdown, by employing data from Geddes et al. (2014). They employ a regime definition emphasizing formal and informal rules for selecting policies and leaders, and their measure of regime failure captures changes from autocracy to democracy, between different autocracy types, and even between regimes of similar type (e.g., between the Personalist Mobutu and Kabila regimes in Zaire/Congo). Initially, we employ a naive assumption and consider pension programs as exogenous - despite the evidence in Table 1 showing they are endogenous to several factors. We run logit and probit models with regime failure as dependent variable, controlling for ethnic fractionalization, GDP per capita, population, military size and resource dependence. We also include the Geddes et al. regime dummies, since autocracy types are widely considered to differ in regime durability (Geddes 1999; Hadenius $\&$ Teorell 2007). We include log regime duration in some models; older regimes are generally at lower risk of being deposed (e.g., Svolik 2012). Yet, tenure length may partly stem from existence of pension programs. Hence, including regime duration may induce post-treatment bias, and we also

\footnotetext{
${ }^{16}$ The results are fairly robust to employing alternative lag-lengths for the independent variables. We also tested system GMM models instrumenting for levels of the endogenous independent variable (regime type) by using lagged differences, and for differences in regime type by using lagged levels (see Roodman 2009), and results are similar.
} 
report models without it.

These models are reported in Appendix Table A.16. Given the plausible argument on how pension programs bolster autocratic regimes, the lack of a statistically significant association between pension programs and regime failure might, at first glance, be surprising. Is there no effect on autocratic survival, after all? Such a conclusion would, however, not only be premature, but incongruent with the argument that $\mathrm{H} 3$ is drawn from. We expected autocrats to implement (expensive) pension programs where the regime perceives its future survival is threatened. In such situations, the regime may initiate pensions to shore up coalition support, or co-opt new groups. Programs should thus tend to exist in contexts where probability of regime survival is, initially, low. Even if pension programs have a positive causal effect on regime survival, pension programs and regime failure may display zero correlation. ${ }^{17}$ Figure 3 shows that the bivariate correlation between pension program adoption and regime breakdown is close to zero when measured contemporaneously. Yet, the correlation is typically positive when regime failure is measured before, and negative when measured more than five years after, pensions are introduced. Also logit and probit regressions including controls display a similar pattern. When pensions are measured 3-5 years before breakdown, they predict lower chances of breakdown, and results are often (weakly) significant (Table A.17). Further, past regime failure - signalling a more unstable political climate - sometimes predicts a higher likelihood of adopting pension programs (Table A.18).

Hence, both our theoretical argument and these preliminary findings suggest that we should model the "selection" of pensions and the effect of these programs on regime survival simultaneously. To this end, we employ Instrumental Variables Probit (IVProbit) models. Since this model can be fairly sensitive to specification choices, we test different combinations of controls and instruments, and also run (more robust) 2SLS models. To produce consistent estimates of the causal effect, we must identify instruments that are strongly correlated with pensions and not directly related to regime failure. Drawing on an insight from the literature on institutions and economic outcomes (Persson \& Tabellini 2003; Knutsen 2011; Huber, Ogorzalek \& Gore 2012; Acemoglu et al. 2014) we construct instruments tapping exogenous regional (and global) variation in the endogenous independent variable.

The underlying notion - backed up by literature on cross-border learning and other diffusion

\footnotetext{
${ }^{17}$ While autocrats cannot perfectly anticipate regime breakdown, the hypothesized pattern only requires that autocrats have consistent expectations in the sense that perceptions of risks of breakdown correlate with actual risk of breakdown.
} 


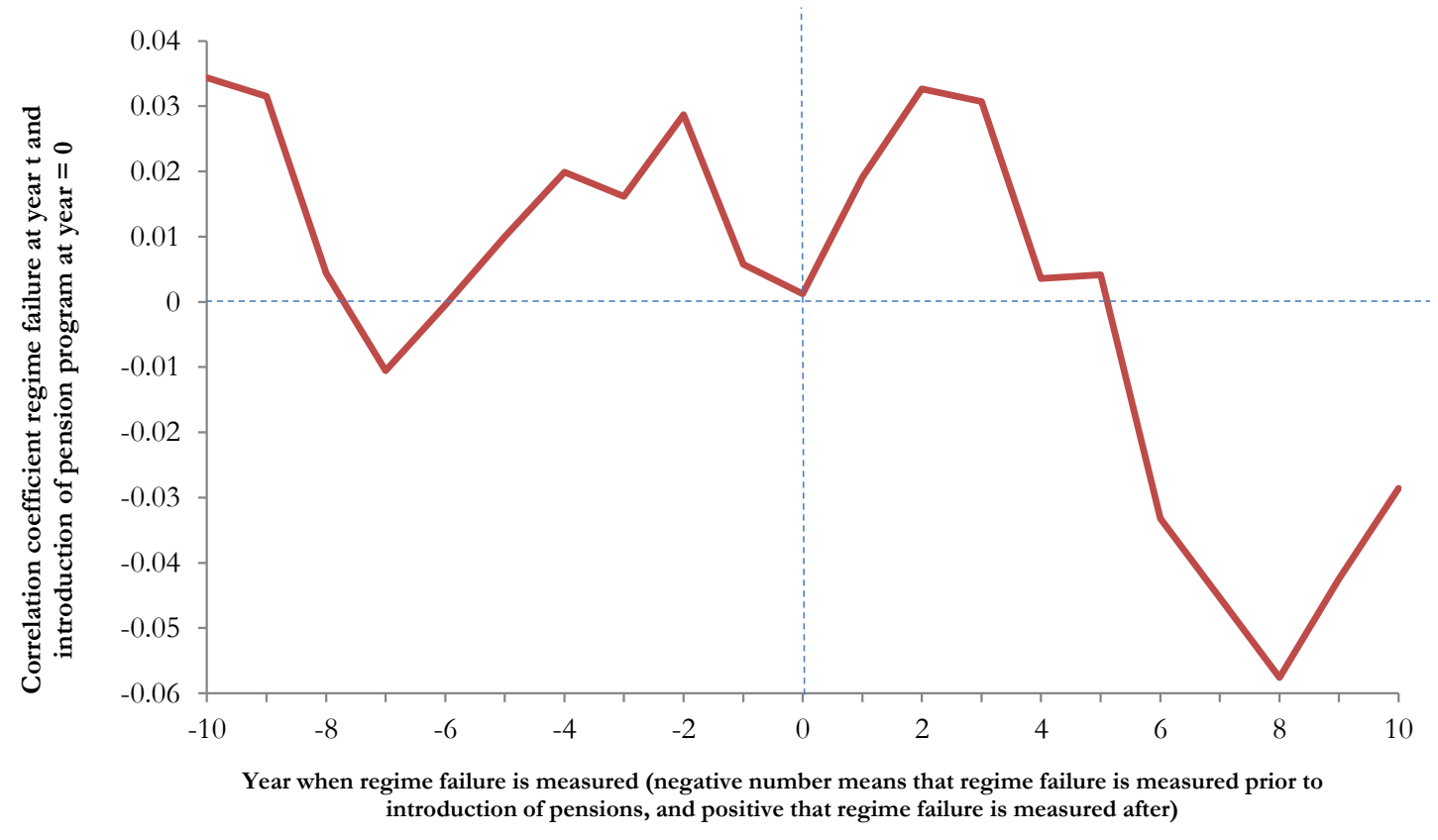

Figure 3: Bivariate correlation coefficients between autocratic regime failure measured at year $t$ and introduction of old-age pensions in year 0 . Correlation coefficients are displayed as three-year moving averages centered on year $t$.

mechanisms for social policy design (e.g., Obinger, Schmitt \& Starke 2012) - is that regimes residing in neighborhoods where most countries have pensions are more likely to adopt and continue such programs, everything else equal. While some cross-country variation in adoption, as argued, stems from perceived regime threats and strategic calculation by the regime, this is not the only source of variation. We aim at isolating the (exogenous) share of variation not affected by strategic adoption; Weyland (2005, 2007), for instance, highlights how various cognitive biases may make leaders more likely to adopt regionally "common models" of such policies, inducing cross-border "learning". Further, once conditioning on covariates (with one caveat related to neighboring regime breakdowns discussed below), neighboring country pension programs should not directly affect regime failure. The exclusion restriction is conditional on the controls included, such as time-trend/year-fixed effects, region-/country-fixed effects and regime age. Hence, our instrument - percentage share of other countries in the region (as defined by Miller 2015) having pensions in that year - is expectedly strong and - while this can never be fully ensured - might satisfy the exclusion restriction. In some models, we add share of (other) countries globally with pension programs, to pick up exogenous global trends. While the latter instrument turns out much weaker than the former, adding it allows for running standard overidentfication tests on the exclusion restriction. 


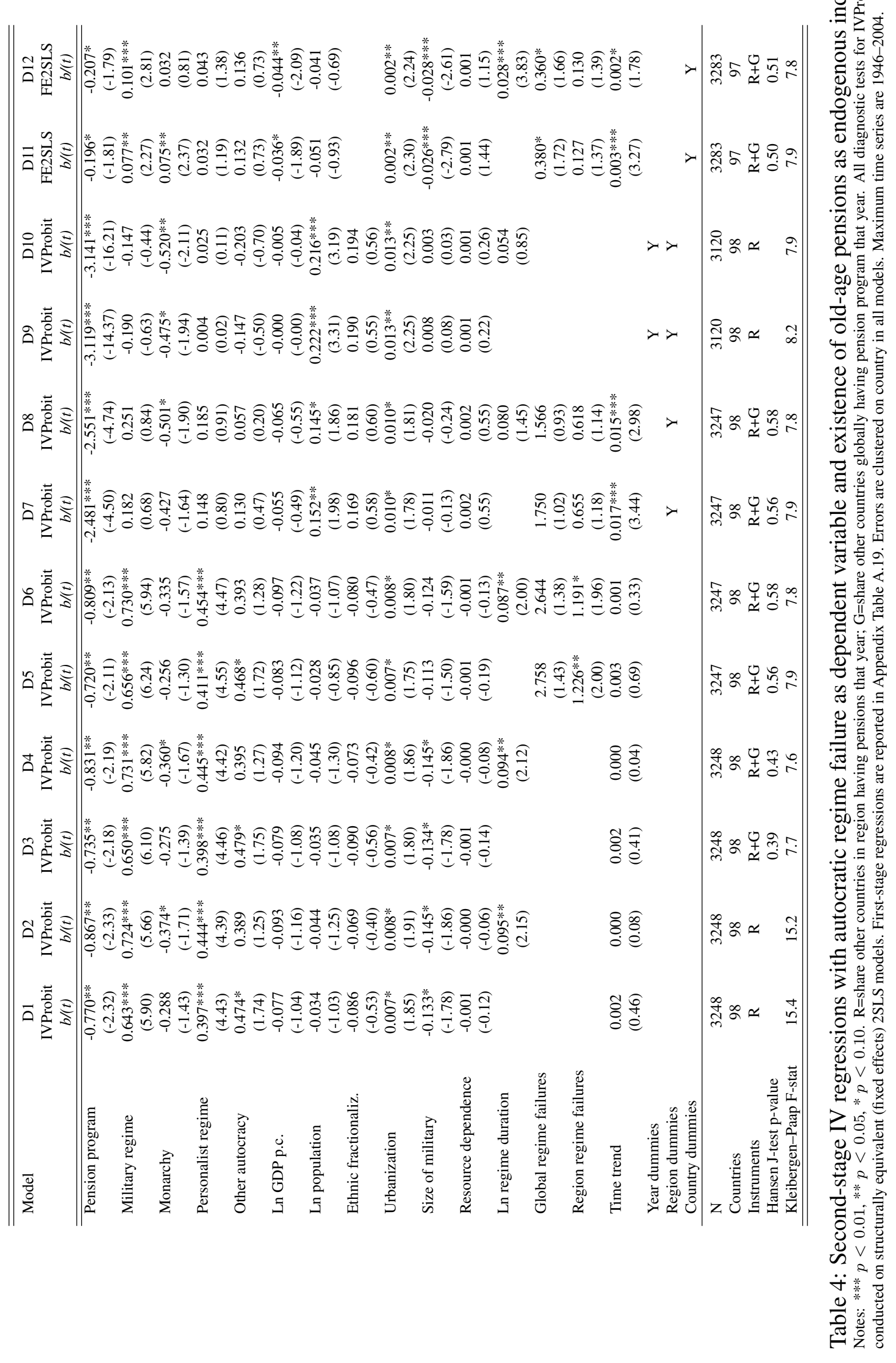


Table 4 reports second-stage results from twelve IV specifications. D1 and D2 (adding log regime duration to D1) only use the "region-share" instrument. This instrument is, quite naturally, highly collinear with the region dummies, but also the year dummies. D1 and D2 omit these dummies, but include a linear time trend. Both models report a clear, negative causal effect (significant 5 percent) of having pension programs on regime failure. Further, the region-share t-value in the first stage (Appendix Table A.19) is high ( $>$ 5), and the Kleibergen-Paap F-values are around 15, suggesting a moderately strong instrument. ${ }^{18}$

Yet, including only one instrument disallows overidentification tests for checking the exclusion restriction. Thus, we add the "global-share" instrument in D3 and D4. This instrument turns out much weaker than the regional, and the Kleibergen-Paap F-values drop to about 8, suggesting a modest (downwards) weak instrument bias. ${ }^{19}$ Nonetheless, the effect of pensions is retained, and the Hansen J-test p-values (around .4) indicate that the exclusion restriction holds.

However, one could still, on theoretical grounds, expect the exclusion restriction to be violated if pensions regionally and globally correlate with incidences of regime failure regionally and globally, and regime failures abroad directly impact on risk of regime failure domestically. This could, for example, stem from the following causal pathway:

Pensions regionally $\rightarrow$ Regional instability $\rightarrow$ Domestic instability $\rightarrow$ Domestic pensions

This pathway assumes that the regime-stabilizing effect of pensions operate in neighboring countries, and that there are spill-over effects on domestic regime stability from regime collapses in neighboring countries, e.g. because opposition actors are spurred to collective action or learn effective strategies from watching events in neighboring countries. If so, the exclusion restriction is violated in the previously discussed models, as there is a direct link between the instrument and dependent variable. To account for this causal pathway potentially affecting results, we control for shares of (other) countries regionally and globally experiencing regime failure (in given year) in D5 and D6. This does not alter the estimated effect of pensions on regime survival, but, as expected, the Hansen J-test p-values increase even further, increasing our confidence that the exclusion restriction holds for these models.

\footnotetext{
${ }^{18}$ Critical-test values for Kleibergen-Paap F-values are not readily calculable, but Cragg-Donald Fvalues (which are much higher), assuming classical errors, by far supersede all conventional criticaltest thresholds.

${ }^{19} \mathrm{IV}$-estimates are biased towards the single-equation estimates, which in our case are closer to zero, proportionally to the instruments' weakness.
} 
D7 and D8 include region-fixed effects. While this clearly weakens the first-stage t-value of our regional instrument (to, respectively, 1.1 and 2.1) due to collinearity, the absolute t-values for pensions on survival increase to, respectively, 4.5 and 4.7. We tried substituting the time trend in D7 and D8 with year dummies, but these models did not converge. After omitting the regional and global regime failure variables, and using only the regional instrument, these IVprobit regressions (D9 and D10) run. Still, the dummies lead to exceedingly high collinearity with the instrument in the first stage, and we thus put less trust in the results. But, if we are to believe them, there is a strong effect of pensions on regime breakdown $(t<-14)$. Finally, D11 and D12 are fixed effects 2SLS specification using both the regional and global instruments. These are conservative models, controlling for country-specific effects, and they report a causal effect of pension programs significant at 10 percent. Although results are slightly weakened (see Appendix) when lagging all independent variables one additional year, the finding is fairly robust. Ideally, we would test whether withdrawing and introducing pension programs have different effects on regime survival. Our argument indicated that withdrawing a program is particularly dangerous for autocrats. This may well explain why so few autocracies have abolished major pension programs, with the side-effect that we cannot estimate separate models on implementing and abolishing pensions. With this caveat in mind, the results above suggest that pensions guard against regime breakdown in autocracies, supporting $\mathrm{H} 3 .^{20}$

Our models not only indicate a statistically significant but also a substantively large effect, although confidence intervals around the point predictions are wide (see Figure 4). For illustration, Model D1 predicts that the Mussolini regime had about 1.7 percent chance of breakdown in Italy1925. Had the regime not posited a pension program, however, the best estimate is 8.8 percent. The model indicates that the personalist Perón regime was less consolidated, with a 7.3 percent breakdown probability in Argentina-1952. However, our best guess of this probability is 24.8 percent if Perón had removed the Argentine pension system. Figure 4 also reports the predicted probability in a (non-pension) observation that actually observed a breakdown of its military regime, Thailand-1973. Student protests in Bangkok, following rising middle class discontent with the economic situation, resulted in an intervention by the Thai King and subsequent regime change. Perhaps, if the regime had instituted pensions covering the discontent middle class groups of Bangkok, they might have been less willing to support the students' cause against the regime, leading to a different outcome. Model

\footnotetext{
${ }^{20}$ In the Appendix, we discuss similar results when only considering breakdowns followed by democratic transitions, finding evidence that pensions mitigate prospects for democratization.
} 


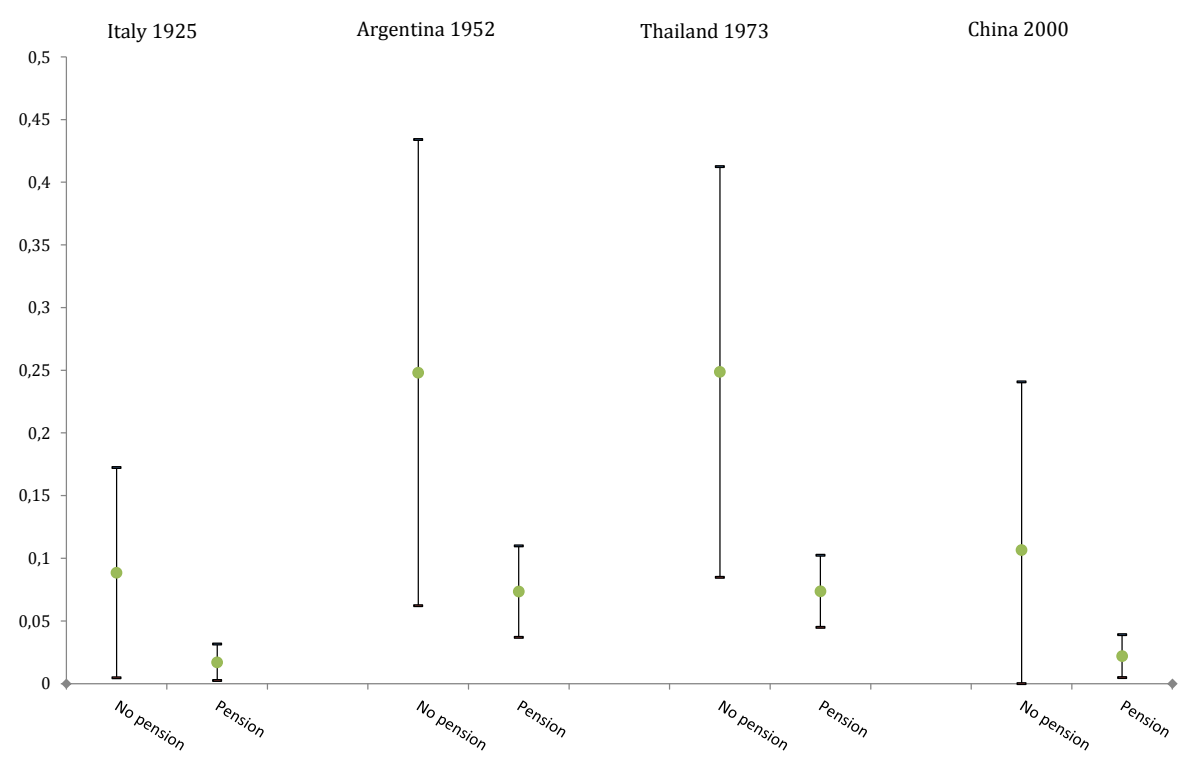

Figure 4: Predicted probabilities of regime breakdown (from Model D1) with 90\% CIs.

All covariates set at actual values, except hypotheticals on pensions (Thailand-1973 did not have pension system, but the other three did) and Italy-1925 (not coded by GWF) is coded as dominant-party regime.

D1 indeed predicts a 24.9 percent chance of breakdown for Thailand-1973, which changes to 7.3 percent with a pension program in place. Finally, China-2000 had about 2 percent chance of regime failure, but this would have been above 10 percent without a Chinese pension system, according to Model D1. ${ }^{21}$ Although these point estimates are very uncertain, there is seemingly a large effect of pension programs on regime survival.

One might still worry that the correspondence between social programs - here pensions - and regime durability is driven by some unobserved confounder (although some models above do control for country-specific effects). Perhaps more stable regimes, for some reason, adopt social programs more frequently. To probe this we run equivalents to the models in Table 4 for maternity leave rather than pension programs. As for pensions, our prior tests showed no systematic difference in likelihood of adopting or having maternity programs between democracies and dictatorships (which we speculate could stem from many autocracies being concerned with keeping fertility rates high). But, we do not clearly expect that providing benefits to working mothers increases regime survival. Maternity leave

${ }^{21}$ The Chinese state pension system of 1951/58 instituted coverage for the extensive state sector, with higher benefits for trade union members. The system thus covers industrial workers, but also the growing salaried middle classes, placating two decisive groups with strong collective action potential. 
cannot be selectively targeted to any critical supporter. Further, these fiscally smaller programs are associated with lower sunk costs and payments are made contingent on the event of child birth, thus lacking features that make old-age pensions particularly suitable as credible commitment devices. If IV regressions with maternity leave program as endogenous independent variable - and regional and global frequency of such programs as instruments - show similar effects on regime breakdown, we should worry that the pension results are spurious. However, Appendix Table A.21 shows that there is no effect of maternity programs on autocratic survival, whatsoever (most coefficients are actually positively signed). What is more, we find no evidence that work injury-, sickness-, or unemployment benefits affect regime breakdown either. Thus, the typically financially smaller programs that provide benefits contingent on realization of events such as injury or unemployment do not serve the same survival function for autocratic regimes as old-age pensions. Some models suggest a regime-stabilizing effect of family allowances. Yet, this result is not robust, with the coefficient flipping signs when controlling for region- or year-fixed effects. Thus, the evidence supports the notion that pensions constitute a unique and effective survival tool for autocracies. Indeed, Table A.26 shows that the clear effect of pensions from Table 4 holds up when controlling for existence of all other program types.

\section{Conclusion}

Major pension programs are not restricted to democracies. In this paper, we have present a novel argument for why autocratic regimes provide pension programs: Autocrats use pensions to direct resources to critical supporting groups. Targeted pensions are often favored over private goods distribution, because they enable autocrats to credibly commit to future distribution, thereby mitigating the incentives of critical groups to overthrow the regime.

By leveraging the new SPAW dataset, we have systematically tested different implications from this argument, leveraging information from almost 140 countries with time series back to the late 1880s. We find clear patterns in the data that corroborate quite different implications from our argu-

ment. First, while autocracies are less likely than democracies to operate other social programs less suitable for directing resources to autocratic coalitions, democracies and autocracies do not systematically differ in the probabilities of adopting or having pensions. However, democracies operate more universal programs than autocracies. Perhaps most notably, we find robust evidence that pensions have a positive effect on autocratic regime survival, suggesting that implementing pensions constitutes an effective survival strategy for autocratic regimes. 


\section{References}

Acemoglu, D., \& Robinson, J. A. (2006). Economic Origins of Dictatorship and Democracy. New York: Cambridge University Press.

Acemoglu, D., Naidu, S., Restrepo, P., \& Robinson, J. A. (2014). "Democracy Does Cause Growth.” Cambridge, MA.: NBER Working Paper No. 20004.

Albertus, M., \& Menaldo, V. (2012). "If you're against them you're with us: the effect of expropriation on autocratic survival." Comparative Political Studies, 45(8), 973-1003.

Alesina, A., Baquir, R., \& Easterly, W. (1999). "Public Goods and Ethnic Divisions." The Quarterly Journal of Economics, 114(4), 1243-1284.

Ansell, B. W. (2010). From the Ballot to the Blackboard: The Redistributive Political Economy of Education. Cambridge: Cambridge University Press.

Ansell, B. W., \& Samuels, D. J. (2014). Inequality and Democratization: An Elite-Competition Approach. Cambridge: Cambridge University Press.

Beck, N., Katz, J. N., \& Tucker, R. (1998). "Taking Time Seriously: Time-Series-Cross-Section Analysis with a Binary Dependent Variable.” American Journal of Political Science, 42(4), 12601288.

Blundell, R., \& Bond, S. (1998). "Initial conditions and moment restrictions in dynamic panel data models." Journal of Econometrics, 87(1), 115-143.

Boix, C. (2003). Democracy and Redistribution. Cambridge: Cambridge University Press.

Boix, C., Miller, M. K., \& Rosato, S. (2013). “A Complete Data Set of Political Regimes, 1800-2007.” Comparative Political Studies, 46(12), 1523-1554.

Boix, C., \& Svolik, M. W. (2013). "The Foundations of Limited Authoritarian Government: Institutions, Commitment, and Power-Sharing in Dictatorships." Journal of Politics, 75(2), 300-316.

Bueno de Mesquita, B., Smith, A., Siverson, R. M., \& Morrow, J. D. (2003). The Logic of Political Survival. Cambridge, Ma.: MIT Press.

Carter, D. B., \& Signorino, C. S. (2010). "Back to the Future: Modeling Time Dependence in Binary Data." Political Analysis, 18(3), 271-292.

Cheibub, J. A., Gandhi, J., \& Vreeland, J. (2010). "Democracy and dictatorship revisited." Public Choice, 143, 67-101.

Chetty, R. (2006). “A New Method of Estimating Risk Aversion.” American Economic Review, 96(5), 
$1821-1834$.

Collier, R. B. (1999). Paths Towards Democracy. Cambridge: Cambridge University Press.

Desai, R. M., Olosgård, A., \& Yousef, T. M. (2009). "The Logic of Authoritarian Bargains.” Economics \& Politics, 21(1), 93-125.

Epstein, E. C. (1979). “Control and Co-optation of the Argentine Labor Movement.” Economic Development and Cultural Change, 27(3), 445-465.

Esping-Andersen, G. (1990). The three worlds of welfare capitalism. Princeton: Princeton University Press.

Frantz, E., \& Kendall-Taylor, A. (2014). “A dictator's toolkit: Understanding how co-optation affects repression in autocracies." Journal of Peace Research Forthcoming.

Gandhi, J. (2008). Political Institutions under Dictatorship. Cambridge: Cambridge University Press.

Geddes, B. (1999). "What Do We Know About Democratization After Twenty Years?” Annual Review of Political Science, 2, 115-144.

Geddes, B., Wright, J., \& Frantz, E. (2014). “Autocratic Breakdown and Regime Transitions: A New Data Set." Perspectives on Politics, 12(2), 313-331.

Gehlbach, S., \& Keefer, P. (2011). "Investment without democracy: ruling-party institutionalization and credible commitment in autocracies." Journal of Comparative Economics, 39(2), 123-139.

Gehlbach, S., \& Keefer, P. (2012). "Private Investment and the Institutionalization of Collective Action in Autocracies: Ruling Parties and Legislatures.” Journal of Politics, 74(2), 621-635.

Haber, S., \& Menaldo, V. (2011). "Do natural resources fuel authoritarianism? A reappraisal of the resource curse." American Political Science Review, 105(1), 1-26.

Hadenius, A., \& Teorell, J. (2007). "Pathways from Authoritarianism.” Journal of Democracy, 18(1), $143-156$.

Haggard, S., \& Kaufman, R. R. (2008). Development, Democracy, and Welfare States: Latin America, East Asia, and Eastern Europe. Princeton: Princeton University Press.

Harding, R., \& Stasavage, D. (2014). "What Democracy Does (and Doesnât Do) for Basic Services: School Fees, School Inputs, and African Elections.” Journal of Politics, 76(1), 229-245.

Huber, E., \& Stephens, J. D. (2001). Development and crisis of the welfare state: Parties and policies in global markets. Chicago: University of Chicago Press.

Huber, J. D., Ogorzalek, T. K., \& Gore, R. (2012). "Democracy, targeted redistribution and ethnic 
inequality.” New York: Columbia University. Working Paper.

Huntington, S. P. (1991). The Third Wave: Democratization in the Late Twentieth Century. Norman: University of Oklahoma Press.

International Labor Organization. (1922). Legislative Series. Geneva: ILO publishing.

Iversen, T. (2005). Capitalism, democracy, and welfare. Cambridge: Cambridge University Press.

Iversen, T., \& Soskice, D. (2009). "Distribution and redistribution: The shadow of the nineteenth century." World Politics, 61(3), 438-486.

Keohane, R. O. (1984). After Hegemony: Cooperation and Discord in the World Political Economy. Princeton, NJ: Princeton University Press.

Kim, W. (2007). "Social Insurance Expansion and Political Regime Dynamics in Europe, 18801945.” Social Science Quarterly ,88(2), 494-514.

Knutsen, C. H. (2011). "Democracy, Dictatorship and Protection of Property Rights." Journal of Development Studies, 47(1), 164-182.

Kuran, T. (1989). "Sparks and Prairie Fires: A Theory of Unanticipated Political Revolution.” Public Choice, 61(1), 41-74.

Lake, D. A., \& Baum, M. A. (2001). “The Invisible Hand of Democracy: Political Control and the Provision of Public Services.” Comparative Political Studies, 34(6), 587-621.

Lindert, P. H. (2005). Growing Public: Social Spending and Economic Growth since the Eighteenth Century. Volume 1. Cambridge: Cambridge University Press.

Magaloni, B. (2006). Voting for Autocracy: Hegemonic Party Survival and its Demise in Mexico. New York: Cambridge University Press.

Magaloni, B. (2008). "Credible Power-Sharing and the Longevity of Authoritarian Rule.” Comparative Political Studies, 41(4-5), 715-741.

Mares, I. (2005). "Social Protection Around the World: External Insecurity, State Capacity, and Domestic Political Cleavages." Comparative Political Studies, 38(6), 623-651.

Mares, I., \& Carnes, M. E. (2009). “Social Policy in Developing Countries.” Annual Review of Political Science, 12, 93-113.

Meltzer, A., \& Richard, S. (1981). “A rational theory of the size of government.” Journal of Political Economy, 89(5), 914-927.

Mesa-Lago, C. (1978). Social Security in Latin America: pressure groups, stratification, and inequal- 
ity. Pittsburgh: University of Pittsburgh Press.

Milanovic, B. (1998). Income, Inequality, and Poverty During the Transition from Planned to Market Economy. Washington D.C.: The World Bank.

Miller, M. K. (2015). “Democratic Pieces: Autocratic Elections and Democratic Development since 1815.” British Journal of Political Science, 45(3), 501-530.

Moene, K., \& Wallerstein, M. (2001). "Inequality, Social Insurance, and Redistribution.” American Political Science Review, 95(4), 859-874.

Mulligan, C. B., Sala-i-Martin, X., \& Gill, R. (2003). "Do Democracies Have Different Public Policies than Nondemocracies?” Jounal of Economic Perspectives, 18(1), 51-74.

North, D. C., \& Weingast, B. R. (1989). "Constitutions and Commitment: The Institutions Governing Public Choice in Seventeenth Century Englad." Journal of Economic History, 44(4), 803-832.

Obinger, H., \& Petersen, K. (2017). "Mass Warfare and the Welfare State â Causal Mechanisms and Effects.” British Journal of Political Science, 47(1), 203â-227.

Obinger, H., Schmitt, C., \& Starke, P. (2012). "Policy Diffusion and Policy Transfer in Comparative Welfare State Research.” Social Policy \& Administration, 47(1), 111-129.

Persson, T., \& Tabellini, G. (2003). The Economic Effect of Constitutions. Cambridge, MA: MIT Press.

Pierson, P. (2000). "Increasing Returns, Path Dependence, and the Study of Politics." American Political Science Review, 94(2), 251-267.

Ponticelli, J., \& Voth, H.-J. (2011). "Austerity and Anarchy: Budget Cuts and Social Unrest in Europe, 1919-2008." Working paper.

Przeworski, A., Alvarez, M. E., Cheibub, J. A., \& Limongi, F. (2000). Democracy and Development. Cambridge: Cambridge University Press.

Rasmussen, M. B. (2016). “The Social Policy around the World (SPaW) Database: Codebook”. URL: https : //www.researchgate.net/publication/299445433

Rimlinger, G. V. (1971). Welfare Policy and Industrialization in Europe, America and Russia. New York: Wiley.

Roodman, D. (2009). "How to do xtabond2: An introduction to difference and system GMM in Stata.” STATA Journal, 9(1), 86-136.

Rueschemeyer, D., Stephens, E. H., \& Stephens, J. D. (1992). Capitalist Development and Democ- 
racy. Chicago, IL: University of Chicago Press.

Scruggs, L. (2006). “The generosity of social insurance, 1971-2002.” Oxford Review of Economic Policy, 22(3), 349-364.

Stasavage, D. (2005). "Democracy and Educational Spending in Africa." American Journal of Political Science, 49(2), 343-358.

Svolik, M. W. (2012). The Politics of Authoritarian Rule. Cambridge: Cambridge University Press.

Weyland, K. (2005). “Theories of Policy Diffusion: Lessons from Latin American Pension Reform.” World Politics, 57(2), 262-295.

Weyland, K. (2007). Bounded Rationality and Policy Diffusion: Social Sector Reform in Latin America. Princeton: Princeton University Press.

Wintrobe, R. (1998). The Political Economy of Dictatorship. Cambridge: Cambridge University Press.

Wright, J. (2008). "Do Authoritarian Institutions Constrain? How Legislatures Affect Economic Growth and Investment.” American Journal of Political Science, 52(2), 322-343. 


\section{A Online Appendix}

This appendix contains additional information about the coding rules and sources used for constructing the variables from the SPAW dataset, and a number of robustness tests and extensions of the empirical analysis presented in the paper. After presenting some more detail on the coding rules and sources used for the coding of social policy programs, the remaining sections of the appendix are organized such that they cover the robustness tests and extensions found in the different subsections of the empirical analysis.

Hence, after the data discussion, we present descriptive statistics and additional analysis related to the subsection that addresses whether regime type matters for the probability of having pension (and other social policy) programs. These tests include models with alternative sets of control variables, models run on shorter time series and models using alternative measures of democracy than the BoixMiller-Rosato measure that we use as our baseline.

Thereafter, we present additional analysis for the subsection on whether autocracies and democracies differ in terms of how universal or targeted their pension programs are. This sub-section include robustness tests of the models on pension systems, but we also report universalism indices constructed for the other social policy programs. Further, the sub-section contains different models that robustness test whether our assumptions regarding the measurement level of the universalism index matters, including ordinal logit and probit models.

We finally present descriptive statistics and results for the subsection addressing whether pension programs affect probability of regime breakdown. More specifically, we first present the "naive" models that do not account for the fact that the adoption of pension programs is endogenous, and which thus yield biased results, and versions of these models experimenting with different lag-lengths. This sub-section also contains the first-stage results from the IV probit and FE 2SLS models treating pension programs as endogenous, robustness tests of the IV models reported in the paper, as well as IV models on regime breakdown treating the other social policy programs as endogenous regressors. Finally, it includes an extended discussion and IV regression results when democratization rather than autocratic regime failure is the dependent variable. 


\section{A.1 SPAW - notes on coding rules and sources}

In this section, we outline, in more detail, how our coding in SPAW differs from previous attempts to code the introduction of major social policy laws. Further, we provide more information on how the information used for constructing the Universalism Indices is coded. Finally, we report and discuss the main sources used for coding the SPAW variables used in the paper.

As noted in the paper, SPAW contains two main categories of variables, namely I) legislative changes and II) program characteristics. To expand on the contents of the second category, program characteristics may be conceptualized as varying along two dimensions, IIa) eligibility and IIb) distributive potential. Eligibility refers to rules defining who can partake, whereas distributive potential concerns the program's inherent capacity to allocate benefits to members. Therefore, eligibility relates to who is covered against risks, and distributive potential to the benefits program members can expect. SPAW measures eligibility by first classifying whether programs are means-tested, employment-based or fully universal, and make further nuances by constructing Universalism indices - with the longest time series starting with the German accident liability insurance of 1871. For distributive potential, SPAW contains numerous variables, including measures of whether program eligibility is constrained by income ceilings; number of days recipients must wait before receiving benefits; number of weeks program benefits extend over; and, whether the state subsidizes programs.

Regarding I), the main differences in the scoring of existence of major social policy programs between the SPAW and previous coding efforts (Cutright 1965; Collier and Messick 1975; Hicks 1995; Mares and Carnes 2009) is the more precise definition of what constitutes a major law, what type of programs are considered as social policy programs, and how to deal with federal states. We discuss how we dealt with these and other issues below. Importantly, we only consider a program as a major welfare law if it covers (at least) one major social group. These groups are agricultural workers; industrial/production workers; small-firm workers; self-employed; students; employers; temporary/casual workers; family/domestic workers. The SPAW operationalization thus excludes from being considered as an above minimum-level program the early social legislation that tended to be restricted to, for instance, miners, sailors, postal workers, transport workers, and those employed in various forms of public service (military, civil servants, judges and so on). As noted, we employ this criterion for coding social policy programs divided into six areas: sickness leave; maternity leave; unemployment; disability/work injury; family allowances; and, old-age pensions. 
Another source of difference between the SPAW coding and other datasets concerns how to deal with programs in federal states. Social policy legislation might be absent at the federal level, but be prevalent at the state-level, but often far more so in some states (within a country) than others. It is difficult to ensure cross-country comparability in the coding of federal-state legislation (in part due to lack of comparable sources). It is not clear how previous databases have solved this problem. In order to be consistent, we have thus only employed national legislation, meaning that state or provincial legislation is not included in the coding. Quite naturally, one might worry that this underestimate the extent of social regulation in federal states compared to in unitary states. For example, federal family benefits in Switzerland was for a long time restricted to farmers only, with the various Cantons having introduced measures to cover most urban workers. So, in effect, most categories of workers ended up with coverage even if not trough the same legislation. At the same time, differences between local and national arrangements also exist in unitary states. For example, in Norway local pensions covered most of the population long before a national pension system was put in place in 1936. It is therefore not entirely certain that this omission only impacts federal states, as also unitary states had encompassing local or regional initiatives. Coding (and aggregating) local regulations both for federal and unitary states, down to the municipality level, is a tremendous task, and we thus consider the choice to only include national legislation the best alternative, in practice.

One common source of disagreement on the introduction of major laws relates to previous studies not separating benefits in kind systems from transfer programs. In order to provide a clear coding and avoid any resulting conflation and misinterpretation, SPAW only codes the latter. It should be noted that even previous datasets that have claimed to measure only transfer programs are sometimes doing otherwise. For example, New Zealand is sometimes coded as having an unemployment program in 1930. Unfortunately, closer inspection with primary sources shows that New Zealand at that time had only introduced an unemployment relief program, where unemployed workers were given public work in exchange for basic assistance. Even if one accepts this as an unemployment insurance program, benefits where not in payments, but instead in kind. New Zealand did not introduce a transfer program before in 1938, an eight year difference between our score and the score from the previous measures.

Further, in the SPAW coding, we have focused on whether groups have the right to become members of an insurance, and not the stronger requirement that they are actively forced so by the government (as is the case in compulsory insurance). Hence, in our main variables used in the paper, 
we make no difference between coverage of major groups resulting from coverage in a voluntary program or whether they are given the option to insure voluntary in a program that is obligatory for other groups. This explains why, for instance, our coded coverage level for Japanese programs is more generous than what is sometime assumed; we take into account that even as compulsory insurance was restricted to urban workers in large firms, other categories of workers could voluntary opt into coverage. We have, however, left out voluntary coverage programs without some form of state subsidies.

Regarding II), the program characteristics measures used in the paper are the Universalism Indices. Numerous sources have been used to code these indices, notably the ILO Legislative series (1919-), US Labor Department SSPTW-reports (1937-), and various national sources such as national law-databases (Scandinavian and Anglo-Saxon countries) and statistical yearbooks (Australian Bureau of Statistics, Various; New Zealand Statistics, Various; Statistics Norway, Various). Previous data collection efforts such as De Mesa and Mesa-Lago (2006); Flora, Alber and others (1983,?); Mesa-Lago (1978, 2007, 2008), and particularly the early M-series reports by the ILO (1922-1936) have also been consulted. The distributions of the Universalism Indices for the six major programs are shown in Figure A.1.
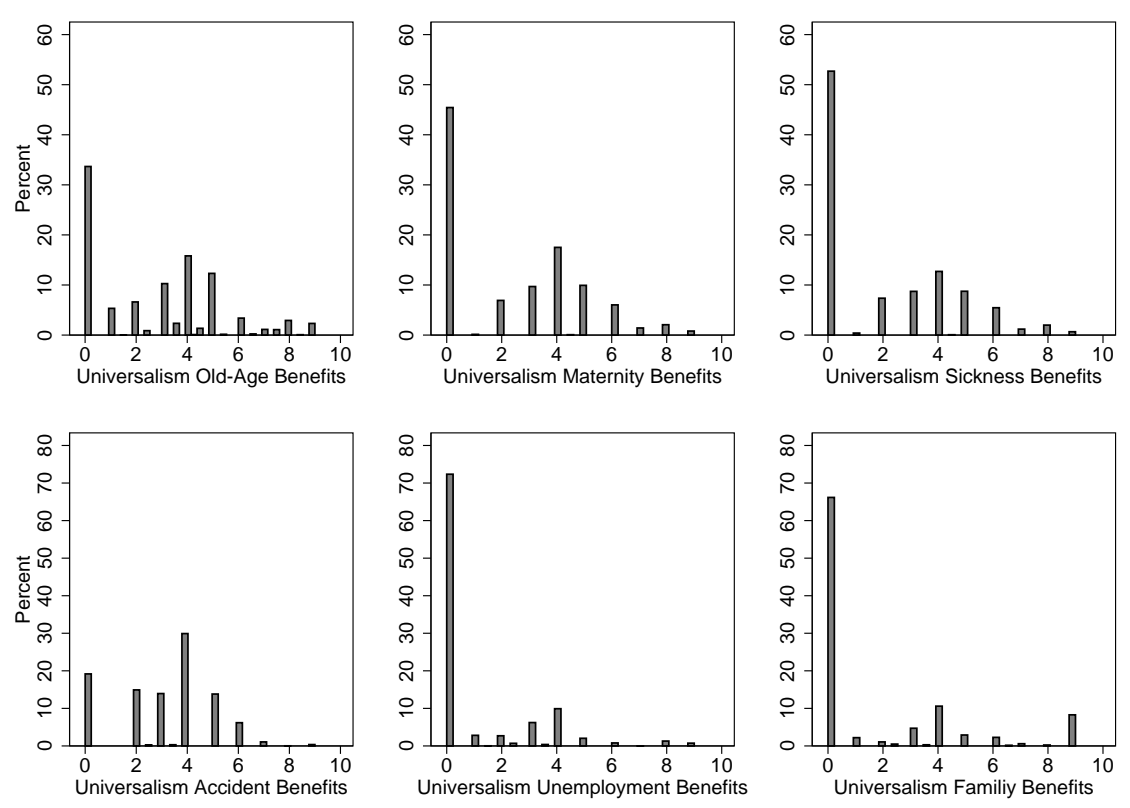

Figure A.1: Distribution on Universalism Index for the six major social policy programs, all SPAW observations.

In coding the Universalism Indices we had to make choices regarding what was to be considered as proper coverage. In coding the extent of coverage, the SPAW variables make no distinction between 
whether this coverage results from voluntary or compulsory insureance or private or social insurance, or whether groups are covered in the same program or have their own program. The latter is important, as coverage was usually extended to urban and rural workers in different programs in continental European countries, with programs for the rural sector coming later than for the urban workers. One issue of concern is that some countries - the present day unemployment insurance in the UK being one example - have enacted two, or even up to three, major programs covering the same risk, for instance with the first being a social insurance program and the second a means-tested program. In order to deal with the presence of such dual-programs, we follow the same strategy as Mares (2005). First, we code each independent program using the universalism metric, and then we take the average of these program scores to arrive at the final universalism score (as observant readers will note from Figure A.1, the universalism scores are not all integer values, and this is the reason). It is important to note that in order to be considered as a dual or triple system, entitlements for the second program must be independent of the first program. A (second) program will not be coded as an independent program if payment in this program is dependent on having received payments from the first program. This follows from the fact that eligibility for the continuation benefit is dependent on first having qualified for the first program. It is therefore hard to consider these as separate programs, which our scoring reflects.

In addition, if a country has enacted a social insurance program covering industrial workers and small-firm workers in urban areas and a second social insurance program for rural workers, we decided to count these groups as if they were covered in the same system. In this instance (if no other groups were covered), the program would be given a universalism score of 4. An alternative solution would have been to first score the two programs independently, and then take the average of two programs as the final score. What this approach takes into account is the degree of segmentation, as coverage was extended through different programs with different conditions and benefits instead of covering both groups in the same program. Following the alternative approach would have resulted in a universalism score of 2.5 (rural program $=$ universalism score of 2; urban program $=$ universalism score of 3 ; final universalism score $2+3 / 2=2.5$ ). The two approaches obvious leads to quite important differences in scoring, and while there may be good reasons to correct for segmentation, the alternative options has larger drawbacks than benefits. In our example, a country would score higher on universalism when not covering rural workers than when covering them under a separate program, 
which clearly is too penalizing. We therefore opted for the first approach in coding the number of groups covered to arrive at the final universalism score.

The perhaps primary source of bias in our coding is that "de jure sources" (and especially the SSPTW) are not always explicit as to how many groups are covered. Sometimes the law specifies "all employees" as eligible, with temporary and domestic workers included in the definition of employees, whereas other times, "all employees" only refer to employees under long-term contracts, and not those in domestic employment. Sometimes additional country sources can be used to determine which definition of employees was used - and we have gone lengths to identify and assess such sources - but in many instances the law itself is ambiguous. In these instances, we therefore developed the following rule of thumb: when "only employees" are stated as covered, we coded the system as covering wage and salaried workers in both industry and agriculture independent of firm size. When instead the law states that "all employees" are covered, we coded the system as covering all forms of wage and salaried work, including temporary, students and domestic workers. The only excluded categories in these systems are self-employed and employers.

As a final word of caution we want to highlight that even if we find our coding procedures clearer and more consistent than previous coding efforts conducted over the same numbers of countries, the SPAW dataset can still be considered "work in progress". As more sources become obtainable, and as scholars and others correct and point out errors in our coding, we will update the SPAW dataset and make these improved versions available to the public. 


\section{A.2 Descriptive statsitics and sources for control variables}

\begin{tabular}{|c|c|c|}
\hline Variable name & Operationalization & Source \\
\hline Region dummies & $\begin{array}{l}\text { Eight regions: Eastern Europe and Soviet Union; Latin America, North Africa and } \\
\text { Middle East; sub-Saharan Africa; Western Europe and British settler colonies; } \\
\text { East Asia; Southeast Asia and the Pacific; South Asia }\end{array}$ & Miller (2015) \\
\hline GDP per capita & The natural logarithm of real GDP per capita, PPP-adjusted & Maddison (2007) \\
\hline Population size & The natural logarithm of (inhabitants/1000) & Maddison (2007) \\
\hline Ethnic Fractionalization index & $1-\sum_{i} s_{i}^{2}$ where $s_{i}$ is the population share of group $i$ & Alesina et al. (2003) \\
\hline Urbanization & Percentage share of population living in urban areas & Miller (2015) \\
\hline Resource dependence & $\frac{\text { Oil+gas }+ \text { coal }+ \text { metals revenues }}{G D P}$ & Miller (2015) \\
\hline Military Size & Percentage share of population in armed forces & Miller (2015) \\
\hline
\end{tabular}

Table A.1: Additional information on the central control variables used in the paper. 


\begin{tabular}{lcccc}
\hline \hline Variable $\backslash$ Statistic & Mean & Standard deviation & Minimum & Maximum \\
\hline \hline Old-age pension system & 0.71 & 0.45 & 0 & 1 \\
Democracy (BMR) & 0.39 & 0.48 & 0 & 1 \\
Ln GDP per capita & 8.11 & 1.02 & 5.38 & 11.08 \\
Ln population & 9.00 & 1.48 & 5.33 & 14.06 \\
Ethnic fractionalization & 0.42 & 0.25 & 0.00 & 0.93 \\
Urbanization & 37.19 & 24.25 & 0 & 100 \\
Size of military & 0.63 & 0.69 & 0 & 12.73 \\
Resource dependence & 4.12 & 9.55 & 0 & 100 \\
\hline \hline
\end{tabular}

Table A.2: Descriptive statistics for the 7881 observations (and variables) entering Model A3, Table 1 in the paper. 


\begin{tabular}{|c|c|c|c|c|c|c|}
\hline & $b /(t)$ & $b /(t)$ & $b /(t)$ & $b /(t)$ & $b /(t)$ & $b /(t)$ \\
\hline \multirow[t]{2}{*}{ Democracy (BMR) } & 0.023 & -0.025 & 0.080 & 0.055 & -0.076 & -0.016 \\
\hline & $(0.06)$ & $(-0.07)$ & $(0.22)$ & $(0.13)$ & $(-0.19)$ & $(-0.04)$ \\
\hline \multirow[t]{2}{*}{ Ln GDP p.c. } & -0.010 & -0.140 & -0.106 & -0.201 & -0.417 & -0.251 \\
\hline & $(-0.04)$ & $(-0.49)$ & $(-0.36)$ & $(-0.64)$ & $(-1.16)$ & $(-0.79)$ \\
\hline \multirow[t]{2}{*}{ Ln population } & $0.449 * *$ & $0.431 * *$ & $0.413 * *$ & $0.414 * *$ & $0.423 * *$ & $0.342 *$ \\
\hline & $(2.53)$ & $(2.43)$ & $(2.36)$ & $(2.28)$ & $(2.16)$ & $(1.84)$ \\
\hline \multirow[t]{2}{*}{ Ethnic fractionaliz. } & -0.956 & -1.029 & -0.857 & -1.004 & -0.940 & -1.330 \\
\hline & $(-1.02)$ & $(-1.07)$ & $(-0.91)$ & $(-1.06)$ & $(-0.92)$ & $(-1.49)$ \\
\hline \multirow[t]{2}{*}{ Urbanization } & $0.066 * * *$ & $0.062 * * *$ & $0.065 * * *$ & $0.063 * * *$ & $0.055 * * *$ & $0.062 * * *$ \\
\hline & (4.04) & (3.96) & (3.92) & $(3.45)$ & (2.66) & (3.76) \\
\hline \multirow[t]{2}{*}{ Size military } & -0.003 & -0.007 & -0.061 & -0.058 & -0.093 & -0.019 \\
\hline & $(-0.02)$ & $(-0.04)$ & $(-0.30)$ & $(-0.28)$ & $(-0.44)$ & $(-0.10)$ \\
\hline Total resources inc. & $\begin{array}{c}-0.000 * * * \\
(-2.73)\end{array}$ & & & & & \\
\hline \multirow[t]{2}{*}{ Resource dependence } & & 0.001 & 0.003 & 0.002 & 0.002 & -0.002 \\
\hline & & $(0.05)$ & $(0.17)$ & $(0.11)$ & $(0.12)$ & $(-0.08)$ \\
\hline \multirow[t]{2}{*}{ Civil War } & & -0.434 & & & & \\
\hline & & $(-1.30)$ & & & & \\
\hline \multirow[t]{2}{*}{ British colony } & & & -0.715 & & & \\
\hline & & & $(-1.53)$ & & & \\
\hline \multirow[t]{2}{*}{ Literacy } & & & & 0.002 & & \\
\hline & & & & $(0.12)$ & & \\
\hline \multirow[t]{2}{*}{ Agriculture (\%) } & & & & & -0.016 & \\
\hline & & & & & $(-1.17)$ & \\
\hline \multirow[t]{2}{*}{ Total trade } & & & & & & $0.000 *$ \\
\hline & & & & & & $(1.79)$ \\
\hline Region dummies & $\mathrm{Y}$ & Y & $\mathrm{Y}$ & $\mathrm{Y}$ & $\mathrm{Y}$ & $\mathrm{Y}$ \\
\hline Year dummies & $\mathrm{Y}$ & $\mathrm{Y}$ & $\mathrm{Y}$ & $\mathrm{Y}$ & $\mathrm{Y}$ & $\mathrm{Y}$ \\
\hline $\mathrm{N}$ & 7586 & 7881 & 7881 & 7773 & 7556 & 7457 \\
\hline Countries & 137 & 137 & 137 & 137 & 137 & 136 \\
\hline
\end{tabular}

Table A.3: Democracies, autocracies, and the existence of pension systems. Robustness testing by including different control variables in Model A3 from Table 1.

Notes: $* * * p<0.01$, $* * p<0.05, * p<0.10$. Logit regressions with errors clustered on country, with existence of minimum old-age pension system as dependent variable. Year dummies, region dummies and constant are omitted from the table. The longest time series extend from the late 1880s to 2004. Control variables are taken either from Miller (2015) or Haber and Menaldo (2011). The regions are: Eastern Europe/Soviet Union; Latin America; North Africa/Middle East, sub-Saharan Africa; Western Europe/British settler colonies; East Asia; Southeast Asia/Pacific; South Asia 


\begin{tabular}{lcccccc}
\hline \hline Model & $\mathrm{A} 1$ & $\mathrm{~A} 2$ & $\mathrm{~A} 3$ & $\mathrm{~A} 4$ & $\mathrm{~A} 5$ & $\mathrm{~A} 6$ \\
& $b /(t)$ & $b /(t)$ & $b /(t)$ & $b /(t)$ & $b /(t)$ & $b /(t)$ \\
\hline \hline Democracy & 0.189 & 0.213 & 0.097 & 0.415 & 0.565 & 0.486 \\
& $(0.45)$ & $(0.51)$ & $(0.24)$ & $(1.22)$ & $(1.56)$ & $(1.38)$ \\
Ln GDP p.c. & $0.515^{*}$ & $0.689^{* *}$ & -0.193 & 0.130 & 0.193 & -0.199 \\
& $(1.74)$ & $(2.45)$ & $(-0.62)$ & $(0.76)$ & $(0.96)$ & $(-0.61)$ \\
Ln population & & $0.437^{* * *}$ & $0.407^{* *}$ & & $0.305^{* *}$ & $0.297^{* *}$ \\
& & $(2.72)$ & $(2.25)$ & & $(2.34)$ & $(2.11)$ \\
Ethnic fraction. & & -0.606 & -1.033 & & -0.261 & -0.685 \\
& & $(-0.59)$ & $(-1.05)$ & & $(-0.42)$ & $(-0.97)$ \\
Urbanization & & & $0.067 * * *$ & & & $0.029 * *$ \\
& & & $(3.93)$ & & & $(2.53)$ \\
Size military & & & 0.004 & & & 0.119 \\
Resource dependence & & & $(0.02)$ & & & $(1.11)$ \\
& & & 0.004 & & & 0.002 \\
Region dummies & $\mathrm{Y}$ & $\mathrm{Y}$ & $(0.22)$ & & & $(0.09)$ \\
Year dummies & $\mathrm{Y}$ & $\mathrm{Y}$ & $\mathrm{Y}$ & $\mathrm{Y}$ & $\mathrm{Y}$ & $\mathrm{Y}$ \\
\hline $\mathrm{N}$ & 9081 & 8224 & 7770 & 2108 & 1817 & 1660 \\
\hline \hline
\end{tabular}

Table A.4: Democracies, autocracies, and existence (A1-A3) or adoption (A4-A6) of pension systems. Robustness testing when lagging all independent variables 1 year.

Notes: $* * * p<0.01, * * p<0.05, * p<0.10$. Logit regressions with errors clustered on country. Existence of minimum old-age pension system is dependent variable in $\mathrm{A} 1-\mathrm{A} 3$ and adoption in A4-A6 (here, countries already having systems are omitted). Year dummies, region dummies and constant are omitted from table. Maximum time series (independent variables) extend from late 1880s-2003. 


\begin{tabular}{|c|c|c|c|c|c|c|c|c|}
\hline Model & $\begin{array}{c}\mathrm{A} 1 \\
b /(t)\end{array}$ & $\begin{array}{c}\mathrm{A} 2 \\
b /(t)\end{array}$ & $\begin{array}{l}\text { A3 } \\
b /(t)\end{array}$ & $\begin{array}{l}\mathrm{A} 4 \\
b /(t)\end{array}$ & $\begin{array}{l}\text { A5 } \\
b /(t)\end{array}$ & $\begin{array}{l}\text { A6 } \\
b /(t)\end{array}$ & $\begin{array}{l}\text { A7 } \\
b /(t)\end{array}$ & $\begin{array}{l}\text { A8 } \\
b /(t)\end{array}$ \\
\hline Democracy & $\begin{array}{l}0.559 \\
(1.42)\end{array}$ & $\begin{array}{c}0.919 * * \\
(2.24)\end{array}$ & $\begin{array}{l}0.668 \\
(1.58)\end{array}$ & $\begin{array}{l}0.497 \\
(1.45)\end{array}$ & $\begin{array}{l}0.369 \\
(1.10)\end{array}$ & $\begin{array}{l}0.309 \\
(0.94)\end{array}$ & $\begin{array}{l}0.415 \\
(1.27)\end{array}$ & $\begin{array}{l}0.361 \\
(1.13)\end{array}$ \\
\hline Ln GDP p.c. & $\begin{array}{l}0.203 \\
(1.07)\end{array}$ & $\begin{array}{c}0.401 * \\
(1.66)\end{array}$ & $\begin{array}{l}0.169 \\
(0.44)\end{array}$ & $\begin{array}{l}0.198 \\
(1.02)\end{array}$ & $\begin{array}{l}-0.099 \\
(-0.30)\end{array}$ & $\begin{array}{l}0.059 \\
(0.37)\end{array}$ & $\begin{array}{c}0.098 \\
(0.53)\end{array}$ & $\begin{array}{l}-0.142 \\
(-0.45)\end{array}$ \\
\hline Ln population & & $\begin{array}{c}0.471 * * * \\
(2.62)\end{array}$ & $\begin{array}{c}0.479 * * \\
(2.39)\end{array}$ & $\begin{array}{c}0.335 * * * \\
(2.67)\end{array}$ & $\begin{array}{c}0.306 * * \\
(2.26)\end{array}$ & & $\begin{array}{c}0.227 * * \\
(2.02)\end{array}$ & $\begin{array}{l}0.188 \\
(1.63)\end{array}$ \\
\hline Ethnic fractionalization & & $\begin{array}{l}-0.558 \\
(-0.69)\end{array}$ & $\begin{array}{l}-1.266 \\
(-1.54)\end{array}$ & $\begin{array}{l}-0.228 \\
(-0.38)\end{array}$ & $\begin{array}{l}-0.713 \\
(-1.03)\end{array}$ & & $\begin{array}{l}0.443 \\
(0.75)\end{array}$ & $\begin{array}{l}0.340 \\
(0.52)\end{array}$ \\
\hline Urbanization & & & $\begin{array}{c}0.032 * \\
(1.84)\end{array}$ & & $\begin{array}{c}0.031 * * * \\
(2.58)\end{array}$ & & & $\begin{array}{l}0.014 \\
(1.32)\end{array}$ \\
\hline Size military & & & $\begin{array}{l}-0.131 \\
(-0.49)\end{array}$ & & $\begin{array}{l}-0.045 \\
(-0.45)\end{array}$ & & & $\begin{array}{l}0.142 \\
(1.31)\end{array}$ \\
\hline Resource dependence & & & $\begin{array}{l}-0.013 \\
(-0.50)\end{array}$ & & $\begin{array}{l}-0.010 \\
(-0.45)\end{array}$ & & & $\begin{array}{l}0.002 \\
(0.12)\end{array}$ \\
\hline Region dummies & Y & Y & $\mathrm{Y}$ & $\mathrm{Y}$ & $\mathrm{Y}$ & Y & $\mathrm{Y}$ & $\mathrm{Y}$ \\
\hline Year dummies & Y & $\mathrm{Y}$ & Y & $\mathrm{Y}$ & Y & & & \\
\hline Linear time trend & & & & & & $\mathrm{Y}$ & $\mathrm{Y}$ & $\mathrm{Y}$ \\
\hline Years w.o. pension dummies & Y & Y & Y & & & & & \\
\hline Year w.o. pension cubic splines & & & & $\mathrm{Y}$ & Y & $\mathrm{Y}$ & $\mathrm{Y}$ & $\mathrm{Y}$ \\
\hline $\mathrm{N}$ & 824 & 724 & 668 & 1316 & 1225 & 5286 & 4795 & 3202 \\
\hline
\end{tabular}

Table A.5: Democracies, autocracies, and adoption of pension systems. Robustness testing when including dummies for years without pension systems or cubic splines on number of years without pension systems to further account for temporal dependence.

Notes: $* * * p<0.01, * * p<0.05, * p<0.10$. Logit regressions with errors clustered on country. Adoption of minimum old-age pension system is dependent variable (countries already having systems are omitted). Year dummies, linear time trend region dummies, dummies for year without pensions, cubic splines for year without pensions and constant are omitted from table. Maximum time series (independent variables) extend from late 1880s-2003. Please note that the models using dummies for year without pensions have very few observations when also including year dummies. We also tested such models substituting the year dummies with a linear time trend, but these models did not converge. Also, the most parsimonious model (only BMR, GDP p.c. and region dummies) that included year dummies and cubic splines for years without pension did not converge. 


\begin{tabular}{lcccc}
\hline \hline Model & $\mathrm{A} 1$ & $\mathrm{~A} 2$ & $\mathrm{~A} 3$ & $\mathrm{~A} 4$ \\
& $b /(t)$ & $b /(t)$ & $b /(t)$ & $b /(t)$ \\
\hline \hline Polity 2 & 0.019 & 0.017 & 0.009 & 0.024 \\
& $(0.73)$ & $(0.68)$ & $(0.34)$ & $(1.05)$ \\
Ln GDP p.c. & $0.562^{*}$ & $0.747^{* * *}$ & -0.039 & 0.315 \\
& $(1.89)$ & $(2.65)$ & $(-0.13)$ & $(1.64)$ \\
Ln population & & $0.387^{* *}$ & $0.355^{* *}$ & $0.258^{*}$ \\
& & $(2.47)$ & $(2.03)$ & $(2.14)$ \\
Ethnic fraction. & & -0.565 & -1.039 & -0.267 \\
& & $(-0.57)$ & $(-1.11)$ & $(-0.44)$ \\
Urbanization & & & $0.060^{* * *}$ & \\
& & & $(3.91)$ & \\
Size military & & & -0.045 & \\
& & & $(-0.21)$ & \\
Resource dependence & & & 0.003 & \\
& & $\mathrm{Y}$ & $(0.18)$ & \\
Region dummies & $\mathrm{Y}$ & $\mathrm{Y}$ & $\mathrm{Y}$ & $\mathrm{Y}$ \\
Year dummies & $\mathrm{Y}$ & 8316 & 7886 & 1364 \\
\hline $\mathrm{N}$ & 9091 & 137 & 137 & 111 \\
Countries & 139 & & & \\
\hline \hline
\end{tabular}

Table A.6: Democracies, autocracies, and the existence (A1-A3) or adoption (A4) of pension systems (the two other models on adoption, resembling A1 and A3 did not converge). Robustness testing using Polity 2 rather than BMR.

Notes: $* * * p<0.01,{ }^{* *} p<0.05,{ }^{*} p<0.10$. Logit regressions with errors clustered on country, with existence of minimum old-age pension system as dependent variable in A1-A3 and introduction of such a system as dependent in A4 (here, countries already having such systems are omitted). Year dummies, region dummies and constant are omitted from the table. 


\begin{tabular}{lcccccc}
\hline \hline Model & $\mathrm{A} 1$ & $\mathrm{~A} 2$ & $\mathrm{~A} 3$ & $\mathrm{~A} 4$ & $\mathrm{~A} 5$ & $\mathrm{~A} 6$ \\
& $b /(t)$ & $b /(t)$ & $b /(t)$ & $b /(t)$ & $b /(t)$ & $b /(t)$ \\
\hline \hline Democracy (BMR) & 0.331 & 0.195 & 0.126 & $0.692^{* *}$ & $0.628^{*}$ & 0.562 \\
& $(0.61)$ & $(0.41)$ & $(0.27)$ & $(2.06)$ & $(1.78)$ & $(1.61)$ \\
Ln GDP p.c. & 0.409 & $0.758^{* * *}$ & 0.149 & 0.013 & 0.278 & 0.132 \\
& $(1.44)$ & $(2.68)$ & $(0.50)$ & $(0.07)$ & $(1.36)$ & $(0.41)$ \\
Ln population & & $0.537 * * *$ & $0.583^{* * *}$ & & $0.380^{* * *}$ & $0.462^{* * *}$ \\
& & $(3.19)$ & $(2.97)$ & & $(2.61)$ & $(3.09)$ \\
Ethnic fraction. & & 0.165 & -0.288 & & 0.068 & -0.432 \\
& & $(0.15)$ & $(-0.28)$ & & $(0.09)$ & $(-0.53)$ \\
Urbanization & & & $0.058^{* * *}$ & & & 0.019 \\
& & & $(3.40)$ & & & $(1.39)$ \\
Size military & & & -0.007 & & & 0.012 \\
Resource dependence & & & $-0.03)$ & & & $(0.09)$ \\
& & & -0.001 & & & 0.001 \\
Region dummies & $\mathrm{Y}$ & $\mathrm{Y}$ & $\mathrm{Y}$ & $\mathrm{Y}$ & $\mathrm{Y}$ & $\mathrm{Y}$ \\
Year dummies & $\mathrm{Y}$ & $\mathrm{Y}$ & $\mathrm{Y}$ & $\mathrm{Y}$ & $\mathrm{Y}$ & $\mathrm{Y}$ \\
\hline $\mathrm{N}$ & 6366 & 6239 & 6073 & 772 & 772 & 760 \\
\hline \hline
\end{tabular}

Table A.7: Democracies, autocracies, and the existence (A1-A3) or adoption (A4-A6) of pension systems. Robustness testing on restricted sample from 1946.

Notes: $* * * p<0.01$, $* * p<0.05, * p<0.10$. Logit regressions with errors clustered on country, with existence of minimum old-age pension system as dependent variable in A1-A3 and introduction of such a system as dependent in A4-A6 (here, countries already having such systems are omitted). Year dummies, region dummies and constant are omitted from the table. 


\begin{tabular}{lcccccc}
\hline \hline Model & $\mathrm{A} 1$ & $\mathrm{~A} 2$ & $\mathrm{~A} 3$ & $\mathrm{~A} 4$ & $\mathrm{~A} 5$ & $\mathrm{~A} 6$ \\
& $b /(t)$ & $b /(t)$ & $b /(t)$ & $b /(t)$ & $b /(t)$ & $b /(t)$ \\
\hline \hline Democracy (BMR) & 0.403 & 0.262 & 0.178 & $0.746^{* *}$ & $0.687^{*}$ & $0.654^{*}$ \\
& $(0.74)$ & $(0.54)$ & $(0.38)$ & $(2.11)$ & $(1.84)$ & $(1.72)$ \\
Communist regime & 1.916 & 1.330 & 1.637 & $0.981^{*}$ & $0.941^{*}$ & $1.146^{* *}$ \\
& $(0.91)$ & $(0.74)$ & $(0.95)$ & $(1.77)$ & $(1.86)$ & $(2.12)$ \\
Ln GDP p.c. & 0.478 & $0.794^{* * *}$ & 0.172 & 0.029 & 0.302 & 0.164 \\
& $(1.62)$ & $(2.69)$ & $(0.56)$ & $(0.16)$ & $(1.43)$ & $(0.50)$ \\
Ln population & & $0.519^{* * *}$ & $0.558^{* * *}$ & & $0.387^{* * *}$ & $0.468^{* * *}$ \\
& & $(2.98)$ & $(2.76)$ & & $(2.60)$ & $(3.09)$ \\
Ethnic fraction. & & 0.316 & -0.116 & & 0.240 & -0.257 \\
& & $(0.28)$ & $(-0.11)$ & & $(0.32)$ & $(-0.31)$ \\
Urbanization & & & $0.064 * * *$ & & & 0.020 \\
Size military & & $(3.45)$ & & & $(1.41)$ \\
Resource dependence & & & -0.140 & & & -0.075 \\
& & & $(-0.55)$ & & & $(-0.53)$ \\
Region dummies & $\mathrm{Y}$ & $\mathrm{Y}$ & -0.002 & & & 0.001 \\
Year dummies & $\mathrm{Y}$ & $\mathrm{Y}$ & $\mathrm{Y}$ & $\mathrm{Y}$ & $\mathrm{Y}$ & $\mathrm{Y}$ \\
\hline $\mathrm{N}$ & 6330 & 6203 & 6038 & 765 & 765 & 753 \\
\hline \hline
\end{tabular}

Table A.8: Democracies, autocracies, and the existence (A1-A3) or adoption (A4-A6) of pension systems. Robustness testing when controlling for Communist regimes (post-1946 sample, using coding from Cheibub, Gandhi and Vreeland 2010).

Notes: $* * * p<0.01,{ }^{*} * p<0.05,{ }^{*} p<0.10$. Logit regressions with errors clustered on country, with existence of minimum old-age pension system as dependent variable in A1-A3 and introduction of such a system as dependent in A4-A6 (here, countries already having such systems are omitted). Year dummies, region dummies and constant are omitted from the table. 


\begin{tabular}{lcccccc}
\hline \hline Model & $\mathrm{A} 1$ & $\mathrm{~A} 2$ & $\mathrm{~A} 3$ & $\mathrm{~A} 4$ & $\mathrm{~A} 5$ & $\mathrm{~A} 6$ \\
& $b /(t)$ & $b /(t)$ & $b /(t)$ & $b /(t)$ & $b /(t)$ & $b /(t)$ \\
\hline \hline Democracy (DD) & $1.025^{* *}$ & $0.807^{*}$ & 0.595 & $0.943^{* * *}$ & $0.870^{* *}$ & $0.795^{* *}$ \\
& $(2.06)$ & $(1.71)$ & $(1.33)$ & $(2.66)$ & $(2.41)$ & $(2.05)$ \\
Ln GDP p.c. & 0.316 & $0.676^{* *}$ & 0.123 & 0.047 & 0.333 & 0.174 \\
& $(1.09)$ & $(2.14)$ & $(0.39)$ & $(0.26)$ & $(1.55)$ & $(0.54)$ \\
Ln population & & $0.497^{* * *}$ & $0.559^{* * *}$ & & $0.412^{* *}$ & $0.500^{* * *}$ \\
& & $(2.89)$ & $(2.73)$ & & $(2.54)$ & $(2.96)$ \\
Ethnic fractionaliz. & & 0.421 & -0.096 & & 0.242 & -0.243 \\
& & $(0.36)$ & $(-0.09)$ & & $(0.32)$ & $(-0.29)$ \\
Urbanization & & & $0.057 * * *$ & & & 0.019 \\
& & & $(3.46)$ & & & $(1.34)$ \\
Size military & & & -0.100 & & & 0.012 \\
& & & $(-0.37)$ & & & $(0.09)$ \\
Resource dependence & & & 0.001 & & & 0.003 \\
& & $\mathrm{Y}$ & $(0.03)$ & & & $(0.19)$ \\
Region dummies & $\mathrm{Y}$ & $\mathrm{Y}$ & $\mathrm{Y}$ & $\mathrm{Y}$ & $\mathrm{Y}$ & $\mathrm{Y}$ \\
Year dummies & 6232 & 6105 & 5969 & 753 & 753 & 741 \\
\hline $\mathrm{N}$ & & & & & & $\mathrm{Y}$ \\
\hline \hline
\end{tabular}

Table A.9: Democracies, autocracies, and the existence (A1-A3) or adoption (A4-A6) of pension systems. Robustness testing on restricted sample from 1946 and using the DD measure of democracy. Notes: $* * * p<0.01, * * p<0.05, * p<0.10$. Logit regressions with errors clustered on country, with existence of minimum old-age pension system as dependent variable in A1-A3 and introduction of such a system as dependent in A4-A6 (here, countries already having such systems are omitted). Year dummies, region dummies and constant are omitted from the table. 


\section{A.3 Robustness tests and extensions for Section 5.2}

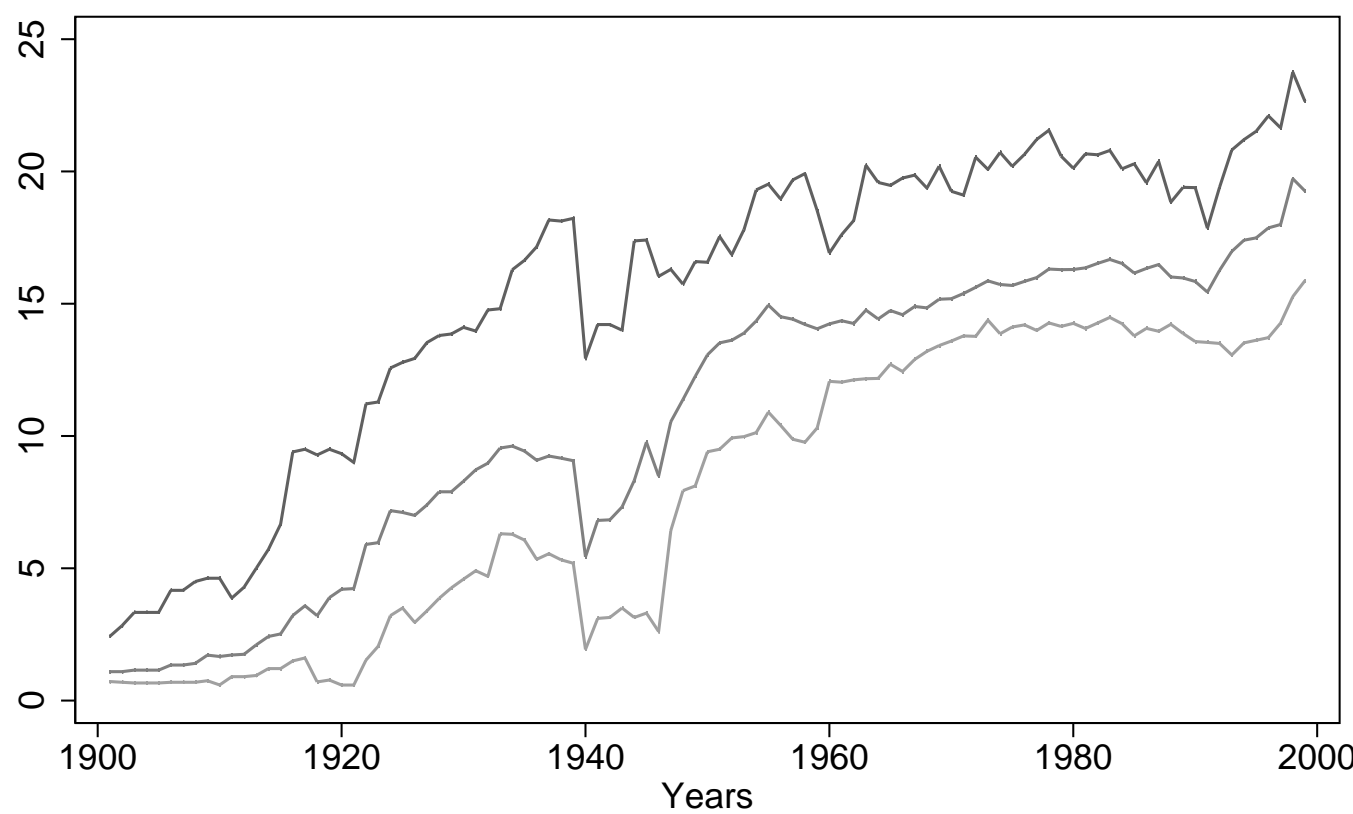

Universalism in Democracies Universalism in Autocracies Universalism in All Regimes

Figure A.2: Average score on Welfare State Universalism Index (aggregated over the six major social policy programs; ranging from 0-54) - for democracies, for autocracies, and average for all observations - over time. 


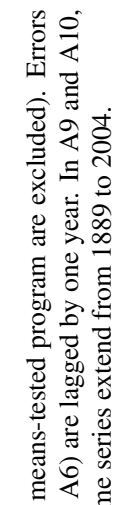

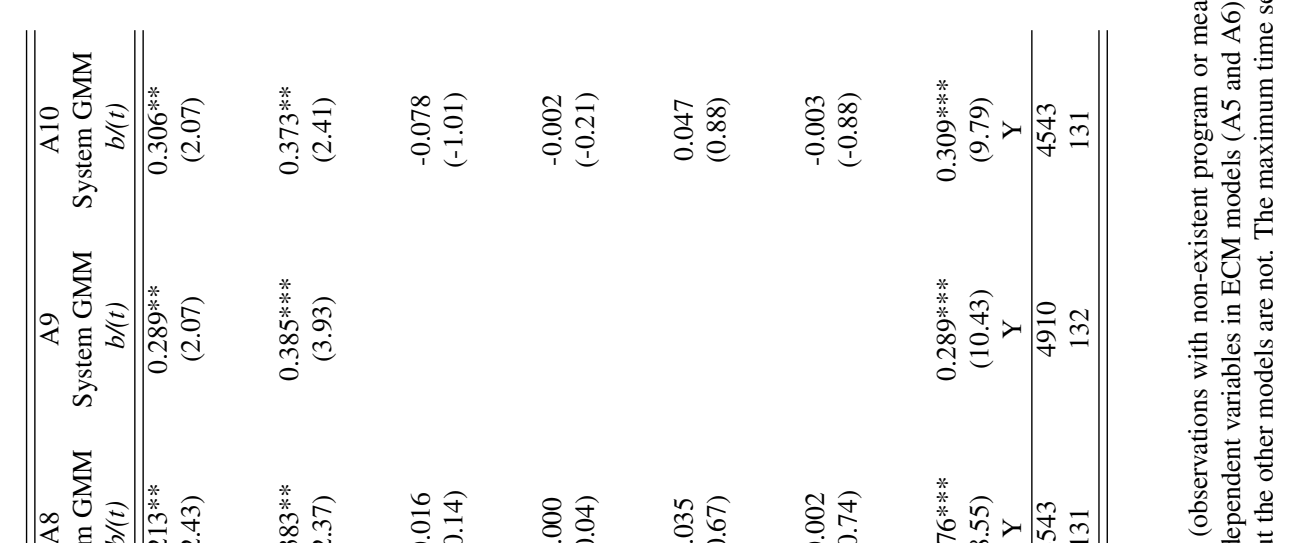

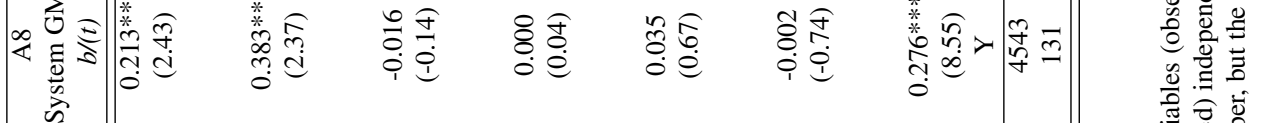

|

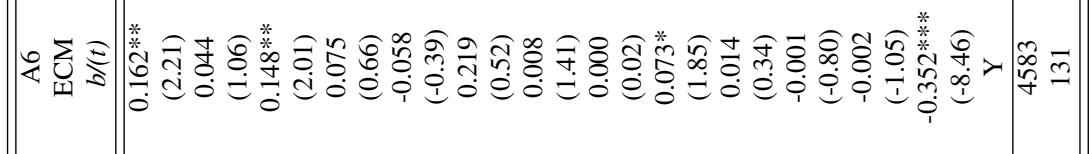

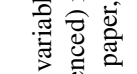

密:

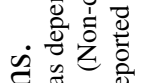

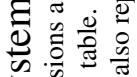

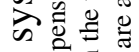

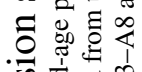

능 可方

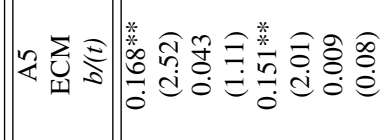

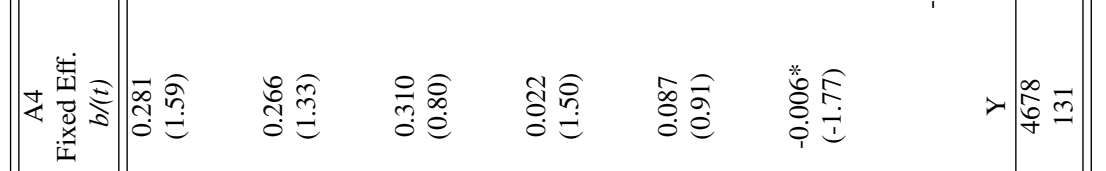

¿훙ㅎㅇ

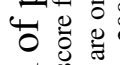

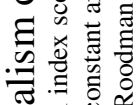

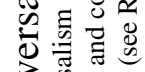

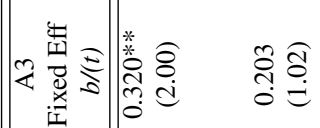

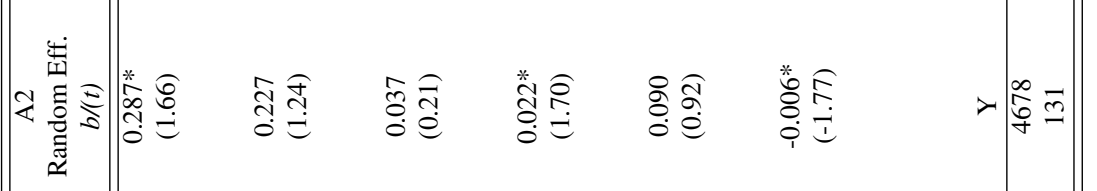

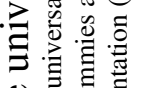

宅焉

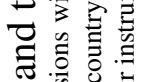

仓ै

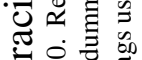

원의

号 $\vee$.

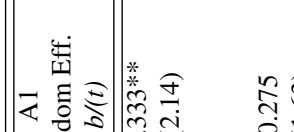

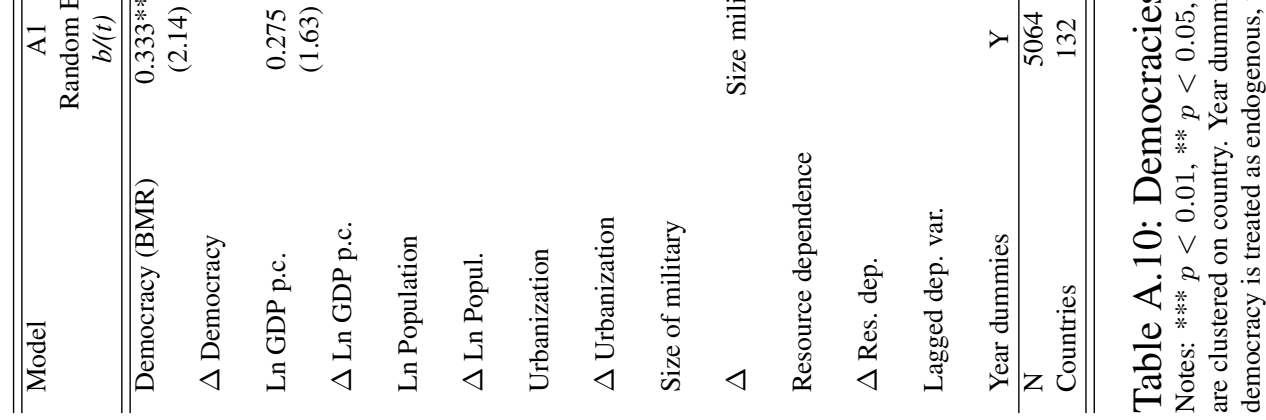




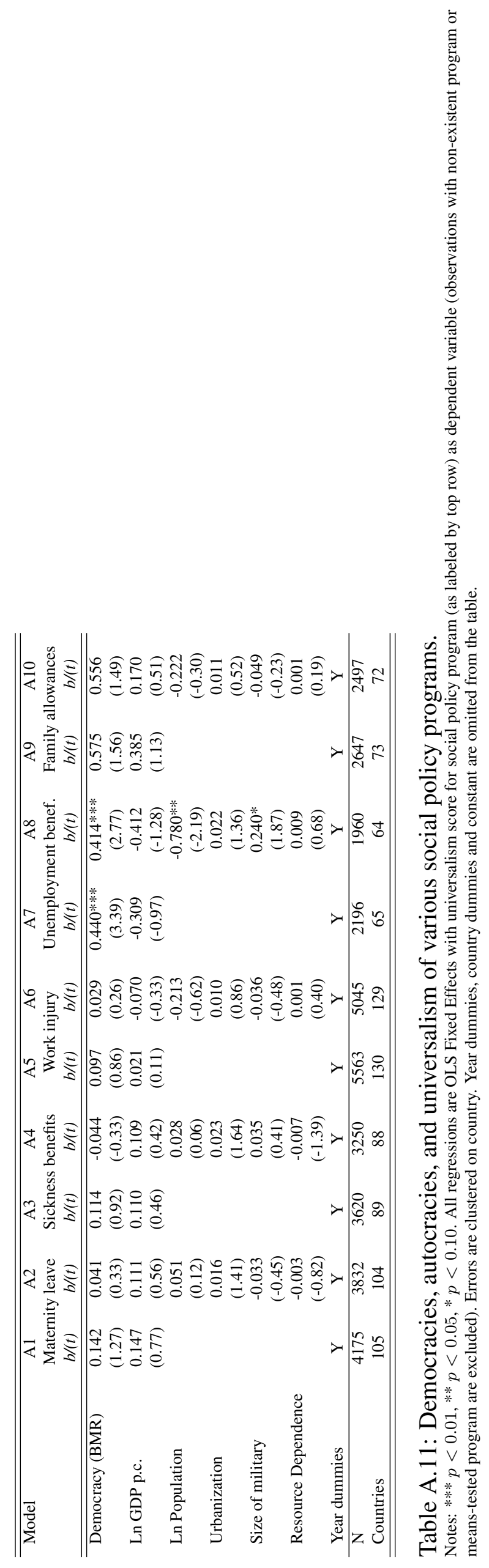




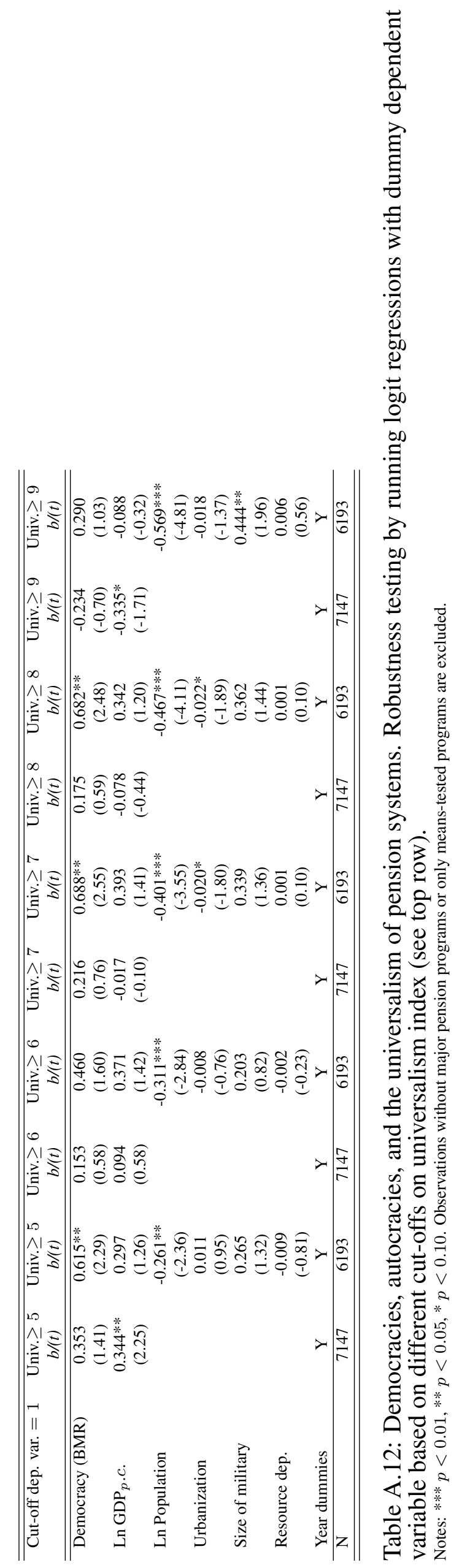




\begin{tabular}{lcccc}
\hline \hline & \multicolumn{2}{c}{ RE Ordinal Logit } & \multicolumn{2}{c}{ RE Ordinal Probit } \\
& $b /(t)$ & $b /(t)$ & $b /(t)$ & $b /(t)$ \\
\hline \hline Democracy (BMR) & $0.649 * * *$ & $0.599 * * *$ & $0.477 * * *$ & $0.419 * * *$ \\
& $(6.25)$ & $(5.36)$ & $(8.61)$ & $(7.07)$ \\
Ln GDP p.c. & $0.787 * * *$ & $0.633^{* * *}$ & $0.391 * * *$ & $0.313 * * *$ \\
& $(6.57)$ & $(4.74)$ & $(6.26)$ & $(4.46)$ \\
Ln Population & & $0.712^{* * *}$ & & $0.239 * *$ \\
& & $(3.71)$ & & $(2.47)$ \\
Urbanization & & $0.043^{* * *}$ & & $0.027 * * *$ \\
& & $(6.42)$ & & $(7.96)$ \\
Size of military & & $0.531 * * *$ & & $0.220 * * *$ \\
& & $(6.40)$ & & $(4.88)$ \\
Resource Dependence & & $-0.014 * * *$ & & $-0.007 * *$ \\
& & $(-2.89)$ & & $(-2.47)$ \\
Year dummies & $\mathrm{Y}$ & $\mathrm{Y}$ & $\mathrm{Y}$ & $\mathrm{Y}$ \\
\hline $\mathrm{N}$ & 5064 & 4678 & 5064 & 4678 \\
\hline \hline
\end{tabular}

Table A.13: Democracies, autocracies, and the universalism of pension systems. Robustness testing by running random effects ordinal logit or random effects ordinal probit regressions.

Notes: $* * * p<0.01$, ** $p<0.05, * p<0.10$. The maximum time series extend from the late 1880 s to 2004 . Constants and year dummies are omitted from the table. 


\begin{tabular}{|c|c|c|c|c|c|c|c|c|}
\hline \multirow[t]{2}{*}{ Model } & \multicolumn{2}{|c|}{ No lag (benchmark) } & \multicolumn{2}{|c|}{ 1-year lag } & \multicolumn{2}{|c|}{ 3-year lag } & \multicolumn{2}{|c|}{ 5-year lag } \\
\hline & $b /(t)$ & $b /(t)$ & $b /(t)$ & $b /(t)$ & $b /(t)$ & $b /(t)$ & $b /(t)$ & $b /(t)$ \\
\hline Democracy (BMR) & $\begin{array}{c}0.320 * * \\
(2.00)\end{array}$ & $\begin{array}{l}0.281 \\
(1.59)\end{array}$ & $\begin{array}{c}0.347 * * \\
(2.09)\end{array}$ & $\begin{array}{l}0.302 \\
(1.65)\end{array}$ & $\begin{array}{c}0.348 * * \\
(2.12)\end{array}$ & $\begin{array}{l}0.300 * \\
(1.67)\end{array}$ & $\begin{array}{c}0.361 * * \\
(2.22)\end{array}$ & $\begin{array}{c}0.303^{*} \\
(1.73)\end{array}$ \\
\hline Ln GDP p.c. & $\begin{array}{l}0.203 \\
(1.02)\end{array}$ & $\begin{array}{l}0.266 \\
(1.33)\end{array}$ & $\begin{array}{l}0.213 \\
(1.07)\end{array}$ & $\begin{array}{l}0.259 \\
(1.32)\end{array}$ & $\begin{array}{l}0.241 \\
(1.20)\end{array}$ & $\begin{array}{l}0.273 \\
(1.45)\end{array}$ & $\begin{array}{c}0.288 \\
(1.36)\end{array}$ & $\begin{array}{l}0.289 \\
(1.55)\end{array}$ \\
\hline Ln Population & & $\begin{array}{l}0.310 \\
(0.80)\end{array}$ & & $\begin{array}{l}0.314 \\
(0.82)\end{array}$ & & $\begin{array}{l}0.312 \\
(0.83)\end{array}$ & & $\begin{array}{l}0.306 \\
(0.81)\end{array}$ \\
\hline Urbanization & & $\begin{array}{l}0.022 \\
(1.50)\end{array}$ & & $\begin{array}{l}0.022 \\
(1.46)\end{array}$ & & $\begin{array}{l}0.021 \\
(1.44)\end{array}$ & & $\begin{array}{l}0.020 \\
(1.32)\end{array}$ \\
\hline Size of military & & $\begin{array}{l}0.087 \\
(0.91)\end{array}$ & & $\begin{array}{l}0.088 \\
(0.90)\end{array}$ & & $\begin{array}{l}0.103 \\
(1.00)\end{array}$ & & $\begin{array}{l}0.145 \\
(1.52)\end{array}$ \\
\hline Resource dependence & & $\begin{array}{c}-0.006^{*} \\
(-1.77)\end{array}$ & & $\begin{array}{l}-0.005 \\
(-1.28)\end{array}$ & & $\begin{array}{l}-0.004 \\
(-0.99)\end{array}$ & & $\begin{array}{l}-0.003 \\
(-0.56)\end{array}$ \\
\hline Year dummies & $\mathrm{Y}$ & $\mathrm{Y}$ & $\mathrm{Y}$ & $\mathrm{Y}$ & $\mathrm{Y}$ & $\mathrm{Y}$ & $\mathrm{Y}$ & $\mathrm{Y}$ \\
\hline $\mathrm{N}$ & 5064 & 4678 & 5058 & 4655 & 5016 & 4589 & 4931 & 4477 \\
\hline
\end{tabular}

Table A.14: Democracies, autocracies, and universalism of pension systems. Robustness testing when lagging all independent variables, with lag-length specified in top row.

Notes: $* * * p<0.01,{ }^{*} p<0.05, * p<0.10$. All regressions are OLS Fixed Effects with Universalism Index for pensions is dependent variable, and observations without pension program or only means-tested program are excluded. Country dummies, year dummies and constant are omitted from table. Errors are clustered on country. 


\section{A.4 Robustness tests and extensions for Section 5.3}

\begin{tabular}{lcccc}
\hline \hline Variable $\backslash$ Statistic & Mean & Standard deviation & Minimum & Maximum \\
\hline \hline Regime failure & 0.05 & 0.23 & 0 & 1 \\
Old-age pension system & 0.71 & 0.41 & 0 & 1 \\
Regional pension share & 0.82 & 0.41 & 0 & 1 \\
Global pension share & 0.85 & 0.21 & 0.53 & 0.98 \\
Military regime & 0.15 & 0.36 & 0 & 1 \\
Monarchy & 0.11 & 0.31 & 0 & 1 \\
Personalist regime & 0.26 & 0.44 & 0 & 1 \\
Other autocracy & 0.01 & 0.11 & 0 & 1 \\
Ln GDP per capita & 7.81 & 0.93 & 5.78 & 11.08 \\
Ln population & 9.10 & 1.36 & 5.97 & 14.06 \\
Ethnic fractionalization & 0.51 & 0.25 & 0.00 & 0.93 \\
Urbanization & 33.97 & 20.88 & 0 & 100 \\
Size of military & 0.66 & 0.74 & 0 & 7.68 \\
Resource dependence & 6.42 & 12.73 & 0 & 100 \\
\hline \hline
\end{tabular}

Table A.15: Descriptive statistics for the 3248 observations (and variables) entering Model D3, Table 4 in the paper. 


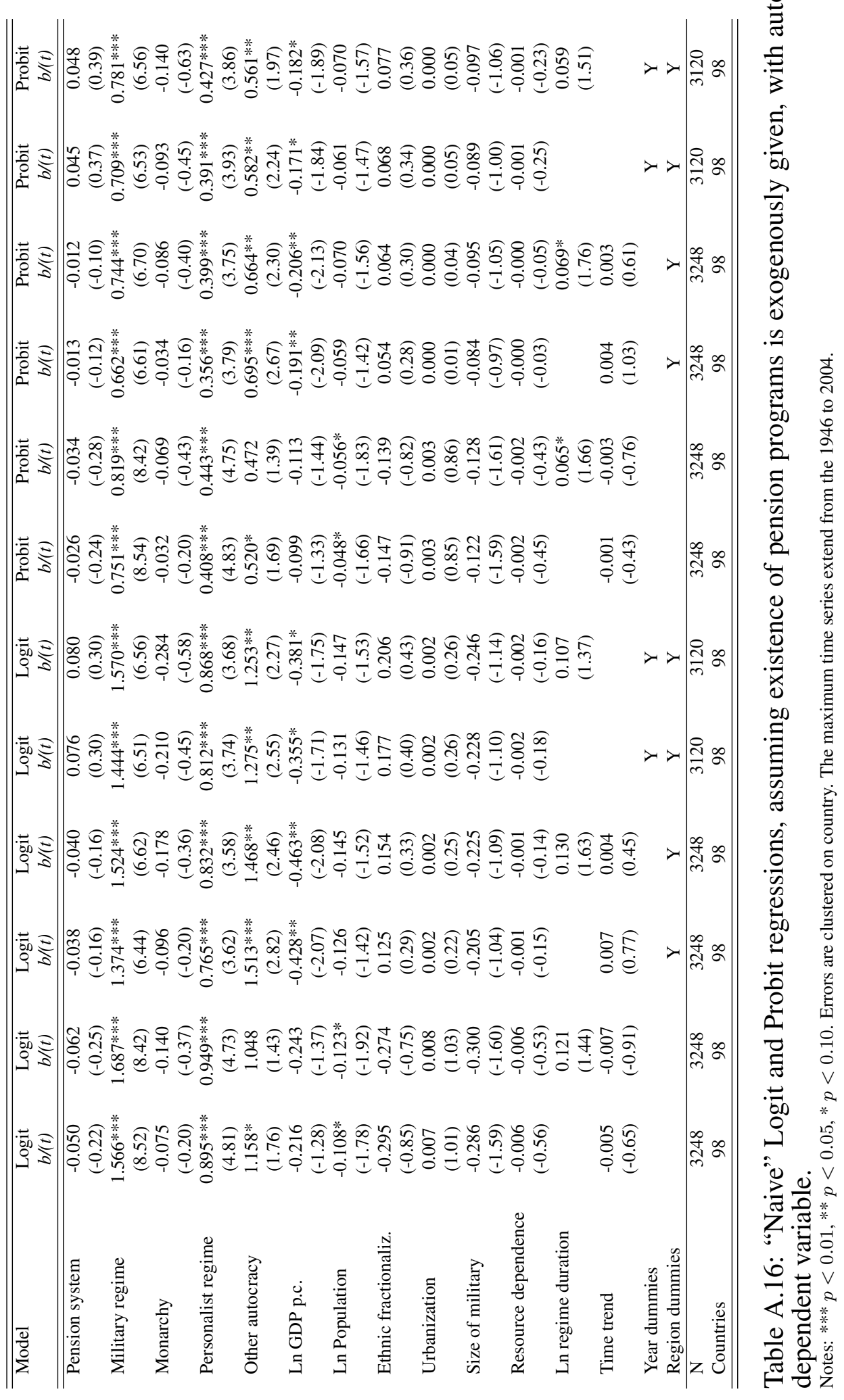




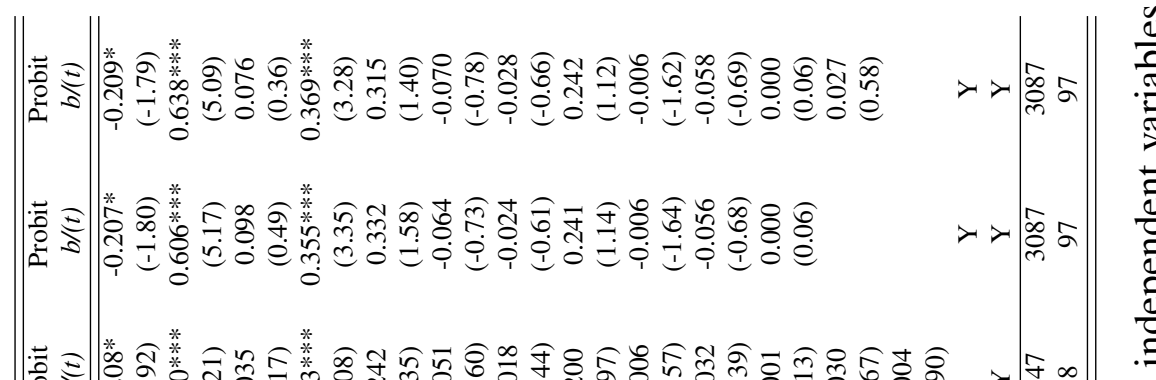

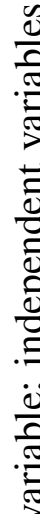

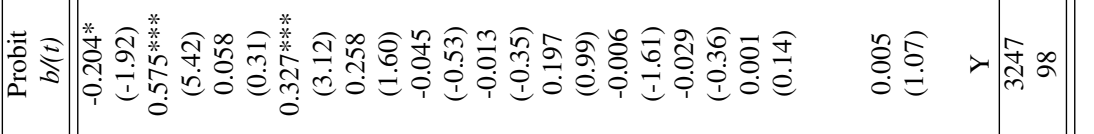

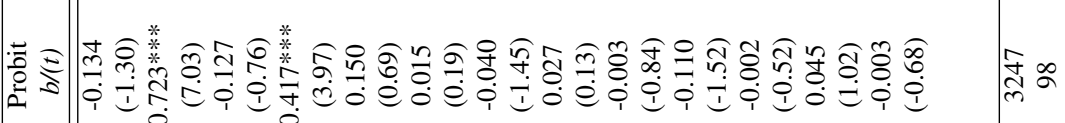

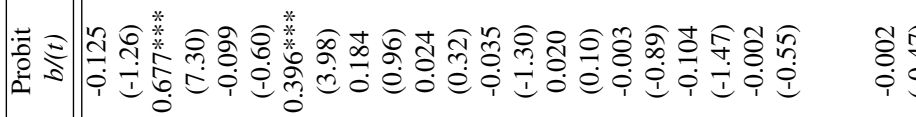

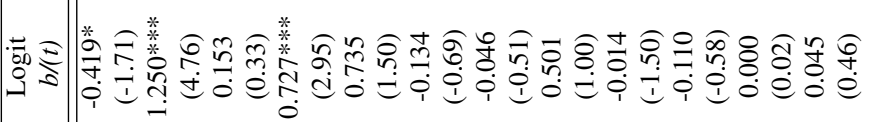

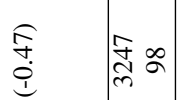
ส

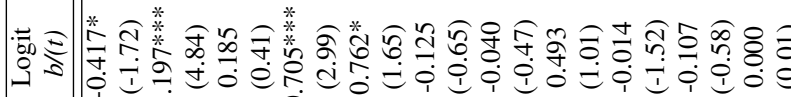

$>>\widehat{d}$

$\stackrel{\Xi}{\Xi}$

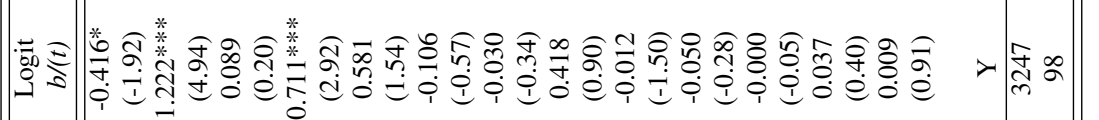

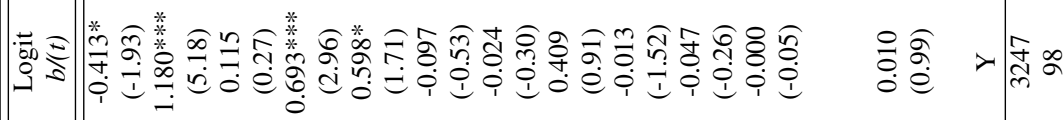

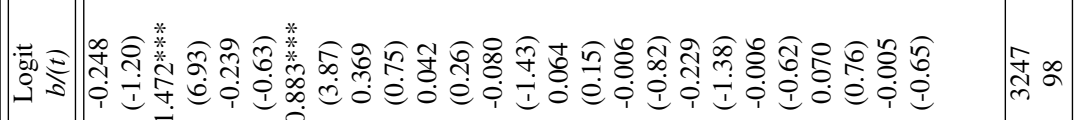

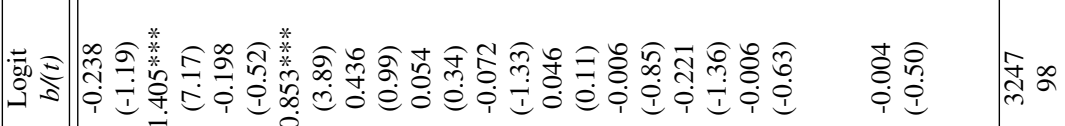




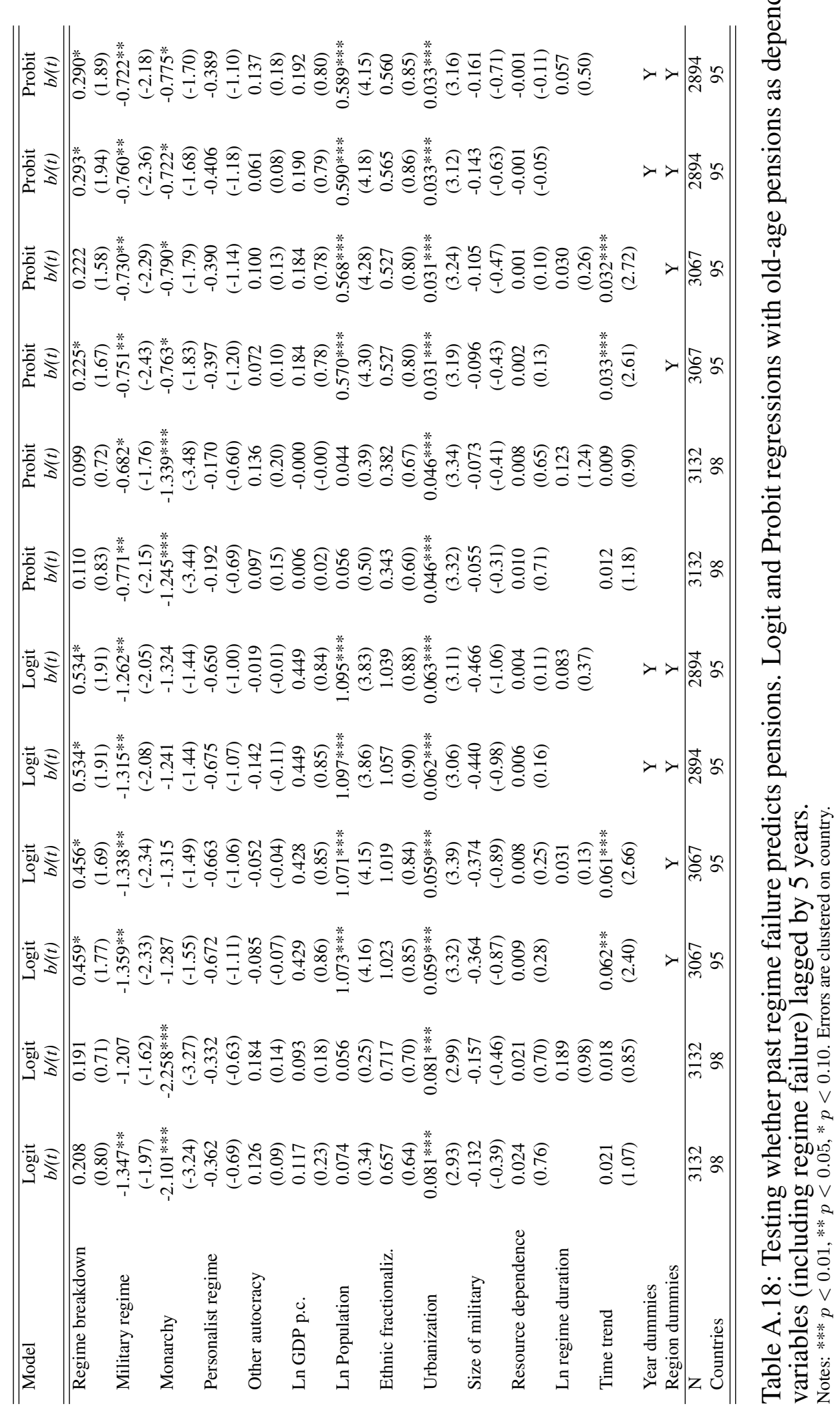




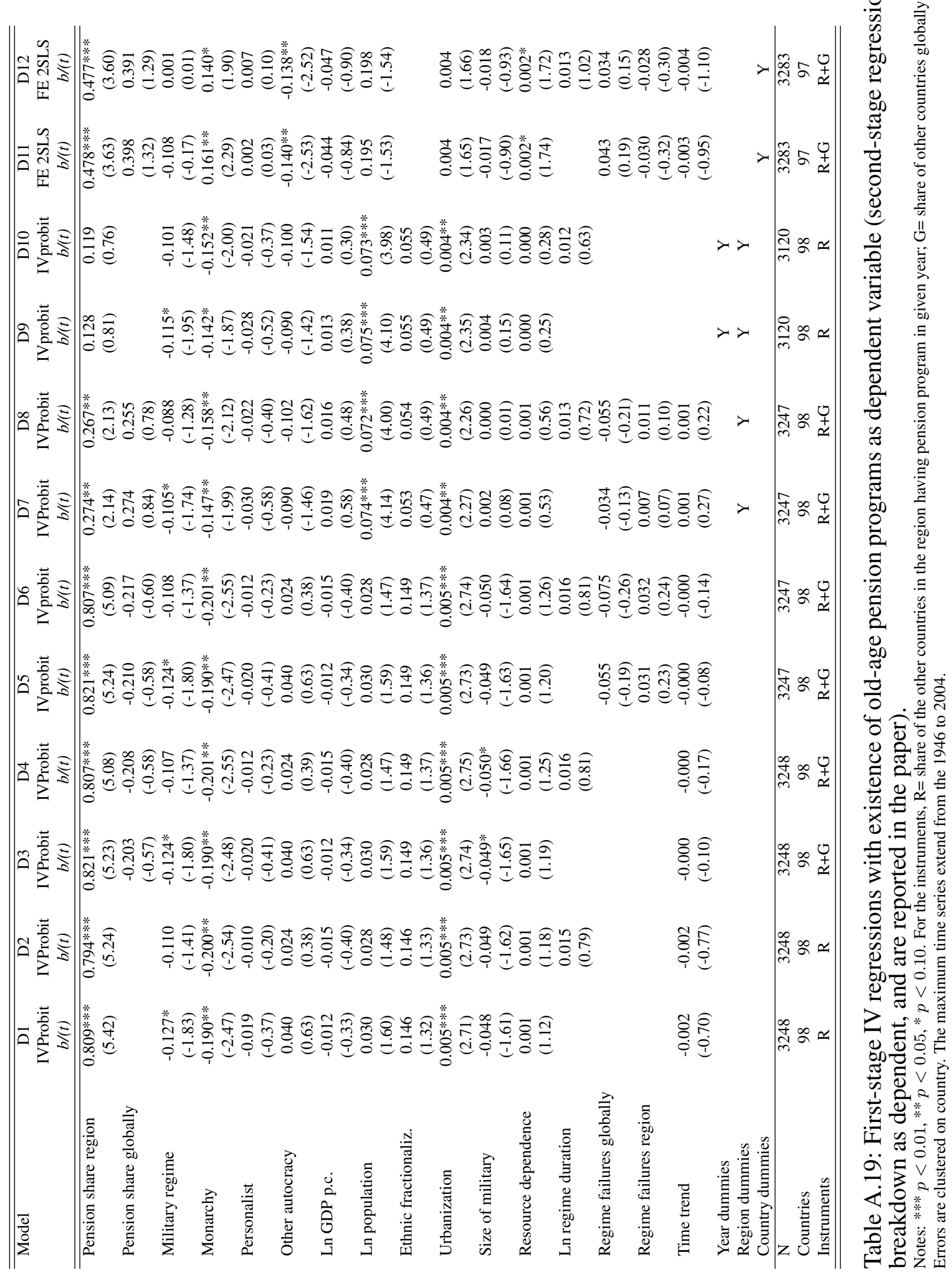




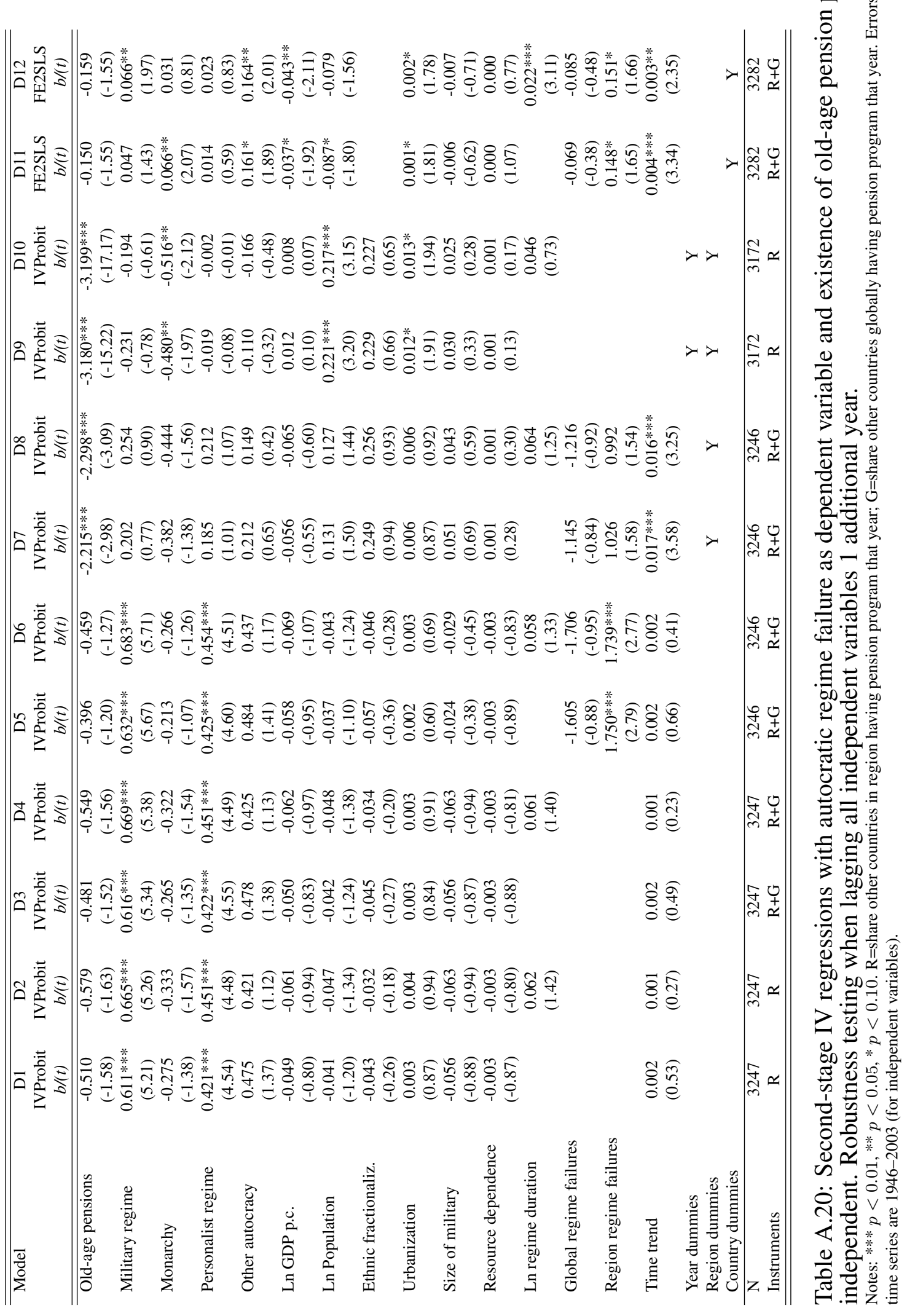




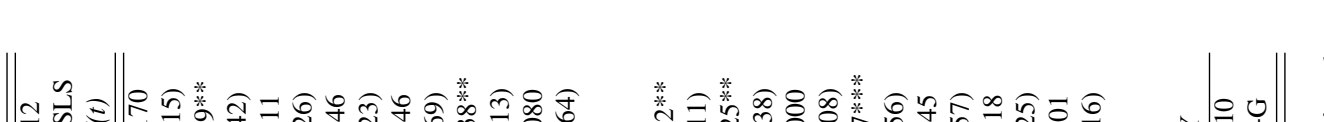

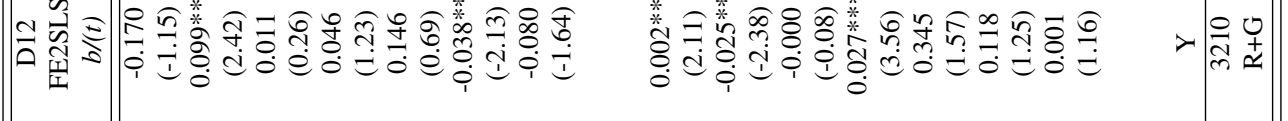

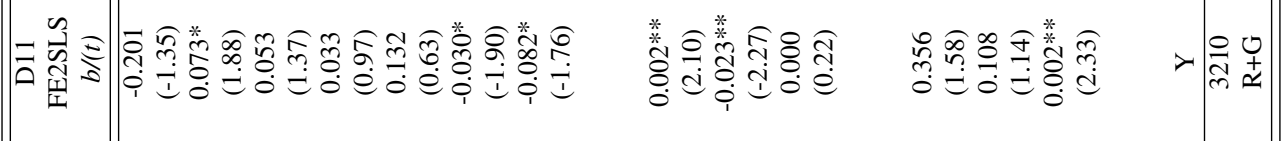

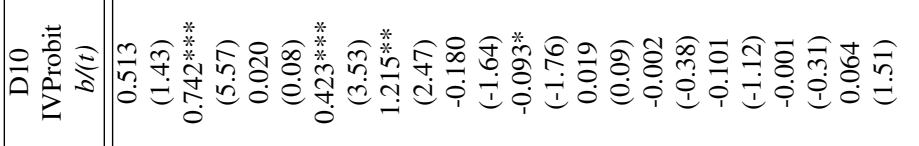

م.

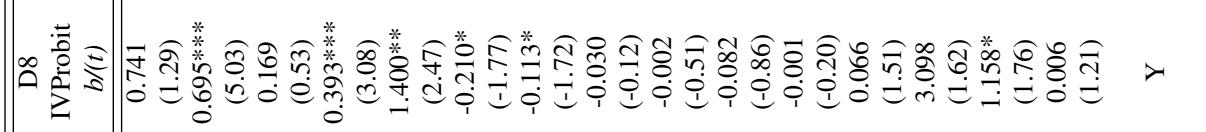

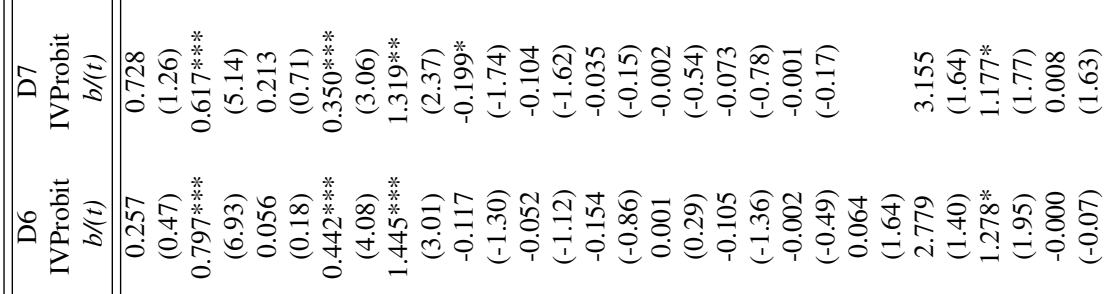

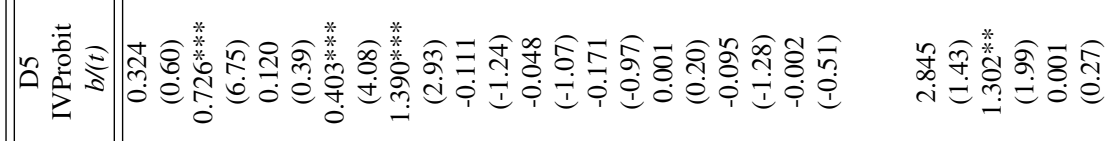

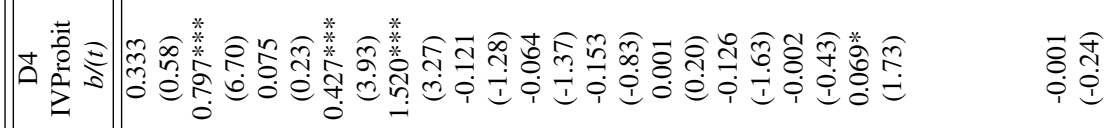

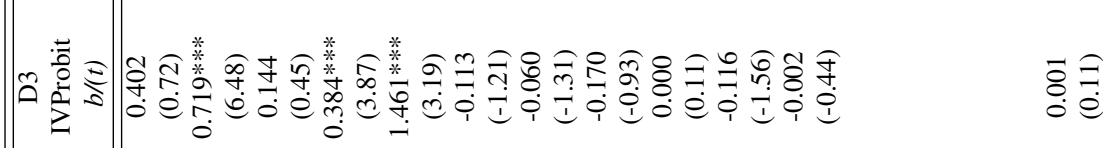

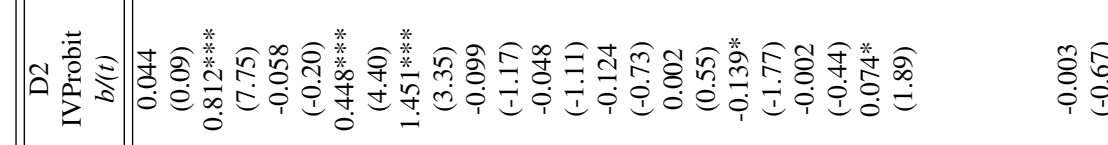

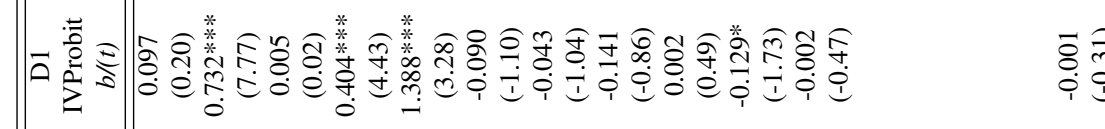

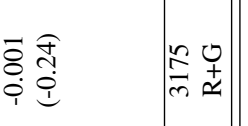

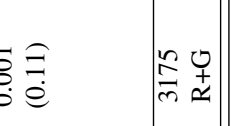

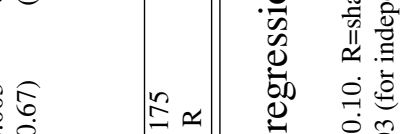

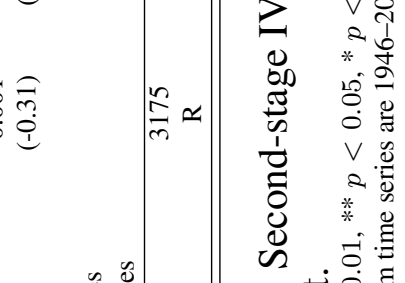

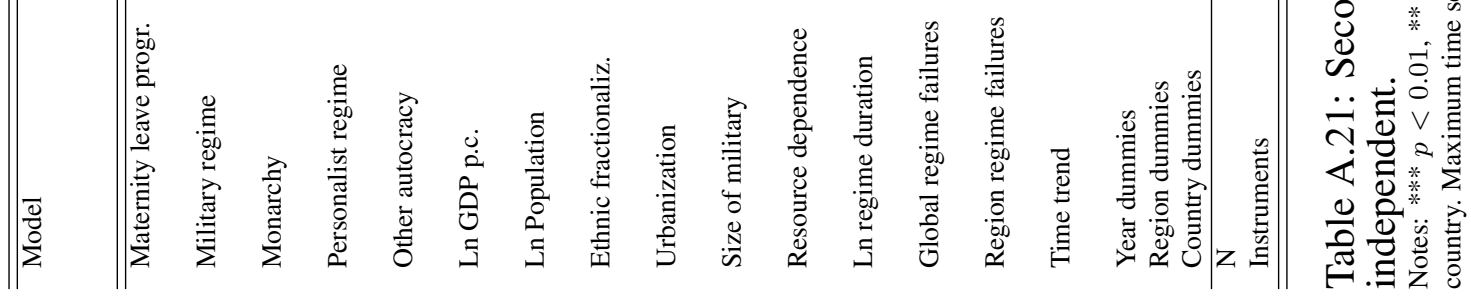




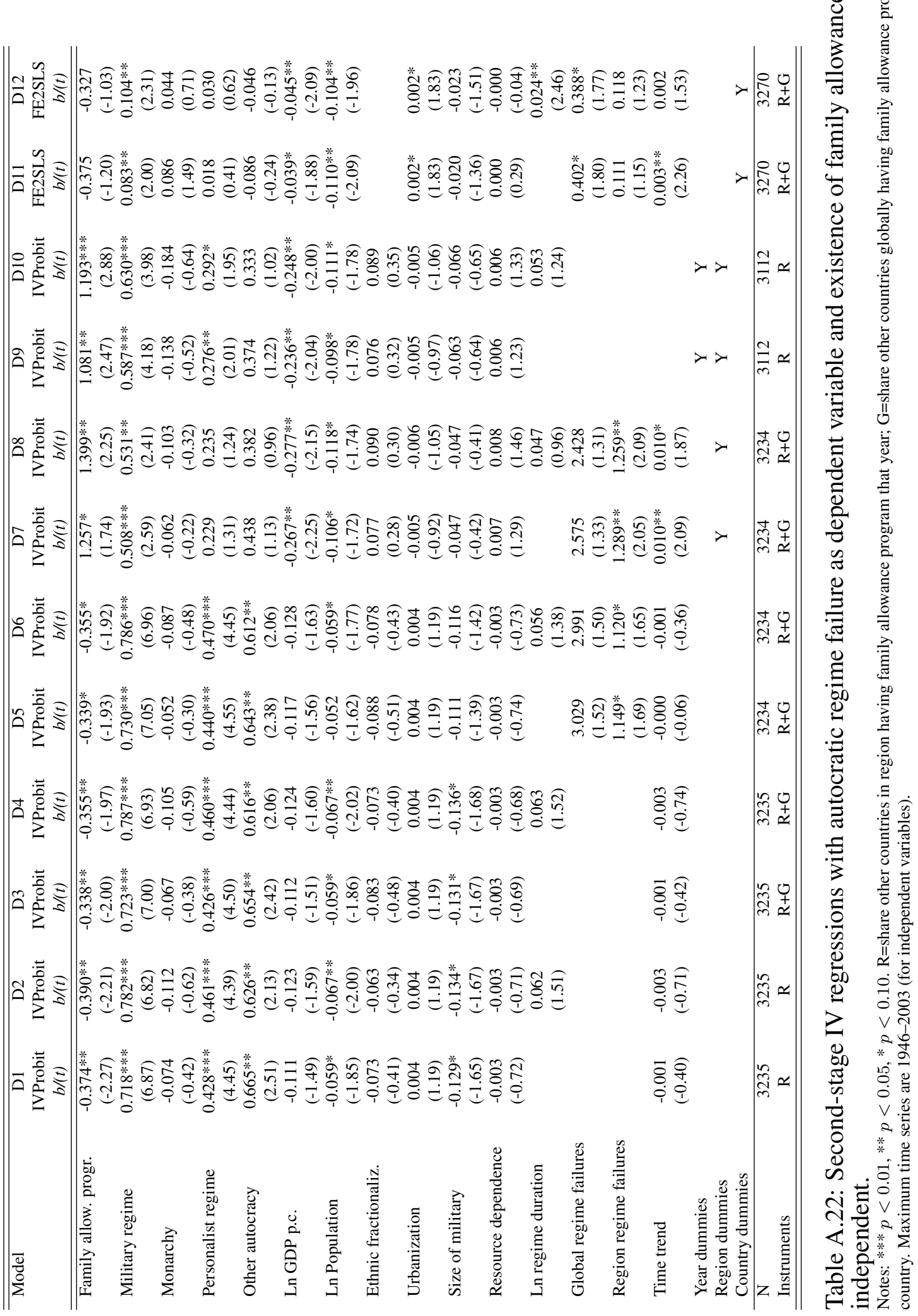




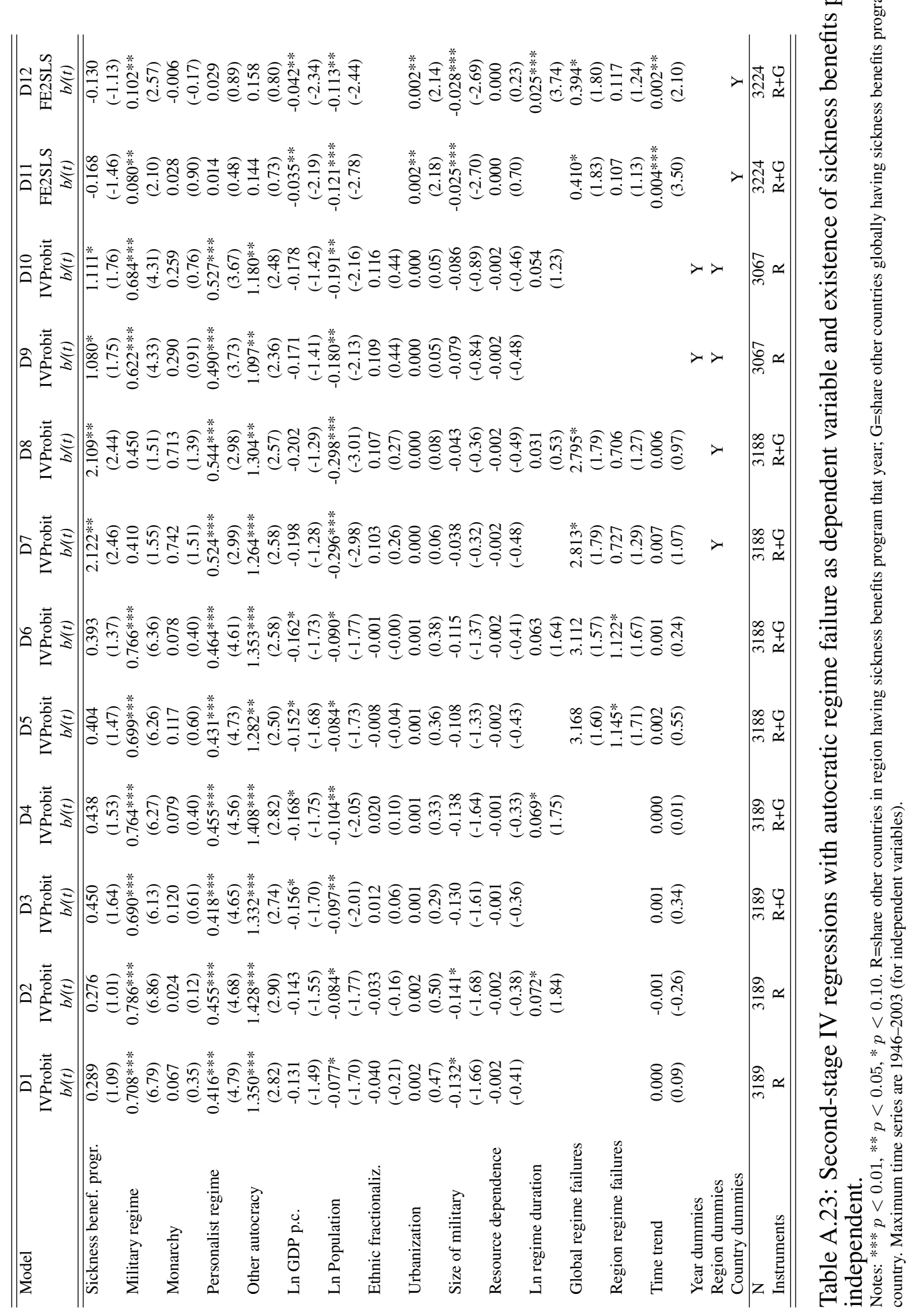




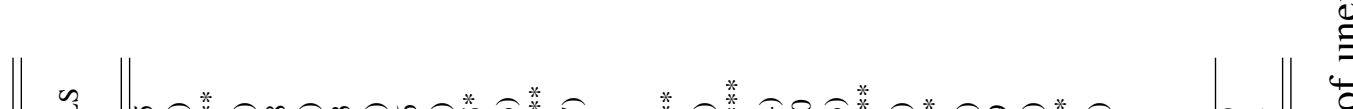

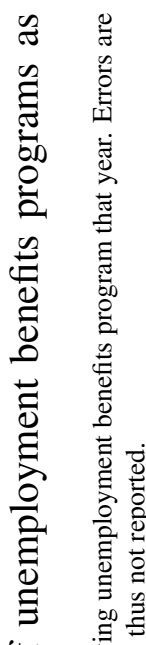

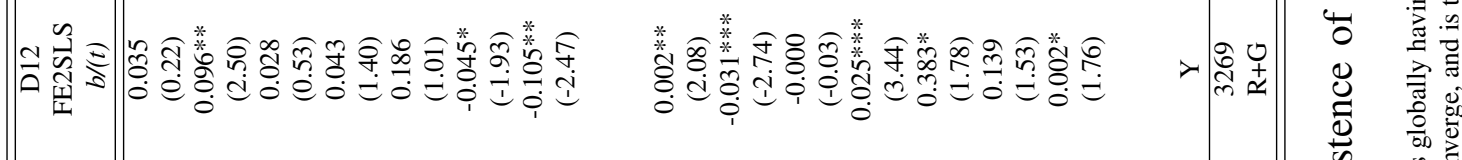

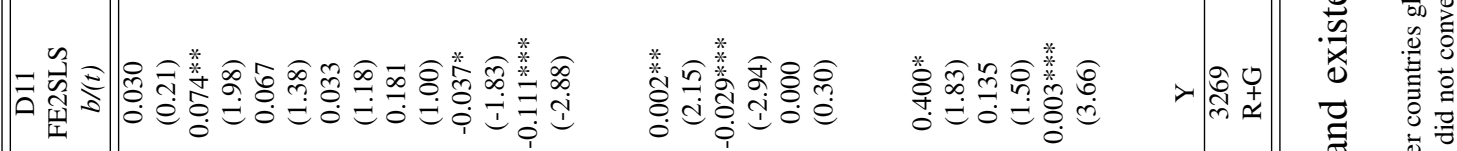

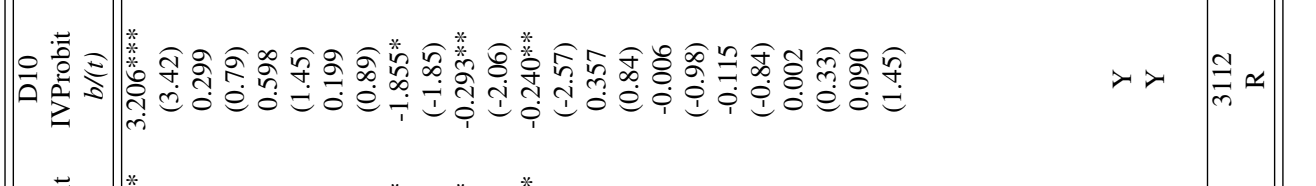

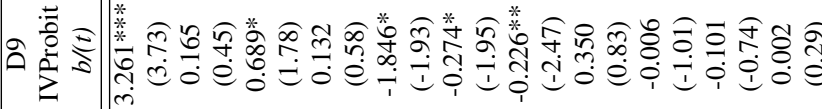

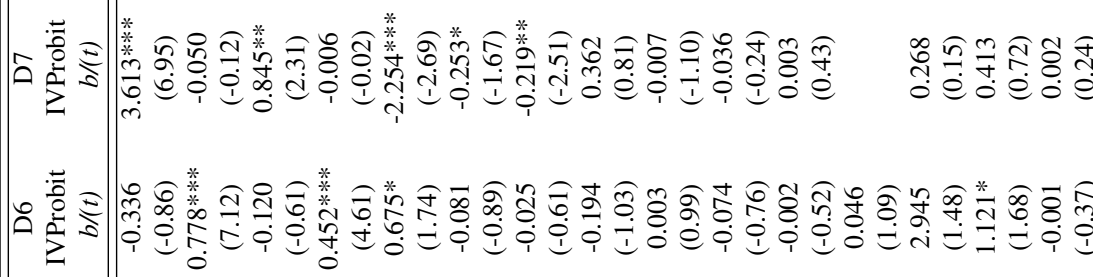

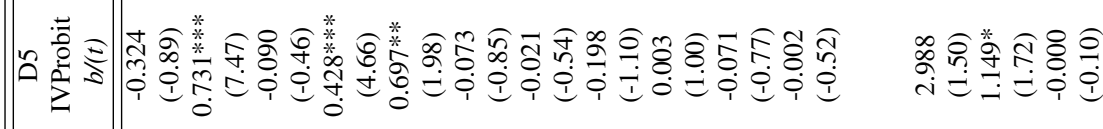

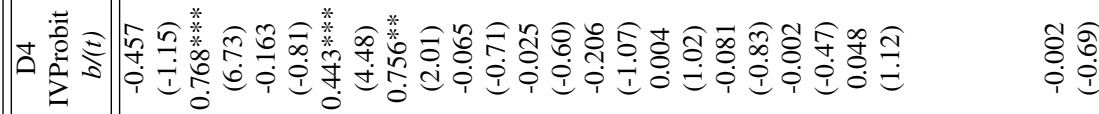

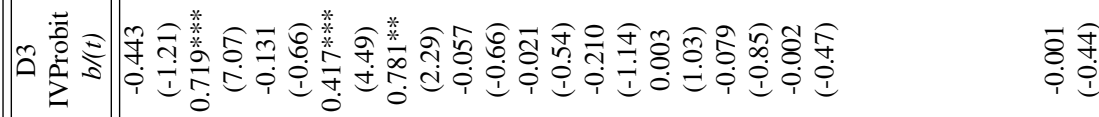

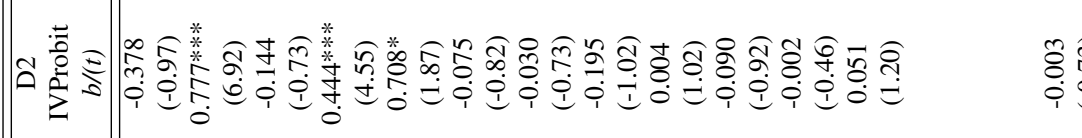

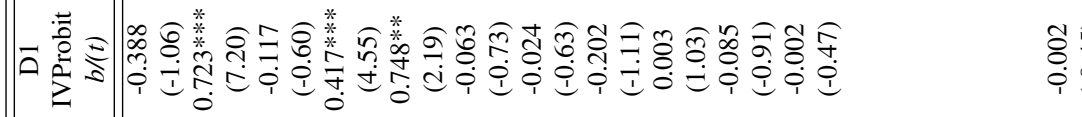

客

त̂̃

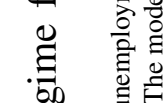

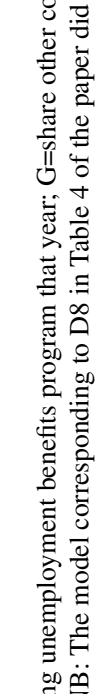

\begin{tabular}{ll|}
$\infty$ & 0 \\
$\tilde{n}$ & \multirow{2}{*}{}
\end{tabular}

.

도유.

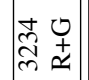

을 $\stackrel{0}{\leftrightarrows}$

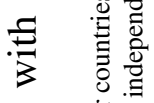

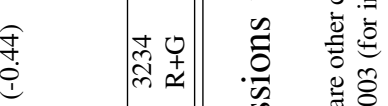

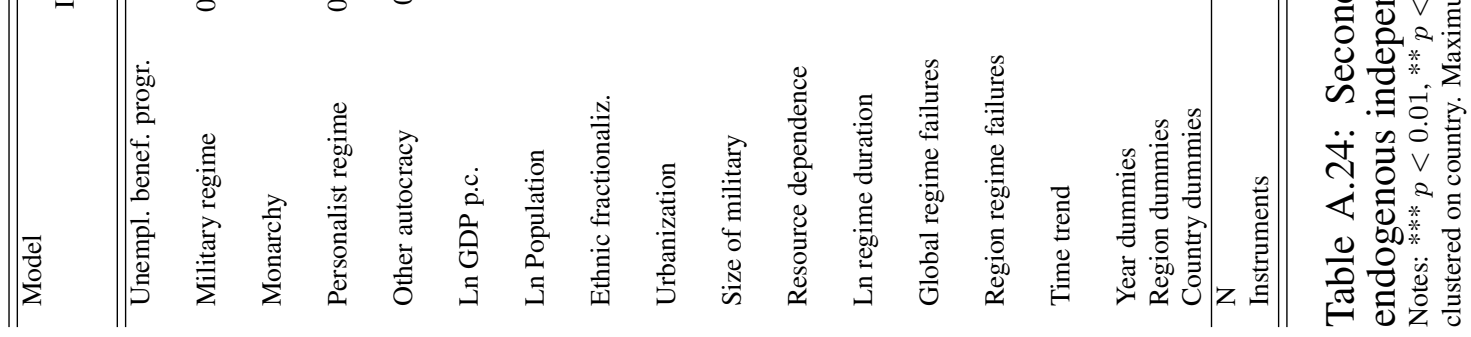




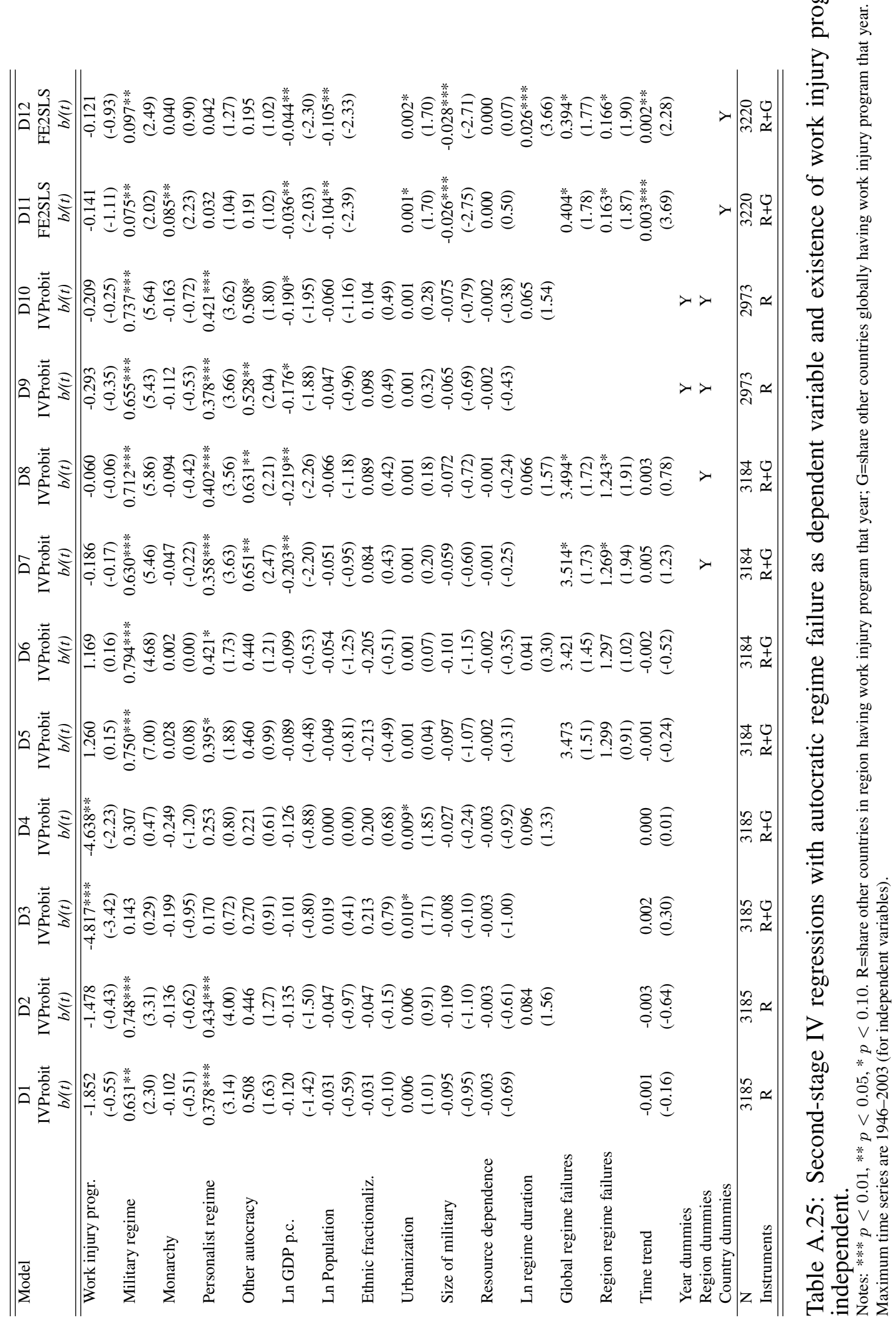




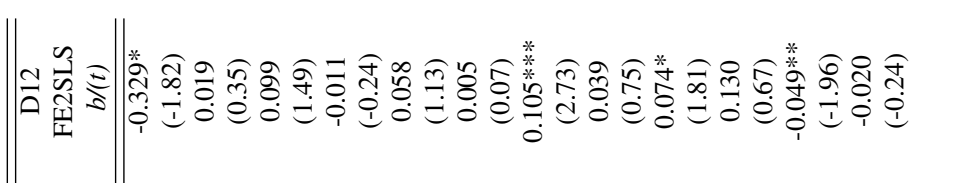

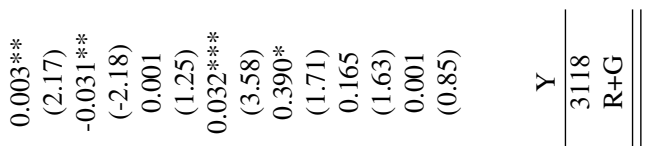

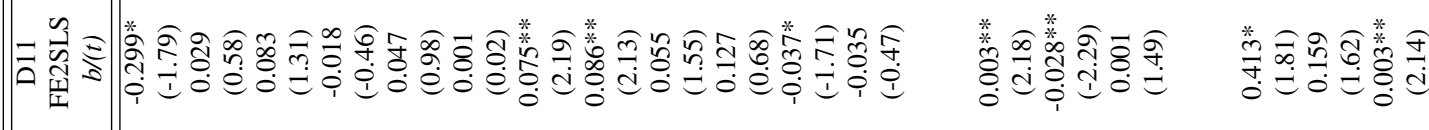

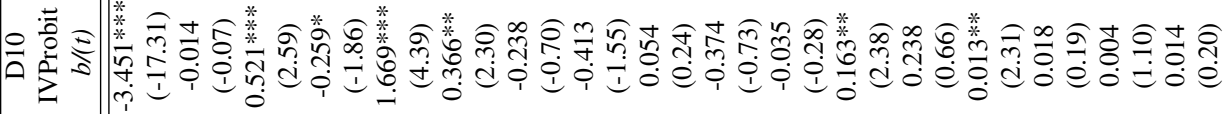

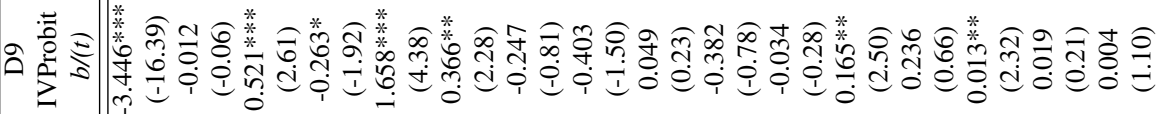

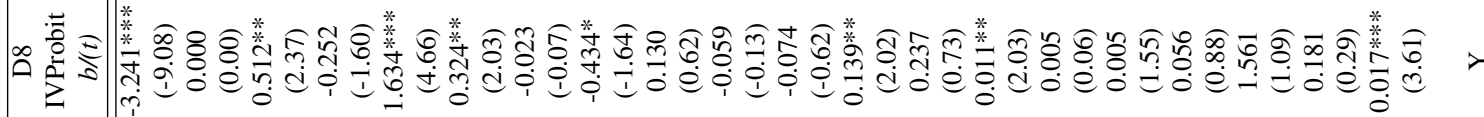

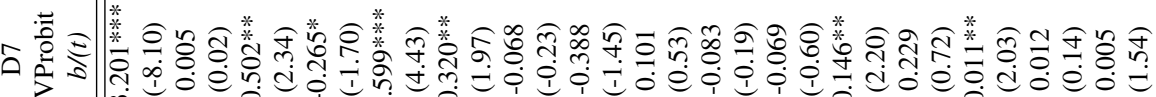

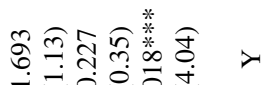

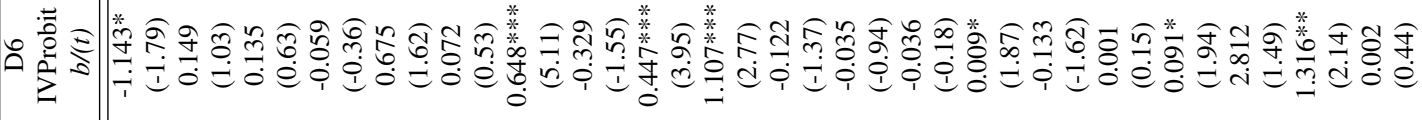

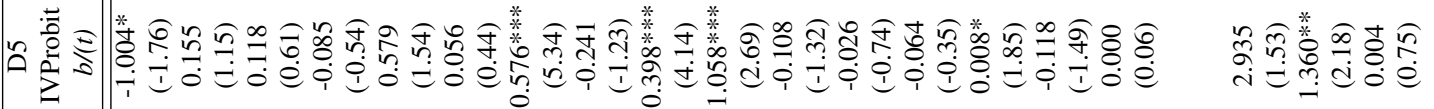

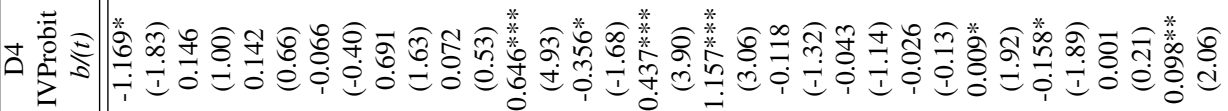

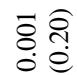

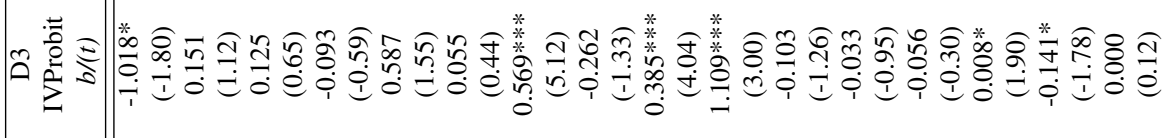

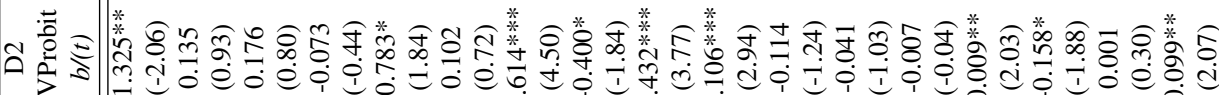

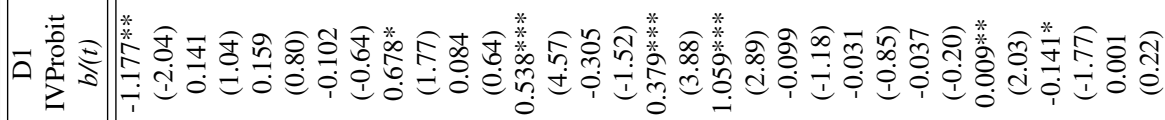

के

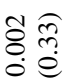

$8 \stackrel{8}{\circ}$
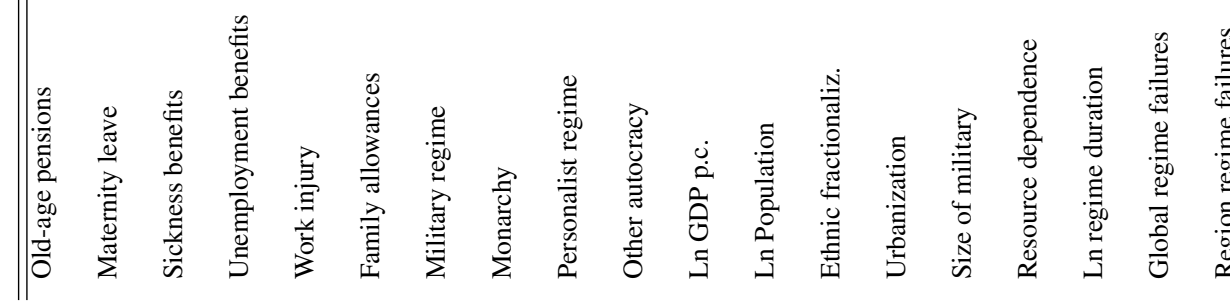
The following tables present results pertaining to an extension of the studied relationship between old-age pensions and regime survival, namely the relationship between pension systems and democratic transitions. Only about one-third of the autocratic regime breakdowns in our sample lead to a democratic transition; i.e., a regime change where the new regime replacing the old autocratic regime is a democracy (according to the operationalization by Geddes, Wright and Frantz (2014)). Given the substantive interest of democratic transitions, and the scholarly attention paid to the determinants of democratization, we wanted to test this more closely.

Theoretically, we would expect the same negative relationship between Acemoglu and Robinson's (2006) model highlight the lack of tools for credible commitment as the key explanation of democratization. According to our argument, however, pension programs allow autocrats to credibly commit to future distribution - thereby avoiding the fate of the pressured dictator of Acemoglu and Robinson, who has to allow political liberalization. Indeed, we do find evidence that pension programs in autocracies inhibit democratization. We employ similar specifications as for autocratic breakdown, modeling pension programs as endogenous using the same instrumentation strategy. Models E1-E12 in Appendix Table A.28 thus resemble D1-D12 in Table 4 of the paper except for the dependent variable; "democratization" is coded as changes from any autocracy to democracy in the following year according to Geddes et al. (2014). Table A.27 provides the corresponding first-stage results.

184 autocratic breakdowns were included in Model D1 of Table 4 in the paper, but only 68 democratization instances enter Model E1. Nonetheless, the results are strikingly similar; E1 indicates a clear negative effect of pension programs on democratization $(\mathrm{t}=-2.5)$. Again, we find large substantive estimated effects - to illustrate with the cases highlighted the paper, if pension programs had been removed from Mussolini Italy and Perón Argentina, for example, the predicted probabilities of democratization increase from 0.3 to 4.4 percent (Italy-1925) and 2.3 to 18.2 percent (Argentina-1952).

As with the result on pensions and autocratic regime breakdown, the democratization result is robust; the $12 \mathrm{t}$-values in Appendix Table A.28 vary between -2.0 and -16.4. The Sargan-test p-values are lower for the democratization models, but the hypothesis that the exclusion restriction holds is never rejected at 5 percent. Although not robust, we also find indications that pension programs inhibit democratization when using a BMR-based democratization measure and running models (omitting controls with short time series) on the entire sample from late-1880s-2004. These models comprise 116 countries and 103 democratization experiences, and are reported in Appendix Table A.29. 
In sum, despite the relatively few democratization experiences, the overall evidence suggests that pension systems in autocracies lower the chances of democratization. 


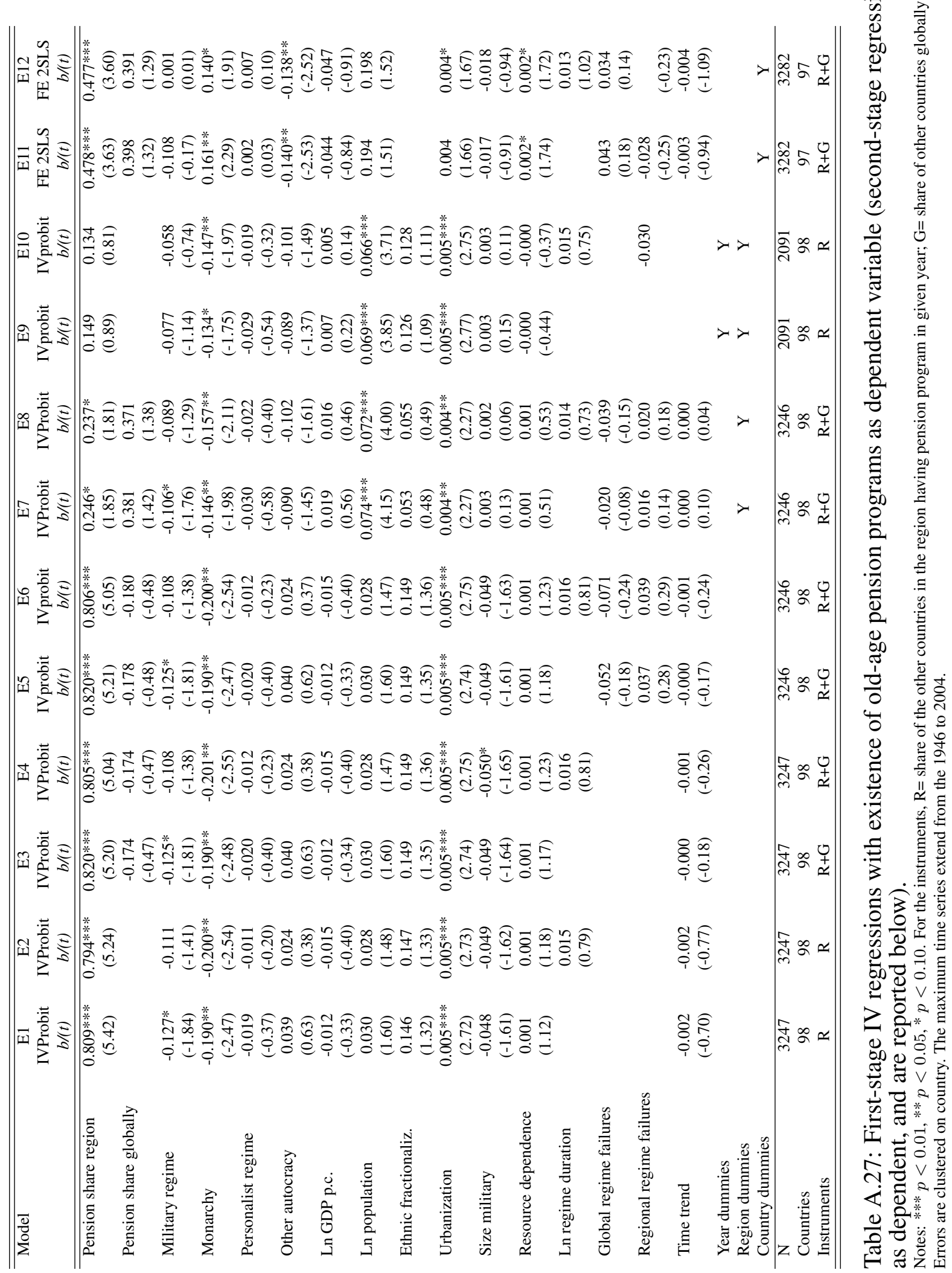




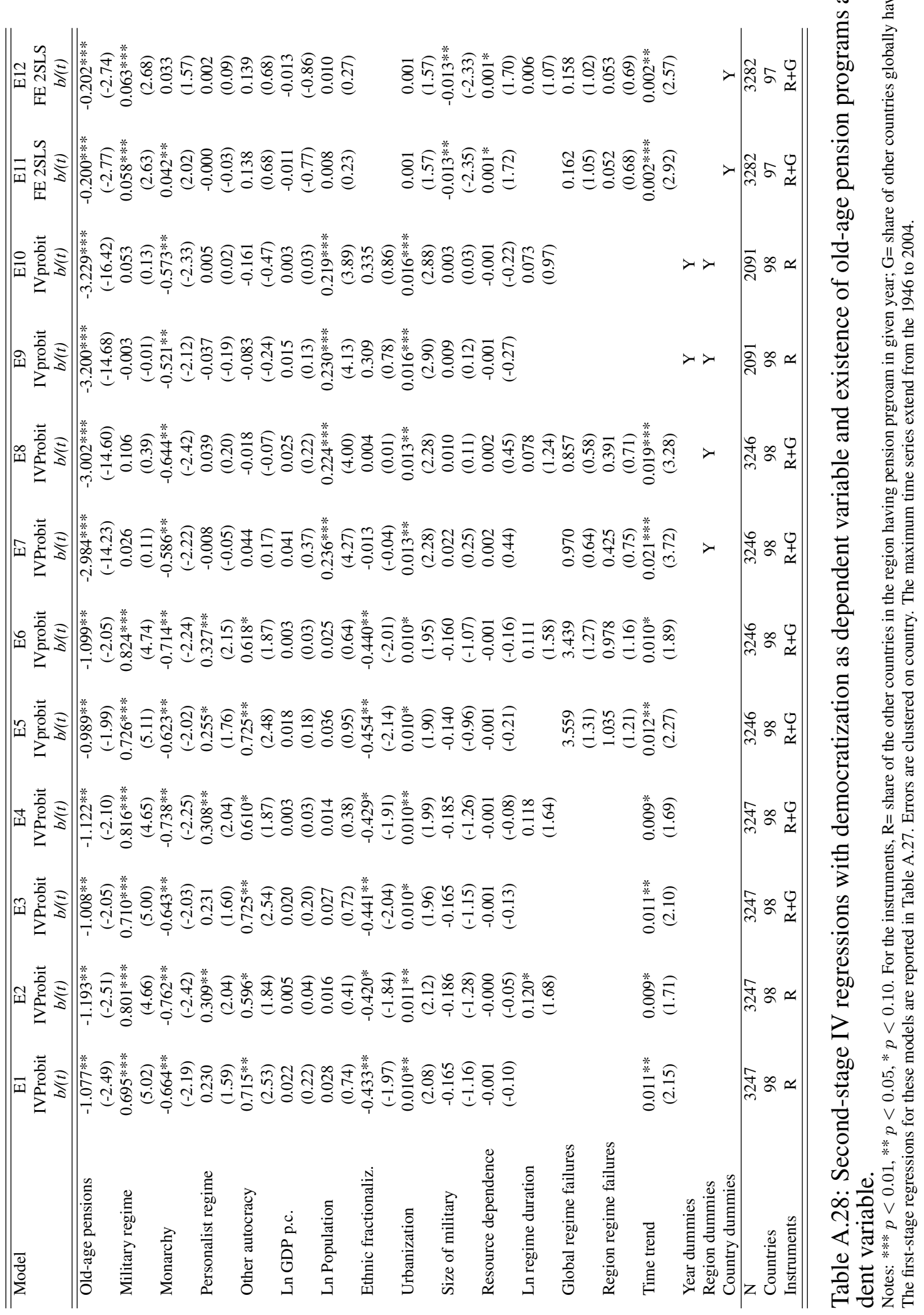




\begin{tabular}{|c|c|c|c|c|c|}
\hline & $\begin{array}{c}1 \\
b /(t)\end{array}$ & $\begin{array}{c}2 \\
b /(t)\end{array}$ & $\begin{array}{c}3 \\
b /(t)\end{array}$ & $\begin{array}{c}4 \\
b /(t)\end{array}$ & $\begin{array}{c}5 \\
b /(t)\end{array}$ \\
\hline \multicolumn{6}{|l|}{ Second-stage model } \\
\hline \multirow[t]{2}{*}{ Pension program } & 0.270 & 0.288 & -0.971 & $-1.038 *$ & $-2.127 * *$ \\
\hline & $(0.80)$ & $(0.85)$ & $(-1.61)$ & $(-1.70)$ & $(-2.30)$ \\
\hline \multirow[t]{2}{*}{ Ln GDP p.c. } & 0.133 & 0.133 & -0.010 & -0.009 & 0.033 \\
\hline & (1.64) & (1.64) & $(-0.12)$ & $(-0.11)$ & $(0.39)$ \\
\hline \multirow[t]{2}{*}{ Ln population } & $0.061 *$ & 0.060 & $0.104 * *$ & $0.107 * *$ & $0.157 * * *$ \\
\hline & $(1.65)$ & (1.64) & $(2.01)$ & $(2.08)$ & $(2.67)$ \\
\hline \multirow[t]{2}{*}{ Ethnic fractionaliz. } & -0.189 & -0.188 & -0.020 & -0.022 & 0.037 \\
\hline & $(-0.88)$ & $(-0.88)$ & $(-0.08)$ & $(-0.08)$ & $(0.13)$ \\
\hline \multirow[t]{2}{*}{ Urbanization } & 0.002 & 0.002 & 0.007 & 0.007 & $0.011^{*}$ \\
\hline & $(0.48)$ & $(0.46)$ & $(1.47)$ & $(1.54)$ & $(1.84)$ \\
\hline \multirow[t]{2}{*}{ Size military } & -0.125 & -0.125 & -0.063 & -0.060 & -0.080 \\
\hline & $(-1.22)$ & $(-1.22)$ & $(-0.52)$ & $(-0.50)$ & $(-0.72)$ \\
\hline \multirow[t]{2}{*}{ Resource dependence } & -0.016 & -0.016 & -0.006 & -0.006 & -0.007 \\
\hline & $(-1.46)$ & $(-1.46)$ & $(-0.67)$ & $(-0.66)$ & $(-0.87)$ \\
\hline \multirow[t]{2}{*}{ Time trend } & 0.002 & 0.002 & $0.019 * * *$ & $0.020 * * *$ & \\
\hline & $(0.86)$ & $(0.82)$ & (4.04) & (4.11) & \\
\hline \multirow{2}{*}{\multicolumn{2}{|c|}{$\begin{array}{l}\text { Region dummies } \\
\text { Year dummies }\end{array}$}} & & $\mathrm{Y}$ & $\mathrm{Y}$ & $\mathrm{Y}$ \\
\hline & & & & & Y \\
\hline \multicolumn{6}{|l|}{ First-stage model } \\
\hline \multirow[t]{2}{*}{ Regional share pensions } & $0.815 * * *$ & $0.826^{* * *}$ & $0.579 * * *$ & $0.507 * * *$ & $0.255^{*}$ \\
\hline & $(8.43)$ & (6.80) & (6.14) & $(4.20)$ & $(1.93)$ \\
\hline \multirow[t]{2}{*}{ Global share pensions } & & -0.078 & & 0.323 & \\
\hline & & $(-0.31)$ & & $(1.44)$ & \\
\hline \multirow[t]{2}{*}{ Ln GDP p.c. } & -0.004 & -0.004 & 0.001 & -0.001 & 0.014 \\
\hline & $(-0.15)$ & $(-0.17)$ & $(0.05)$ & $(-0.06)$ & $(0.65)$ \\
\hline \multirow[t]{2}{*}{ Ln population } & $0.017 *$ & $0.017^{*}$ & $0.044 * * *$ & $0.043 * * *$ & $0.049 * * *$ \\
\hline & $(1.71)$ & $(1.72)$ & $(3.67)$ & $(3.64)$ & $(3.67)$ \\
\hline \multirow[t]{2}{*}{ Ethnic fractionaliz. } & 0.062 & 0.065 & -0.022 & -0.021 & 0.004 \\
\hline & $(0.79)$ & $(0.81)$ & $(-0.25)$ & $(-0.24)$ & $(0.04)$ \\
\hline \multirow[t]{2}{*}{ Urbanization } & $0.004 * * *$ & $0.004 * * *$ & $0.004 * * *$ & $0.004 * * *$ & $0.004 * * *$ \\
\hline & $(2.91)$ & $(2.92)$ & (3.61) & (3.64) & (2.99) \\
\hline \multirow[t]{2}{*}{ Size military } & -0.024 & -0.024 & -0.004 & -0.005 & -0.003 \\
\hline & $(-0.99)$ & $(-0.99)$ & $(-0.18)$ & $(-0.22)$ & $(-0.12)$ \\
\hline \multirow[t]{2}{*}{ Resource dependence } & 0.001 & 0.001 & 0.001 & 0.001 & 0.000 \\
\hline & $(0.65)$ & $(0.67)$ & $(0.65)$ & $(0.57)$ & $(0.15)$ \\
\hline \multirow[t]{2}{*}{ Time trend } & 0.000 & 0.001 & $0.002 * *$ & -0.000 & \\
\hline & $(0.14)$ & $(0.54)$ & $(2.33)$ & $(-0.08)$ & \\
\hline Region dummies & & & $\mathrm{Y}$ & $\mathrm{Y}$ & Y \\
\hline Year dummies & & & & & $\mathrm{Y}$ \\
\hline $\mathrm{N}$ & 5535 & 5535 & 5535 & 5535 & 3061 \\
\hline Countries & 116 & 116 & 116 & 116 & 116 \\
\hline Instruments & $\mathrm{R}$ & $\mathrm{R}+\mathrm{G}$ & $\mathrm{R}$ & $\mathrm{R}+\mathrm{G}$ & $\mathrm{R}$ \\
\hline
\end{tabular}

Table A.29: IV probit regressions with existence of old-age pension programs as dependent variable in first-stage and democratization as dependent variable in second-stage regressions. Robustness tests run on long-time series sample using democratization variable based on BMR

Notes: ${ }^{* * *} p<0.01,{ }^{*} p<<0.05, * p<0.10$. The maximum time series extend from the late 1880 s to 2004 . Errors are clustered on country. Constants and year dummies are omitted from the table. The instrumental variables are the shares of other countries in the region (R)/globally (G) that have in place an old-age pension system. The model including region and year dummies and both instruments did not converge. 


\section{References}

Alesina, Alberto, Arnaud Devleeschauwer, William Easterly, Sergio Kurlat and Romain Wacziarg. 2003. "Fractionalization.” Journal of Economic Growth 8(2):155-194.

Boix, Carles, Michael Miller and Sebastian Rosato. 2013. “A Complete Data Set of Political Regimes, 1800-2007." Comparative Political Studies 46(12): 1523-1554.

Cheibub, José Antonio, Jennifer Gandhi and James Vreeland. 2010. "Democracy and dictatorship revisited." Public Choice 143:67-101.

Collier, David and Richard E. Messick. 1975. "Prerequisites versus diffusion: Testing alternative explanations of social security adoption.” American Political Science Review 69(04):1299â1315.

Cutright, Philips. 1965. "Political Structure, Economic Development, and National Social Security Programs.” American Journal of Sociology 70(5):537-550.

De Mesa, Alberto A. and Carmelo Mesa-Lago. 2006. "The structural pension reform in Chile: Effects, comparisons with other Latin American reforms, and lessons." Oxford Review of Economic Policy 22(1):149â167.

Flora, Peter, Jens Alber and others. 1983a. State, economy, and society in Western Europe 1815-1975: a data handbook in two volumes. Vol. 1 Campus Frankfurt aM/London/Chicago.

Flora, Peter, Jens Alber and others. 1983b. State, economy, and society in Western Europe 1815-1975: a data handbook in two volumes. Vol. 2 Campus Frankfurt aM/London/Chicago.

Geddes, Barbara, Joseph Wright and Erica Frantz. 2014. "Autocratic Breakdown and Regime Transitions: A New Data Set.” Perspectives on Politics 12(2):313-331.

Haber, Stephen and Victor Menaldo. 2011. "Do natural resources fuel authoritarianism? A reappraisal of the resource curse." American Political Science Review 105(1):1-26.

Hicks, A., Misra J. \& Ng T. N. 1995. "The programmatic emergence of the social security state." American Sociological Review p. 329â349.

Maddison, Angus. 2007. Contours of the World Economy, 1-2030 AD. Oxford: Oxford University Press.

Mares, Isabela. 2005. "Social Protection Around the World: External Insecurity, State Capacity, and Domestic Political Cleavages." Comparative Political Studies 38(6):623-651.

Mares, Isabela and Matthew E. Carnes. 2009. "Social Policy in Developing Countries." Annual Review of Political Science 12:93-113. 
Mesa-Lago, Carmelo. 1978. Social Security in Latin America: pressure groups, stratification, and inequality. Pittsburgh: University of Pittsburgh Press.

Mesa-Lago, Carmelo. 2007. "Social security in Latin America: pension and health care reforms in the last quarter century." Latin American Research Review 42(2):181-201.

Mesa-Lago, Carmelo. 2008. Reassembling Social Security: A Survey of Pensions and Health Care Reforms in Latin America: A Survey of Pensions and Health Care Reforms in Latin America. Oxford University Press.

Miller, Michael K. 2015. "Democratic Pieces: Autocratic Elections and Democratic Development since 1815.” British Journal of Political Science 45(3):501-530. 